
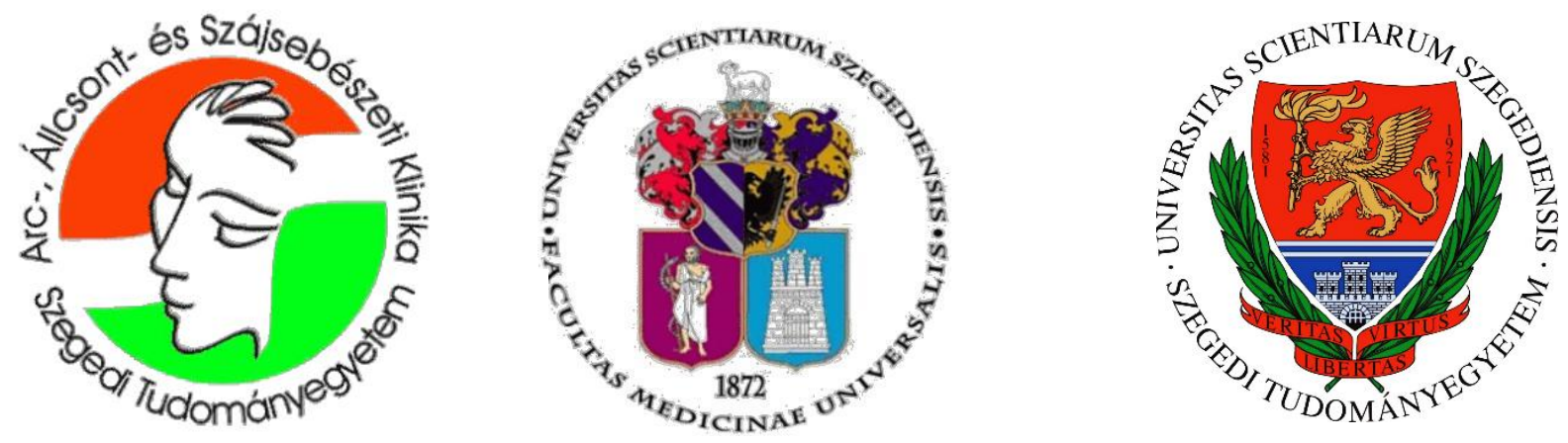

The application of the diagnostic 3-D imaging procedures in maxillofacial orthopedics: The examination of soft tissue changes during conservative and surgical correction of the craniofacial anomalies

Ali Alkhayer, DDS, M.Sc.

Ph.D. Dissertation

Supervisor

Assoc. Prof. Emil Segatto, DDS, Ph.D.

2021

Szeged, Hungary 
The application of the diagnostic 3-D imaging procedures in maxillofacial orthopedics: The examination of soft tissue changes during conservative and surgical correction of the craniofacial anomalies

\author{
Ph.D. Dissertation \\ Ali Alkhayer, DDS, M.Sc. \\ Supervisor \\ Assoc. Prof. Emil Segatto, DDS, Ph.D. \\ Craniofacial Unit \\ Department of Oral and Maxillofacial Surgery
}

Clinical and Experimental Research for Reconstructive and OrganSparing Surgery, Doctoral School of Clinical Medicine

University of Szeged

2021

Szeged, Hungary 


\section{Table of Contents}

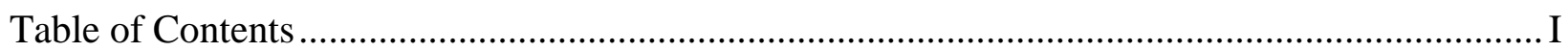

Scientific articles and publications ................................................................................. IV

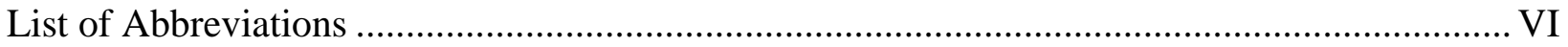

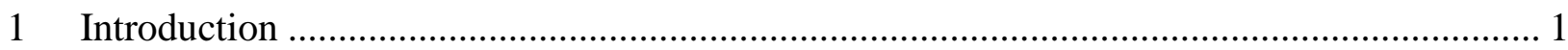

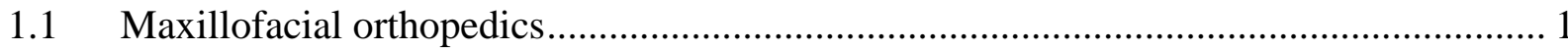

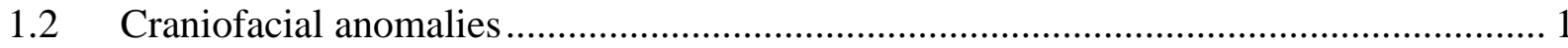

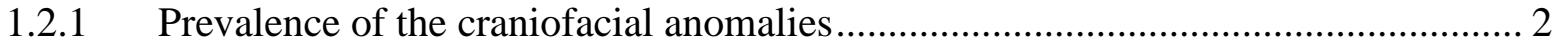

1.3 Skeletal and dental consideration in the transverse dimension ................................... 2

1.3.1 Maxillary transverse deficiency in the mixed dentition period ............................ 3

1.3.2 Conservative correction of the maxillary transverse deficiency ........................... 3

1.3.2.1 Unilateral posterior crossbite in cleft lip and palate .................................. 3

1.3.2.2 Bilateral posterior crossbite ............................................................ 4

1.3.2.3 Skeletal discrepancies ..................................................................... 4

1.4 Surgical correction of the craniofacial deformities: ................................................ 5

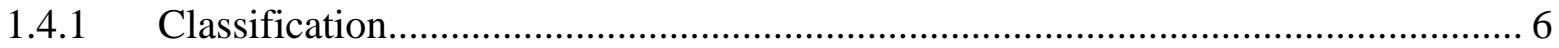

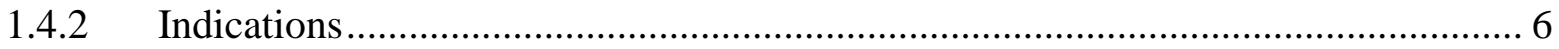

1.4.3 Consequential Outcomes of Treatment.................................................... 7

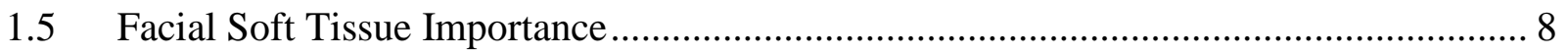

1.5.1 Importance of the facial soft tissue in orthodontic treatment ............................ 8

1.5.2 Importance of the facial soft tissue in surgical treatment ............................... 8

1.5.2.1 The Immediate Response to Orthognathic Surgery ..................................... 9

1.6 Soft tissue Diagnostic Records.................................................................... 10

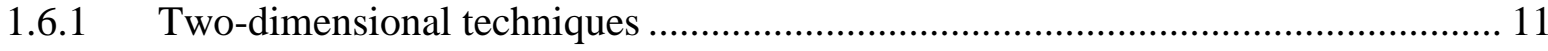


1.6.2 Three-dimensional imaging in orthodontics and maxillofacial orthopedics........... 12

1.6.2.1 Computed Tomography (CT) ………………........................................ 12

1.6.2.2 Intraoral Scanning................................................................................... 12

1.6.2.3 Three dimensional Laser Scanning ............................................................... 13

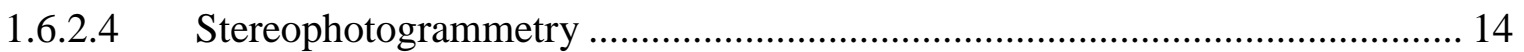

1.6.2.5 Structured-light scanning ...................................................................... 14

1.6.2.6 Video Camera, 4D Imaging and Video Stereophotogrammetry ...................... 15

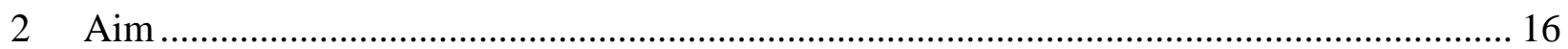

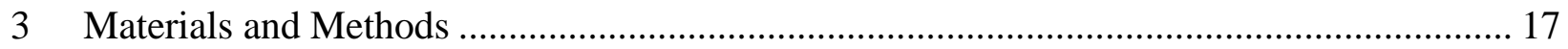

3.1 3D handheld structured-light scanner (Artec Eva) ................................................... 17

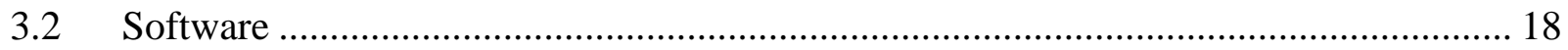

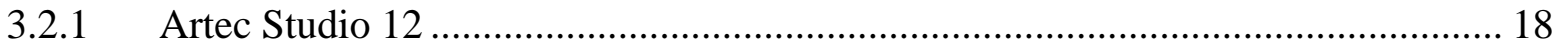

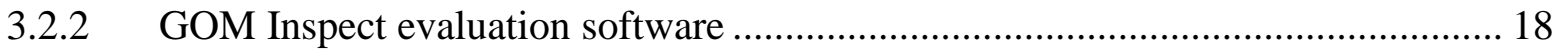

3.3 Computer workgroup ……………………………........................................... 19

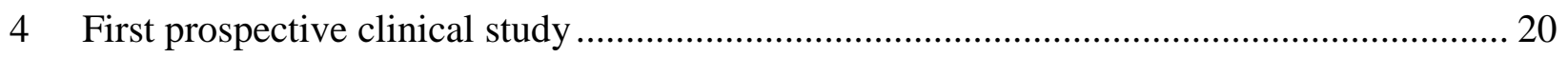

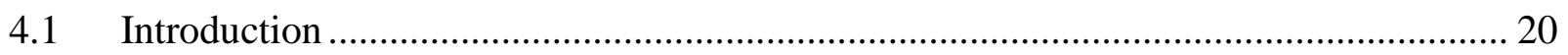

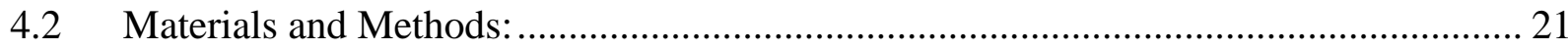

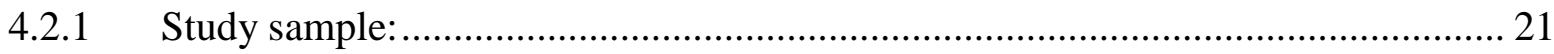

4.2.2 Clinical Protocol ..................................................................................... 22

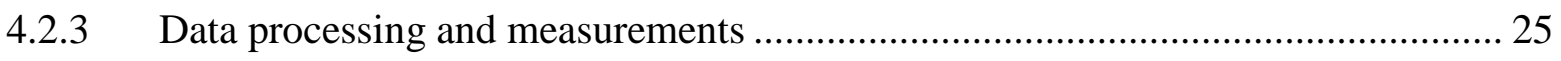

$4.3 \quad$ Statistical Analysis ............................................................................................. 29

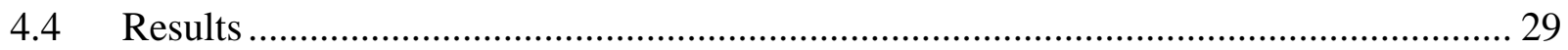

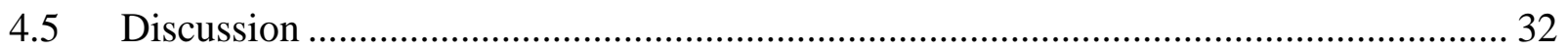

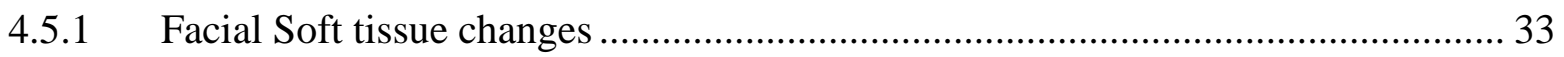

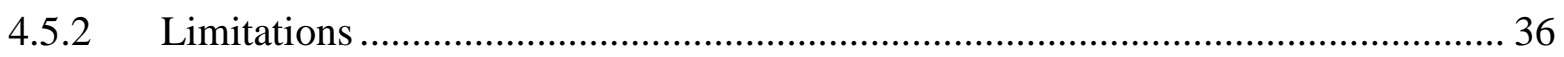




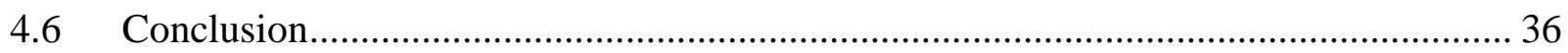

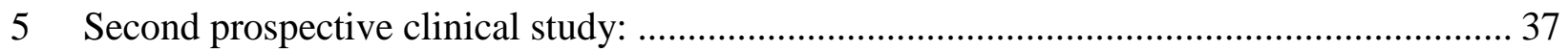

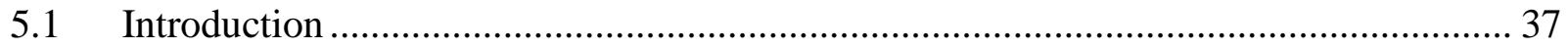

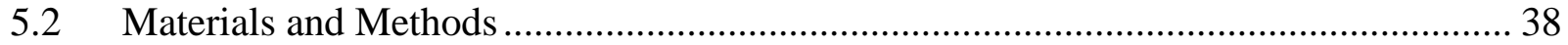

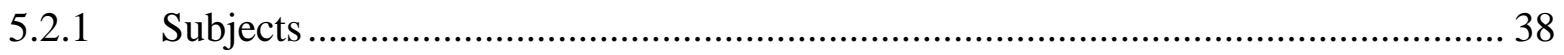

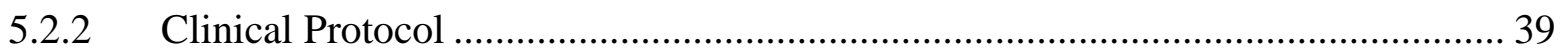

5.2.2.1 Pre-surgical orthodontic treatment .................................................... 39

5.2.2.2 Surgical Planning .............................................................................. 40

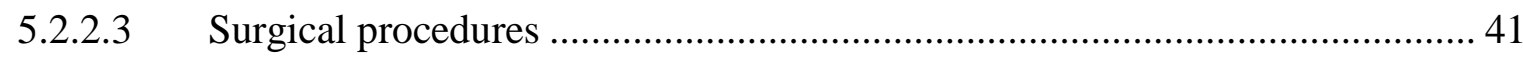

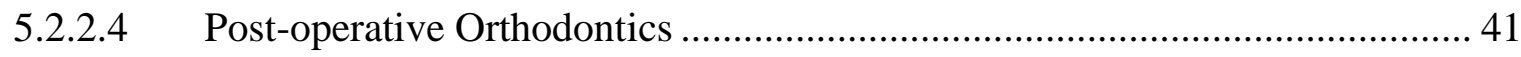

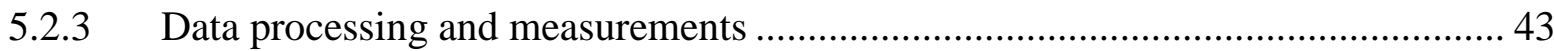

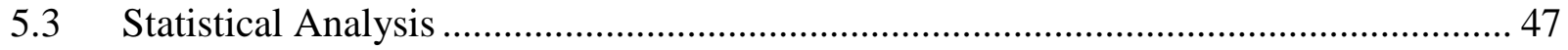

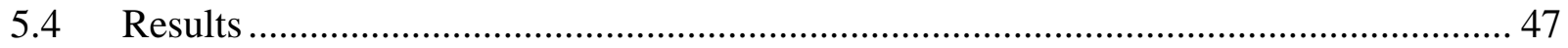

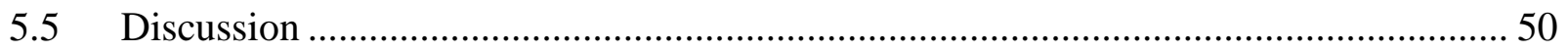

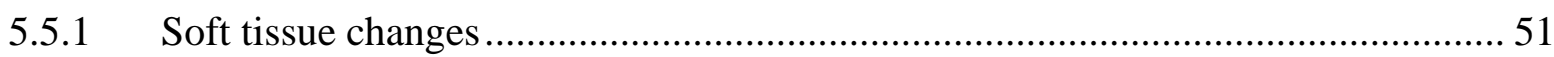

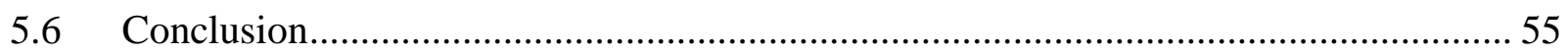

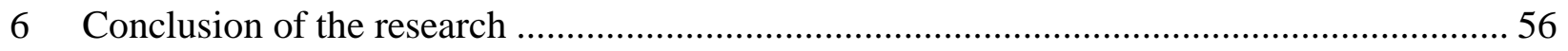

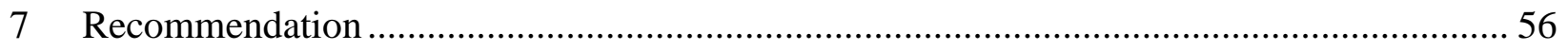

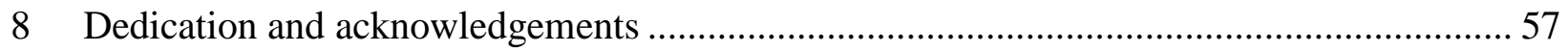

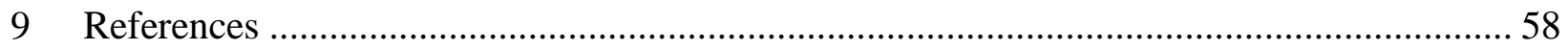




\section{Scientific articles and publications}

Publications related to the thesis

1. Evaluation of the Soft Tissue Changes after Rapid Maxillary Expansion using a Handheld Three-dimensional Scanner: a prospective study

Alkhayer A, Becsei R, Hegedüs L, Párkányi L, Piffkó J, Braunitzer G and Segatto E. Int. J. Environ. Res. Public Health 2021, 18(7), 3379; https://doi.org/10.3390/ijerph18073379 Article type: original article Impact Factor 2019: 2.849

URL: https://www.mdpi.com/1660-4601/18/7/3379/pdf

2. Accuracy of virtual planning in orthognathic surgery: a systematic review Alkhayer A, Piffkó J, Lippold C, Segatto E. Head Face Med 16, 34 (2020). https://doi.org/10.1186/s13005-020-00250-2

Article type: systematic review

Impact Factor2019: 1.882

URL:

https://head-face-med.biomedcentral.com/track/pdf/10.1186/s13005-020-00250-2.pdf

3. Three-dimensional changes of the facial soft tissue after bimaxillary surgery of skeletal class III patients: a prospective study

Alkhayer A, Piffkó J, Segatto E.

Fogorvosi Szemle.

Article type: original article / Under Review/

4. Evaluation of the Upper Airway Morphology in Patients with Class II Malocclusion Using 3-Dimensional Computed Tomography

Alkhayer A, Hasan H, Khalil F

International Dental Journal of Student's Research,

December 2015; 3(4):174-183

Article type: original article

URL: https://www.idjsr.com/uploads/21/1374_pdf.pdf

\section{Other publications:}

1. The Relationship of the Upper Airway Morphology with the Cephalometric Features Determining Sagittal intermaxillary Relationship in Adults Using Three Dimensional Computed Tomography.

Alkhayer A, Hasan H, Khalil F

Tishreen University Journal for Research and Scientific Studies, 2016; 38(2): 265-281 
Article type: original article

URL: http://journal.tishreen.edu.sy/index.php/hlthscnc/article/view/2596/2465

2. Evaluation Of The Relationship Between The Upper Airway Morphology And Facial Growth Type In Adults of The Syrian Coast Using Three Dimensional Computed Tomography.

Alkhayer A, Hasan H, Khalil F

Journal of Al Baath University, 2016; 38(3): 165-191

Article type: original article

URL: http://magazine.albaath-univ.edu.sy/1/pages/2016/3/03.pdf

$\underline{\text { Cumulative impact factor } \mathbf{~} \mathbf{4 . 7 3 1}}$

\section{Scientific Presentations}

- Oral presentation in a congress

Health Sciences and Innovation Conference- DOSZ

January 29-30, 2021, Budapest, Hungary

Title: Three-dimensional changes of the facial soft tissue after bimaxillary surgery of skeletal class III patients: a prospective study.

Award: III Prize

- poster presentation in a congress (international):

${ }^{96}$ th General Session of the International Association for Dental Research (IADR) in conjunction with the IADR Pan European Regional Congress

(July 25 -28, 2018, London, United Kingdom)

Title: Virtual Planning in Orthognathic Surgery - A Systematic Review

- poster presentation in a congress (international):

${ }^{94}$ th Congress of the European Orthodontic Society (EOS)

(Jun 17 - 21, 2018 Edinburgh, United Kingdom)

Title: Evaluation of Accuracies of Virtual Planning Methods Used in Orthognathic Surgery - A Systematic Review)

European journal of orthodontics, volume 40, Issue 5, October 2018.

- poster presentation in a congress (international):

${ }^{96}$ th Congress of the European Orthodontic Society (EOS)

(Jun 10 - 14, 2020 Hamburg, Germany)

Title: Evaluation of the Soft Tissue Changes after Rapid Maxillary Expansion using Handheld Three-dimensional Scanner

European journal of orthodontics, volume 42, Issue 5, 2020. 


\section{List of Abbreviations}

$\begin{array}{ll}\text { CBCT/ CT } & \text { Cone beam/ computed tomography } \\ \text { CFAs } & \text { Craniofacial anomalies } \\ \text { OMSs } & \text { Oral and maxillofacial surgeons } \\ \text { AAOMS } & \text { Association of oral and maxillofacial surgeons } \\ \text { MCA } & \text { Multiple congenital abnormalities } \\ \text { CL/P } & \text { Cleft lip and palate } \\ \text { CO } & \text { Central occlusion } \\ \text { CR } & \text { Central relation } \\ \text { RME } & \text { Rapid maxillary expansion } \\ \text { 2D } & \text { Two-dimensional } \\ \text { 3D } & \text { Three-dimensional } \\ \text { 4D } & \text { Four-dimensional } \\ \text { MRI } & \text { Magnetic resonance imaging } \\ \text { TMJ } & \text { Temporomandibular joint } \\ \text { CMM } & \text { Coordinate measurement machines } \\ \text { LED } & \text { Light emitting diode } \\ \text { STL } & \text { Stereolithography } \\ \text { ICC } & \text { Interclass correlation coefficient } \\ \text { ADRL } & \text { Average distances between the reciprocal landmarks } \\ \text { BSSRO } & \text { Bilateral sagittal split ramus osteotomy } \\ \text { MSS } & \text { Mandibular setback surgery }\end{array}$




\section{Introduction}

\subsection{Maxillofacial Orthopedics}

The concept of maxillofacial orthopedics is directed to the diagnostics, prophylaxis, and correction of the clinical manifestation, face and jaws deformations to achieve some purposes; from those arise the rehabilitation of patients with defects of dentition and craniofacial deformities, treatment of the congenital and acquired defects of the face and jaws, treatment of the jaws fractures and their consequences, elimination of dento-skeletal deformations defects utilizing orthopedic methods and orthopedic treatment of masticatory muscles and temporomandibular joints(1). Therefore, proper diagnosis is essential for ensuring a successful outcome of any applied therapy, including orthodontics and orthognathic surgery

\subsection{Craniofacial anomalies}

Craniofacial anomalies (CFAs) are congenital abnormalities in the bone or soft tissue of the face or head and comprise a wide range of heterogeneous conditions with many associated syndromes.

Patients born with a (CFA) often will present with multiple auxiliary syndromes associated with the initial (CFA). Babies and children with (CFAs) will have difficulty of eating (including regurgitation and aspiration), ear infections, hearing loss, permanent speech impediments, gross jaw deformities of various types, and a broad range of dental-related challenges - all of which are justifications for unavoidable surgical management.

A team of multispecialty providers, orthodontists, and oral and maxillofacial surgeons (OMSs) play an important role in the carefully orchestrated, multistage correctional approach for (CFA) patients, to help restore the jaw and facial structures, leading to normal function and appearance. The standard of care for treatment must consider function, appearance, nutrition, speech, hearing, and emotional and psychological development(2). 


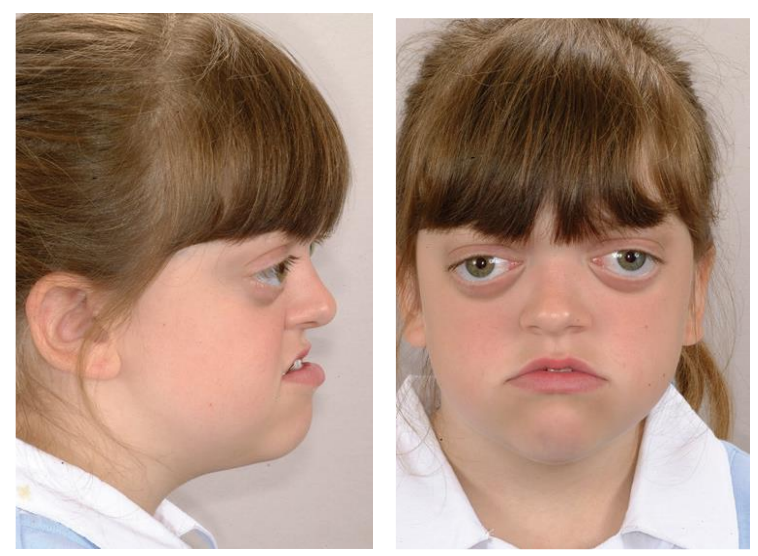

Fig. 1. Facial appearance in Crouzon's syndrome of moderate severity, at age 8 years 8 months(3).

\subsubsection{Prevalence of the craniofacial anomalies}

The frequency of congenital malformations is 310 per 10000 births worldwide. Among them, craniofacial malformations represent between 10-15\% of cases, including ear malformations with a prevalence of 74.1 per 10000 births, followed by cleft lip and palate (CL/P) with 15.9 per 10 000 births (4), and the estimated incidence of the cleft lip without cleft palate according to the American Association of Oral and Maxillofacial Surgeons (AAOMS) was 1 in 940 newborn babies worldwide(2). Orofacial clefts are the most common and serious, and their frequency is highly variable depending on the population(5).

Czeizel AE. calculated in his nice study the occurrence of two or more different congenital abnormalities in the same person which was defined as the Multiple congenital abnormalities (MCA), these cases, including CL/P and posterior CP were evaluated in the population-based, almost-complete data set of the Hungarian Congenital Abnormality Registry, the clinically recognized and notified syndromes and associations were included. He found that the birth prevalence of the recorded cases affected by (MCA) was 4.0 per 1000 total births (range: 3.7-4.5) in Hungary for the period between (1973-1982). He also found that they represent about $10 \%$ of the recorded (CA) in the Hungarian Congenital Abnormality Registry (6).

\subsection{Skeletal and dental consideration in the transverse dimension}

Maxillary transverse deficiency may be one of the most pervasive skeletal problems in the craniofacial region (7). The transverse dimension is often interrelated with the sagittal and vertical dimensions. However, the transverse dimension relates primarily to the posterior occlusion, and any discrepancy is usually manifest as a unilateral or bilateral crossbite of the buccal occlusion. 
Patients with transverse discrepancies should be carefully assessed to determine the best feasible treatment plan especially the primary and mixed dentition(8).

\subsubsection{Maxillary transverse deficiency in the mixed dentition period}

In the preadolescent patient, problems in the transverse dimension are generally identified as skeletal or dental, which may range in severity. A common transverse problem is caused by skeletal maxillary constriction, which is manifest as a dental posterior crossbite. This may be unilateral or bilateral and usually includes multiple teeth. The posterior crossbite is diagnosed in central occlusion (CO), but it should also be assessed in central relation (CR) to identify if a mandibular shift exists. If there is no $\mathrm{CR} / \mathrm{CO}$ mandibular shift then a true unilateral posterior crossbite exists. The cause may be from maxillary constriction or mandibular expansion and may involve one tooth or multiple teeth in a posterior crossbite relationship. A systematic diagnostic approach should identify the contribution of the dental and skeletal components so that the appropriate treatment may be selected based on the severity and the ability of the dentoalveolar component to compensate or camouflage the skeletal pattern(8).

An important caveat in recognizing a transverse problem is to ensure that the diagnosis has defined the skeletal and dental components of the malocclusion. A progressive skeletal asymmetry caused by early condylar fracture or a craniofacial developmental anomaly such as hemifacial microsomia will result in asymmetric mandibular growth with adaptive maxillary dental arch compensation. These cases should be diagnosed and treated early to avoid creating severe skeletal discrepancies. If the skeletal component of the malocclusion is treated solely by dental compensations, the correction of the crossbite may not be stable and could relapse to the initial unilateral crossbite relationship. True skeletal unilateral crossbites may require surgical as well as orthodontic corrections(8).

\subsubsection{Conservative correction of the maxillary transverse deficiency}

\subsubsection{Unilateral posterior crossbite in cleft lip and palate}

Maxillary skeletal asymmetry in unilateral complete clefts of the lip and palate may also be reflected in a unilateral posterior crossbite, which may be expanded with a quad helix type of appliance or rapid maxillary expansion (RME) in the mixed dentition. The cleft maxilla does not have a midpalatal suture, instead, there is a midpalatal cleft covered with repaired and scarred palatal tissues limiting the rate and amount of expansion. The force provided by these appliances allows the soft tissue of the palate to stretch and adapt to the increasing maxillary width. This type 
of orthodontic expansion treatment is often timed to precede the surgical placement of an alveolar bone graft in the mixed dentition stage(9).

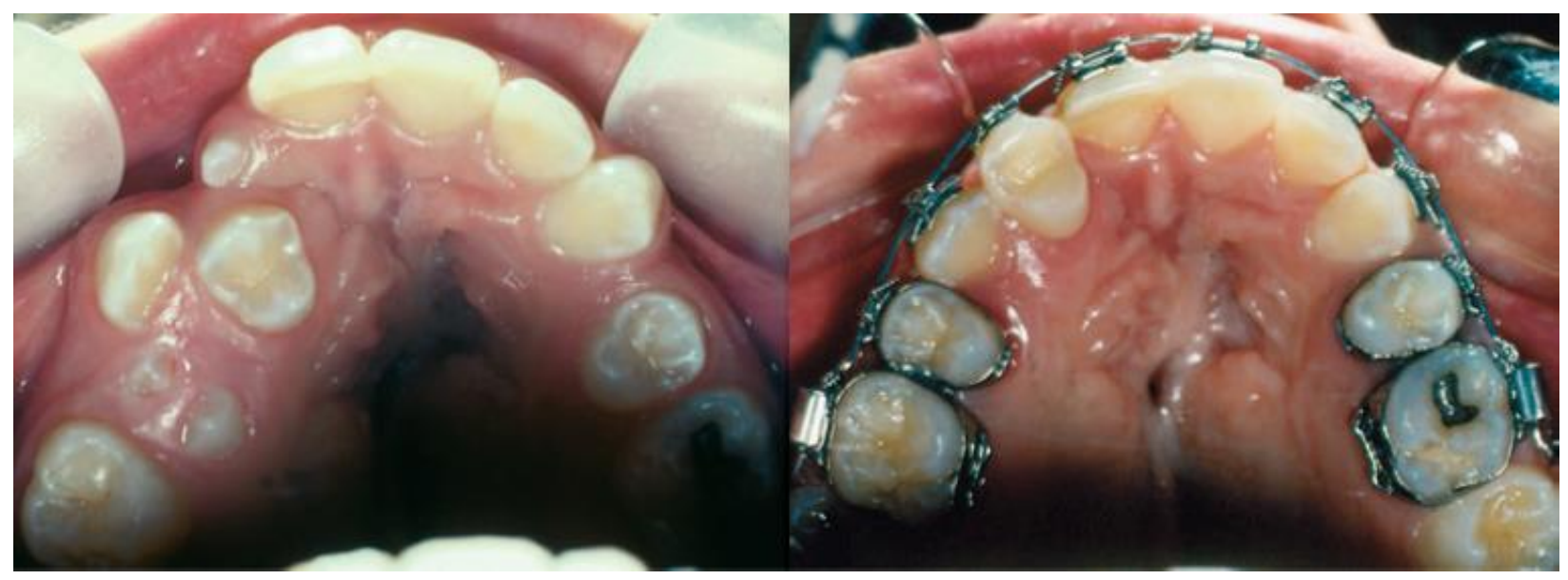

Fig. 2. Maxillary expansion of a unilateral cleft lip and palate in 11 years old patient (3) .

\subsubsection{Bilateral posterior crossbite}

Correction of a posterior crossbite in children and preadolescents may involve the whole buccal segment or may be localized to one or more teeth. If the crossbite or transverse discrepancy has a dental cause, cross elastics or coordinated upper and lower archwires may change the dental relationship by tipping the teeth into their correct axial positions. Similarly, if there is a mild skeletal transverse discrepancy, camouflage by dental compensation may be the treatment of choice. A bilateral posterior crossbite may result from either maxillary constriction or mandibular expansion or be the result of a combination of both. In the older child, more dental and less skeletal change occurs with the quad helix or $\mathrm{W}$ arch appliances therapy(8).

\subsubsection{Skeletal discrepancies}

Typically, skeletal correction involves orthopedic maxillary arch expansion. If a CR/CO shift has resulted in an associated mandibular shift, the bilateral skeletal expansion of the maxilla will also eliminate the shift and correct the unilateral crossbite in the centric occlusal position. The rapid palatal expansion provides an orthopedic force capable of expanding the midpalatal suture and requires a fixed appliance with bands cemented on the first permanent molars and the first premolars. This may be accomplished with a hyrax type appliance screw (Figure 3, A). The patient 
turns the screw twice a day (each turn of the screw expands $1 / 4 \mathrm{~mm}$ ) to produce $0.5 \mathrm{~mm}$ of opening per day and delivering 2000 to $3000 \mathrm{~g}$ of force. In the initial phase of treatment there is more skeletal than dental movement and the force is directed to the maxillary midline over a 7- to 10day period. Some over-expansion is indicated to compensate for the relapse tendency and to help stabilize the increased transverse skeletal width of the maxilla. During this period there may be some dental compensation as the skeletal transverse expansion settles. Following this active palatal expansion, the appliance remains in place for 3-6 months to allow bone to fill in the separated midpalatal suture and for the residual pressure to dissipate from the displaced structures. During this time the median diastema, which normally opens during the active phase of expansion, closes as the central incisors move spontaneously toward the midline. As the teeth are held rigidly by the appliance, the transverse relationship that has been over-expanded at least 2 to $3 \mathrm{~mm}$ maintains the correction. Radiographically, the midline suture opens more anteriorly than posteriorly, resulting in the V-shaped midline translucency (Fig.3, B) (8). Adding of palatal flanges of acrylic to the appliance may add to the skeletal expansion effect and has been advocated by Haas(10).

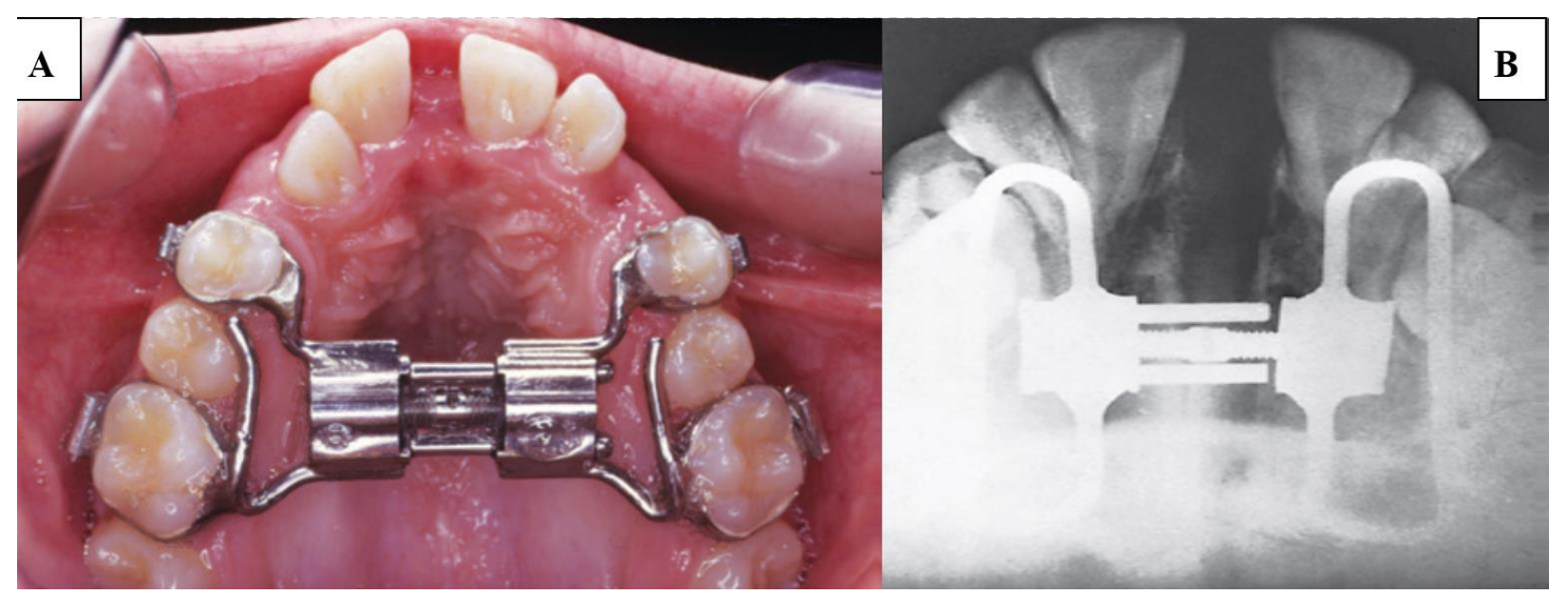

Fig. 3. (A) Hyrax expander with the transverse force across the maxilla that can open the midpalatal suture. (B) Radiographic occlusal view shows suture opening after rapid maxillary expansion(3)

\subsection{Surgical correction of the craniofacial deformities:}

According to the American Association of Oral and Maxillofacial Surgeons (AAOMS), orthognathic surgery is the surgical correction of abnormalities of the mandible, maxilla, or both. The underlying abnormality may be present at birth or may become evident as the patient grows 
and develops or may be the result of traumatic injuries. The primary goal of treatment is to improve function through correction of the underlying skeletal deformity

\subsubsection{Classification}

The classification and analysis of dentofacial skeletal deformities are complex and involves discrepancies in all planes of space. However, they can generally be classified as follows (11):

Congenital anomalies

1. Cleft lip and palate

2. Congenital dentofacial skeletal deformities

Acquired anomalies

1. Traumatic facial skeletal injuries

2. Cysts and tumors of the jaws

3. Obstructive sleep apnea

4. Temporomandibular joint disorders resulting in skeletal malocclusion

a. Rheumatoid arthritis

b. Degenerative arthritis

c. Condylar atrophy

5. Growth disturbances

a. Condylar hyperplasia

\subsubsection{Indications}

Given the relationship between facial skeletal deformities and masticatory dysfunction as well as the limitations of non-surgical therapies to correct these discrepancies. The measurement of these discrepancies must consider dental compensations relating to the malocclusion and the underlying skeletal deformity. Orthognathic surgery should be considered medically appropriate in the following circumstances (11):

A. Anteroposterior discrepancies: established norm $=2 \mathrm{~mm}$

1. Maxillary/mandibular incisor relationship

- Horizontal overjet of $+5 \mathrm{~mm}$ or more

- Horizontal overjet of zero to a negative value

2. Maxillary/mandibular anteroposterior molar relationship discrepancy of $4 \mathrm{~mm}$ or more (norm 0 to $1 \mathrm{~mm}$ )

3. These values represent two or more standard deviation from published norms 
B. Vertical discrepancies

1. Presence of a vertical facial skeletal deformity, which is two or more standard deviations from published norms for accepted skeletal landmarks

2. Open bite

- No vertical overlap of anterior teeth

- Unilateral or bilateral posterior open bite greater than $2 \mathrm{~mm}$

3. Deep overbite with impingement or irritation of buccal or lingual soft tissues of the opposing arch

4. Supra-eruption of a dentoalveolar segment due to lack of occlusion

C. Transverse discrepancies

1. Presence of a transverse skeletal discrepancy, which is two or more standard deviations from published norms

2. Total bilateral maxillary palatal cusp to mandibular fossa discrepancy of $4 \mathrm{~mm}$ or greater, or a unilateral discrepancy of $3 \mathrm{~mm}$ or greater, given the normal axial inclination of the posterior teeth

D. Asymmetries

1. Anteroposterior, transverse, or lateral asymmetries greater than $3 \mathrm{~mm}$ with concomitant occlusal asymmetry.

These indications relate verifiable clinical measurements to significant facial skeletal deformities, maxillary and/ or mandibular facial skeletal deformities associated with masticatory malocclusion. In addition to the above conditions, orthognathic surgery may be indicated in cases where there are specific documented signs of dysfunction. These may include conditions involving airway dysfunction, such as sleep apnea, temporomandibular joint disorders, psychosocial disorders, and speech impairments (11).

\subsubsection{Consequential Outcomes of Treatment}

As a direct effect of the resultant skeletal movements after orthognathic surgery, changes in the soft-tissue drape overlying the facial skeleton may be realized. The soft-tissue changes are inherent to the procedure and must be considered in the surgical workup, which was confirmed in the clinical paper of the American Association of Oral and Maxillofacial Surgeons (AAOMS), and confirm the importance of the soft tissue changes assessment (11). 


\subsection{Facial Soft Tissue Importance}

The concept of facial beauty changed over the centuries. Facial beauty can be defined as harmony and balance among facial proportions, established by skeletal structures, teeth, and soft tissue(12). Improvement of the soft tissue profile depends on many variables related to the anatomy of the face including lip thickness, facial muscle activity, and ethnicity $(13,14)$.

Macgregor et al (1970) considered facial deformity as a social disability affecting individuals and lead to different levels of psychological effects (15).

(Rustemeyer and Gregersen, 2012) found that soft tissue plays an important role in facial esthetics and can even influence psychological aspects of patients and improve their quality of life (16) Thus, clinicians should consider the soft tissue adaptation and soft tissue contours, as well as the normal skeletal relationships and functional occlusion in diagnosis and treatment planning(17)

\subsubsection{Importance of the facial soft tissue in orthodontic treatment}

Facial soft tissue esthetics has been considered at the top of our priorities during our orthodontic treatment.

In 1907, Angle emphasized the importance of soft tissues and facial esthetics in orthodontics. He believed that, to a great extent, that facial harmony and balance depend on the shape and beauty of the mouth(18). (Burstone CJ, 1959) stated that „The desire to improve one's dentofacial esthetics is one of the main reasons patients seek orthodontic treatment"(19), he also demonstrated that, "soft tissue may vary in different persons in thickness, length, and postural tone" and it is necessary to directly evaluate the soft tissue" (20).

Therefore, the orthodontist must understand clearly the necessary correction of the nose-lip-chin relationship of a given patient before making critical decisions relating to extraction versus nonextraction procedures for the correction of malocclusions (21). Thus the treatment goals of orthodontics have changed. This paradigm shift in practice has placed more emphasis on normal soft tissue as a primary treatment goal, whereas functional occlusion and normal skeletal relationships have become secondary $(17,22)$.

\subsubsection{Importance of the facial soft tissue in surgical treatment}

The focus on soft tissue has also emphasized the growing importance of the aesthetic outcomes of surgery, particularly during orthognathic surgery planning (23), because it has the objective of correcting skeletal discrepancies, as well as altering facial balance (24), In these respects, It is important to understand the relationship between the movement of the facial soft tissue envelope 
and the underlying skeletal bases during orthognathic surgery, as it is largely the final soft tissue form and position that determines the aesthetic outcome of treatment $(25,26)$.

(Ryckman MS et al, 2010) emphasized that the ideal positioning of the jaws through orthognathic surgery does not always result in an ideal soft-tissue appearance because the response of a patient's facial soft tissue does not reflect the exact movements of the underlying jaws in a 1:1 ratio (27). Therefore treatment objectives should focus on the final soft tissue changes, and the ideal soft tissue proportions should be considered during the orthognathic surgery planning (28).

(Gill et al, 2017) stated that one should even consider the proposed final position of the soft tissues first and then plan skeletal movements accordingly (26).

Concerning the static soft tissue effects, one must take into consideration the immediate and longterm soft tissue changes to gain a full understanding of the changes that may be seen following treatment. However, they considered that the longer-term effects are complex and are influenced by factors, such as relapse, remodeling, and the aging process (26).

Along with positive changes, certain orthognathic surgical procedures can also have detrimental effects on the soft tissues of the face, particularly in the nasal and submental regions. It is important that these are anticipated and minimized, but also that they are discussed during the planning and consenting stages of treatment as the patients need to understand the implications of treatment.

\subsubsection{The Immediate Response to Orthognathic Surgery}

The immediate soft tissue response to orthognathic surgery is largely determined by the magnitude of the inflammatory response to surgical injury. This has been prospectively investigated in several studies using three-dimensional facial scanning before and after surgery, including both bimaxillary and single jaw procedures (29-31).

Fig. 4 shows data collected in the study of (van der Vlis M et al, 2014) and outlines the reduction of facial swelling. It can be seen that it takes on average 3 weeks for the swelling to reduce by $50 \%, 3$ months for it to reduce by $80 \%$, and even after 6 months, 10 to $15 \%$ resolution needs to occur (31) during the following 6 months. Studies have also found some other interesting trends $(29,30)$ : 


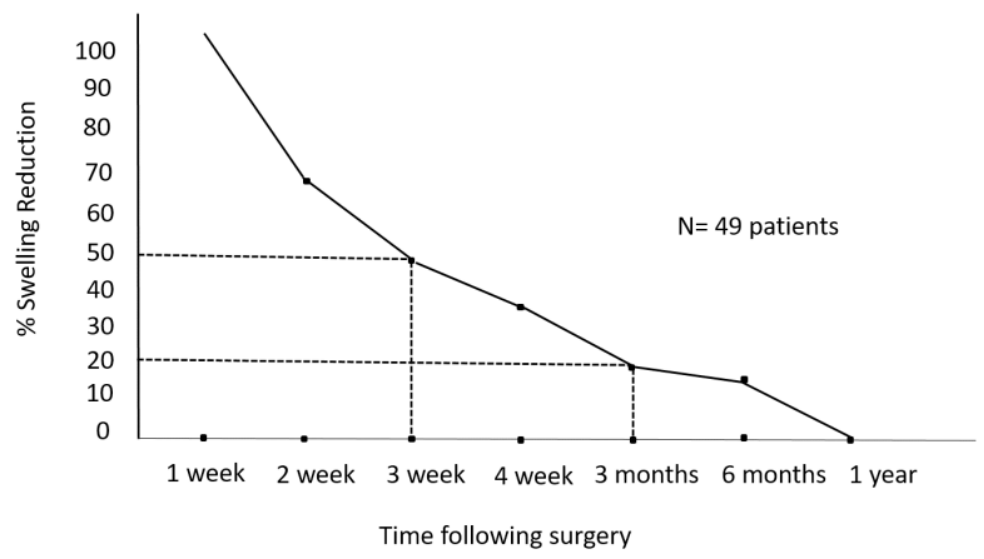

Fig. 4. Facial swelling reduction following orthognathic surgery (31).

1. There is large individual variation in the immediate (<6 months) soft tissue edema (swelling).

2. Peak swelling typically occurs approximately 48 hours after surgery.

3. The swelling may be asymmetrical. Patients and their caregivers should be reassured that this is normal; otherwise, it can become a matter of concern in the postoperative period.

4. There is a vertical gradient in the reduction of swelling with the resolution being quicker in the maxillary region compared with the mandibular region, possibly owing to the effects of gravity on the tissue fluids.

5. Resolution of swelling is also not symmetrical with one side often settling quicker than the other.

From the results of these studies, it is clear that the final soft tissue response, ignoring longer terms of soft tissue changes due to skeletal relapse, cannot be evaluated until at least 6 months, and ideally 12 months, following surgery. It is important that patients are informed of this during the consenting stages of treatment and that any fine-tuning, secondary, adjunctive surgical procedures, for example, rhinoplasty, are ideally planned following this period.

\subsection{Soft tissue Diagnostic Records}

Orthodontic records are one of the main milestones in orthodontic therapy. Records are essential not only for diagnosis and treatment planning but also for follow-up of the case, communicating with colleagues, and evaluating the treatment outcomes(32). 


\subsubsection{Two-dimensional techniques}

Orthodontists normally evaluate soft tissue form via a clinical exam with cephalometric radiographs and $2 \mathrm{D}$ extraoral photographs, focusing on the $2 \mathrm{D}$ profile photographs as the primary soft tissue evaluation tool and facial form analysis.

However, (Da Silveira 2003) found that treatment planning a 3D patient in a 2D way is insufficient as, "facial depth and shape are not accounted for"(33). (Sarver 2001) concluded that 2D facial photographs are prone to distortions in magnification, the patient's head posture/position, as well as the camera position, and the $2 \mathrm{D}$ frontal photographs, often fail to reveal skeletal asymmetries(34).

Clinicians also use the cephalometric soft and hard tissue measurements as a confirmation for the clinically based facial form diagnoses. (Park and Burstone, 1986) stated that we cannot rely on hard tissue dento-skeletal cephalometric measurements to predict facial soft tissue aesthetics, "Orthodontic treatment, by altering the dento-skeletal framework, may produce desirable or undesirable alterations in the external or integumental contours of the face"(35).

(Honrado 2004) also concluded that cephalometric soft tissue is an inadequate tool as they show just the midsagittal soft tissue while ignoring most of the other facial soft tissue(36).

(Jacobson A. \& Jacobson R. 2006) Summarized in their book the limitation of the 2D imaging techniques, as significant amount of radiographic projection error, enlargement, distortion, exposure to radiation, weaknesses of landmark identification, inaccurate duplication of measurements, significant variation in the position of reference points, such as sella turcica, and extreme limitations in assessing soft tissue balance (37). (Erten et al,2018) considered that when the clinician uses 2D imaging to view three-dimensional (3D) anatomical craniofacial structures, some cephalometric structures, and landmarks that do not exist in the patient appear such as mandibular symphysis, articular, pterygoid fossa (32), they also considered that 2D imaging systems are not able to overcome the loss of data when presenting a 3D object through a $2 \mathrm{D}$ view (38).

In 2001, Sarver explained, "Because orthodontics does not yet have morphometric tools for soft tissue evaluation that are comparable in quality and accuracy to those measuring dental and skeletal components, besides 2D and cephalometric soft tissue analysis were shown to be an imperfect means for facial form diagnosing, orthodontists must place greater emphasis on the physical examination of the patient and find better diagnostic methods for better soft tissue analysis (34) 


\subsubsection{Three-dimensional imaging in orthodontics and maxillofacial orthopedics}

After the introduction of 3D imaging systems, it was possible to evaluate structures in real three anatomical dimensions. Besides, not only the hard but also the soft tissues of the craniofacial region can be observed in three dimensions. These new systems have several advantages, they are non-invasive and therefore, repeating of images is not of ethical matter, and also, all images may be stored in digital forms, consequently archiving is much more practical, and extra space need for storage is handled in this way(32).

(Erten O, 2018) considered that 3D imaging systems are especially favorable for patients with craniofacial syndromes and anomalies such as cleft lip and palate (CLP)(32), these 3D imaging methods can be summarized as follows:

\subsubsection{Computed Tomography (CT)}

This scan contains 3D information about not especially hard but also soft tissues. Tomography is divided into fan beam and cone-beam computed tomography (CBCT). Traditional fan-beam tomography has a high radiation dose and it is expensive and not available in every health care hospital. Hence, it is not suitable for routine orthodontic applications. However, owing to the informative data about orofacial pathologies, maxillary sinus, temporomandibular joint (TMJ), orofacial trauma and fractures and craniofacial syndromes, it is still used widely in dentistry(32). Cone-beam computed tomography (CBCT) was designed to overcome some of the limitations of conventional CT scanning (39). Its cost is very low compared with the traditional CT, and more importantly, the 3D visualization with much less radiation dose is possible. However, it is still much higher than conventional 2D imaging systems

CBCT can be used for several approaches in orthodontics, enhancing the diagnosis such as identification of impacted and supernumerary teeth and to quantify the magnitude of the defect such as in patients with CLP (40-42), also for improving differential diagnosis of malocclusions, facial asymmetry, and the craniofacial anomalies.

\subsubsection{Intraoral Scanning}

With the introduction of the intraoral scanning technique, disadvantages of conventional impression techniques such as dimensional changes of impression materials, storage problems, and dental cast errors are overcome. Also, it is easier to take impressions from patients with gag reflexes (32). The development of digital models allows to obtain 3D diagnostic information, 
communicate between laboratory and orthodontists, create virtual set-ups and treatment planning, and fabricate custom-made fixed or removable appliances. Orthodontists can plan the treatment on the digital model, control the bracket positioning, and superimpose the before and after models, also they can be helpful to fabricate the lingual brackets and for indirect bracket bonding. However, according to the systematic review of (Goracci $\mathrm{C}$ et al,2016), inter-arch measurements such as overjet, overbite, molar relationship, and canine relationship need to be verified on virtually occluded digital models (43). Moreover, the time required for full-arch scanning in routine practice can be counted as a disadvantage of this technique (32).

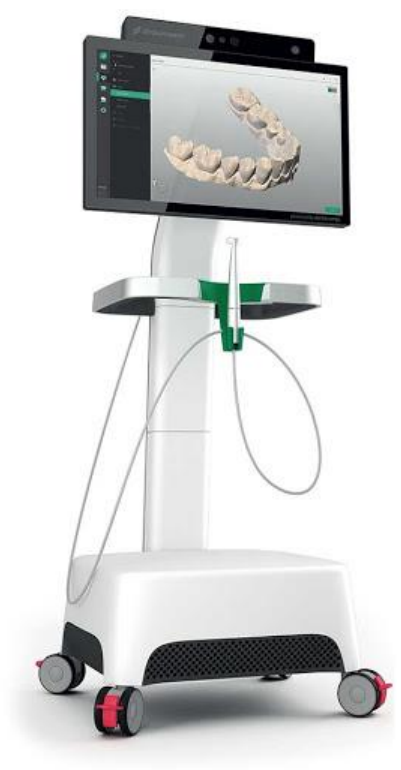

Fig. 5. The intraoral 3D scanner (The Straumann ${ }^{\circledR}$ CARES $^{\circledR}$, Craniofacial unit, Department of Oral and Maxillofacial Surgery, University of Szeged)

\subsubsection{Three dimensional Laser Scanning}

This approach is a less invasive method of capturing the face in comparison to many imaging modalities by avoiding the potentially harmful ionizing radiation encountered with traditional Xray techniques (44). Laser scanning can supply 3D images for treatment planning or evaluating the effects of many orthodontic and surgical procedures $(29,45)$. They have been successfully applied to analyze soft tissue changes following orthognathic surgery $(24,46)$. Drawbacks of this method can include difficulty in capturing fine soft-tissue detail and texture, having to close and protect eyes during scanning, and a relatively lengthy 10-plus second duration of image acquisition(47) 


\subsubsection{Stereophotogrammetry}

This scanning system is based on photographing objects by a pair of configured cameras and combining photos taken from two different directions to create 3D models(32). Studies showed that stereophotogrammetry has many advantages:

- It is a non-invasive and non-contact technique with no radiation exposure (48).

- It is good at capturing facial morphology and soft tissue changes (49-51)

- It has a short acquisition time and user-friendly and can be combined with CBCT images.

$-3 \mathrm{D}$ images can be used as a communication tool between clinicians, thus it is very useful for orthognathic surgery and patients with craniofacial anomalies (52-55). However, tissue reflections, hair, eyebrow, and curved surfaces such as the eyes and ears can influence the image process (56)

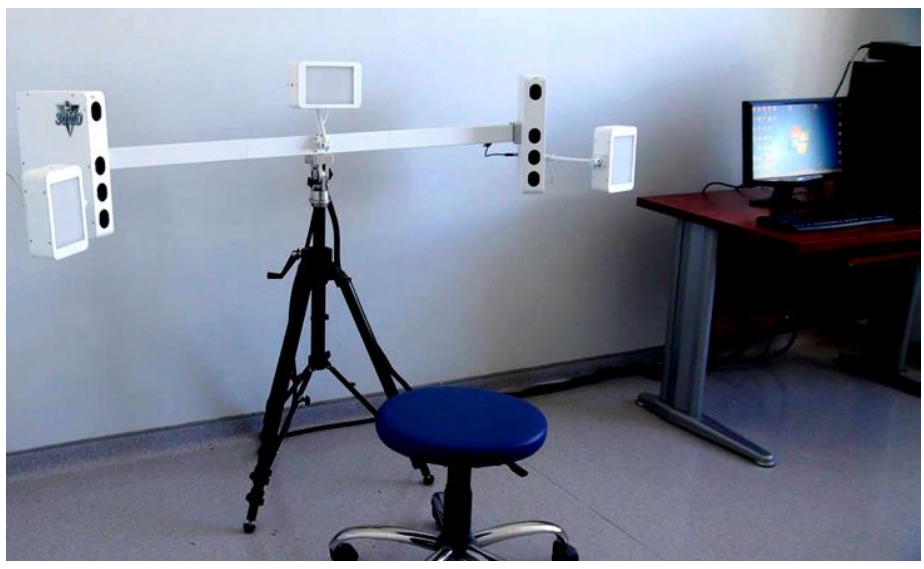

Fig. 6. Stereophotogrammetry with two different coplanar planes for 3D images (57)

\subsubsection{Structured-light scanning}

This technique enables capturing the three-dimensional shape of the face without the use of ionizing radiation. Following light illumination of the face, positioning of illuminated points is integrated with points on $3 \mathrm{D}$ cephalometric tracings. The result is a $3 \mathrm{D}$ shape of the patient's face, viewable on a computer screen. It can be used to combine the facial shape and underlying radiographic data from other sources to study 3D structures for diagnosis, treatment planning, and evaluation of treatment results. This technique has been applied to intraoral imaging in orthodontics, cleft lip analysis, and both cosmetic and orthognathic surgery. The emergence of handheld structured light devices has improved the accuracy, particularly for intraoral and facial scanning purposes $(44,52,58,59)$. 


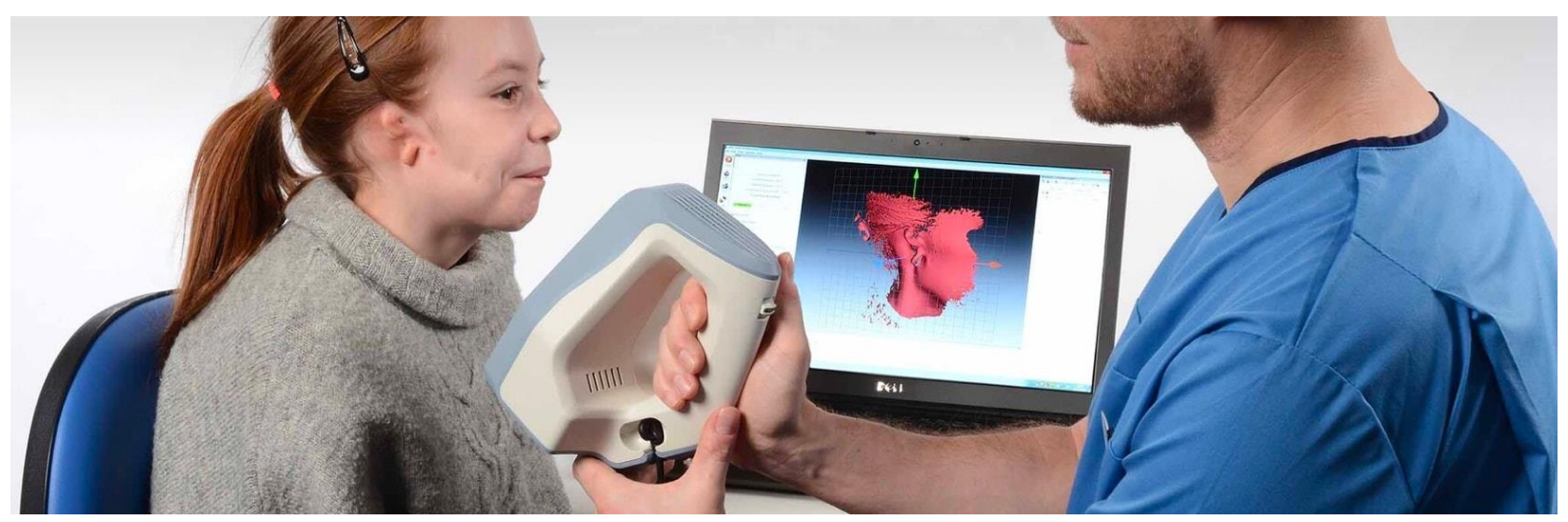

Fig.7. handheld structured- light 3D scanner in action (60)

\subsubsection{Video Camera, 4D Imaging and Video Stereophotogrammetry}

Since the human face has considered a dynamic structure especially the nose, lip, and mouth areas. The newest method is a 4D video capturing, which can record dynamic movements of the human face and enable the analysis of the dynamics of facial expressions (61). Several studies used 4D imaging in patients with CLP and orthognathic surgery to demonstrate asymmetry while making facial expressions, and differences in facial motion between individuals with and without CLP were evaluated (61). With these new technologies, new attempts have been performed to create a real-time 4D virtual patient in dynamic motion (62).
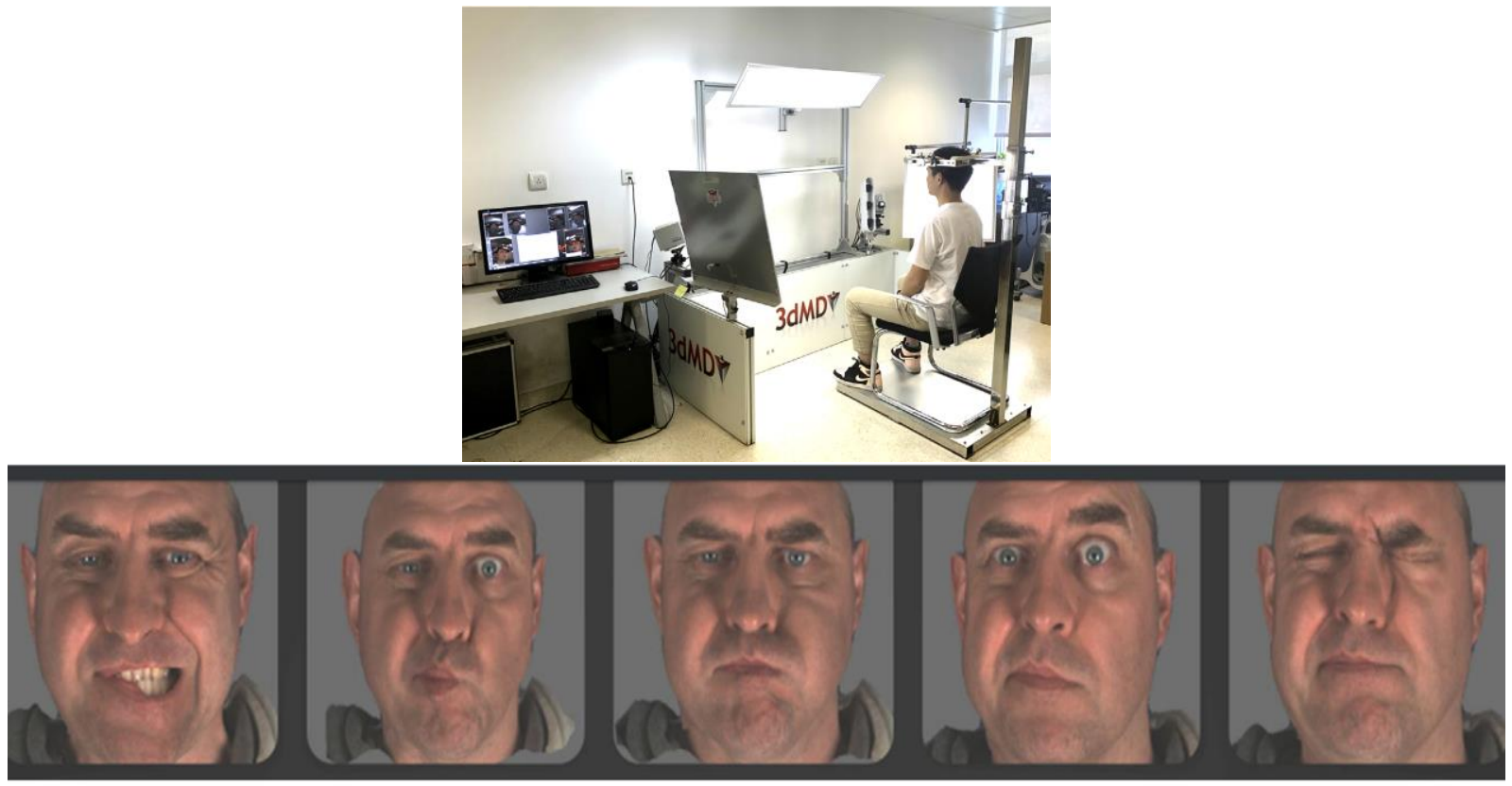

Maximum smile

Lip purse

Cheek puff

Maximum raising of eyebrows

Forceful eye closure

Fig. 8. The 3dMD-Face Dynamic System (3Q) Technologies and the facial expressions recorded $(63,64)$. 


\section{Aim}

- Introducing the 3D handheld structured-light scanner as a new method for prediction of the facial soft tissue changes in maxillofacial orthopedics.

- A comprehensive evaluation of soft tissue changes in various morphological regions of the face during our orthodontic treatment of the craniofacial deformities

- Extensive evaluation of facial soft tissue changes during our surgical correction of the craniofacial anomalies. 


\section{Materials and Methods}

Our research consisted of two prospective clinical studies aimed to assess the facial soft tissue changes, in these two parts, we used some inspection tools which assisted our work

\subsection{D handheld structured-light scanner (Artec Eva)}

Artec Eva (Artec Eva ${ }^{\mathrm{TM}}$; Artec Group, Luxembourg) (Fig. 9) is a professional, high-quality 3D scanner that is being used in a variety of medical, industrial, and animation settings. This scanner uses structured light scanning technology to accurately capture objects in a point-and-shoot manner with a point spacing of $0.1 \mathrm{~mm}$. These scanners work by enabling users to walk around the object intended to be scanned and maneuver the scanner to capture the entire object as completely as possible, capturing and simultaneously processing up to (2000000) points per second. The scanner captures up to 16 frames per second and each frame is a 3D image. These frames are aligned automatically in real-time, which makes scanning easy and fast. Eva scans a dozen times faster than a laser scanner while providing high resolution (up to $0.5 \mathrm{~mm}$.) and high accuracy (up to $0.1 \mathrm{~mm}$ ). It also captures color information at 24 bits per pixel (bpp) with a resolution of 1.3 megapixels (mp). Because of that high quality, the textured models can be used in such industries as CG/Animation, forensics, and medicine (60)

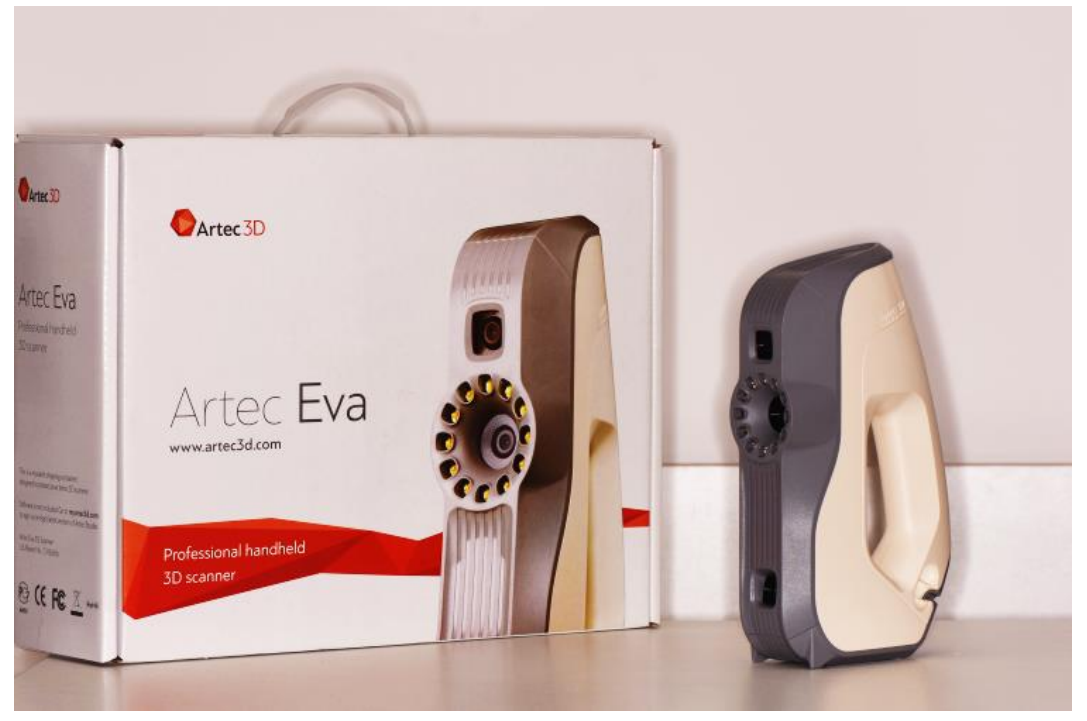

Fig. 9. Artec Eva (Craniofacial unit, Department of Oral and Maxillofacial Surgery, University of Szeged) 


\subsection{Software}

\subsubsection{Artec Studio 12}

Artec Studio is an industry-acclaimed software package for advanced 3D scanning and data processing. This software includes an autopilot mode that automatically chooses the best algorithms for captured data to develop the most accurate 3D model (65).

\section{The most complete and user-friendly version of Artec's award-winning 3D software \\ Cutting-edge $3 \mathrm{D}$ scanning and post-processing software with $3 D$ intelligence, unparalleled speed and ease of use.}

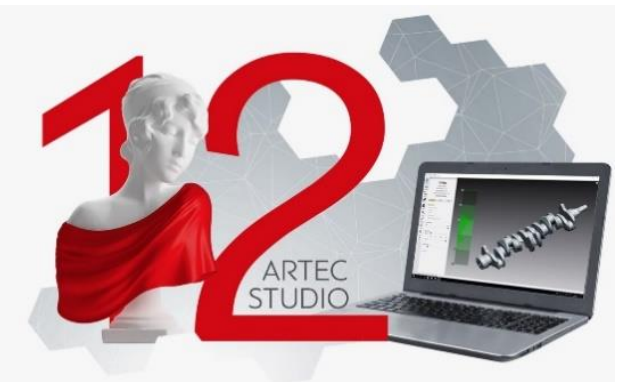

Fig. 10. Artec Studio software V.12 (Craniofacial unit, Department of Oral and Maxillofacial Surgery, University of Szeged)

\subsubsection{GOM Inspect evaluation software}

$3 \mathrm{D}$ inspection processing of polygon meshes communication of measuring results. It is software for analyzing 3D measuring data from a fringe projection or laser scanners, coordinate measurement machines (CMM), and other measuring systems. The GOM software is used in product development, quality control, and production, it also distinguishes between different materials of the scanned object to generate a surface for each material. Besides, the polygonization area can be restricted, which reduces the import to relevant partial areas of the overall volume. All surfaces, even internal structures, can be used for shape and dimension analyses or nominal/actual comparisons(66).

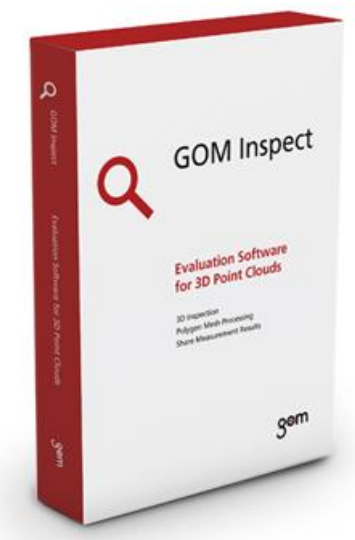

Fig. 11. GOM Inspect Evaluation Software (Craniofacial unit, Department of Oral and Maxillofacial Surgery, University of Szeged) 


\subsection{Computer workgroup}

Desktop-computer with high specifications: (Intel Core i7, CPU@ 3.20 GHz, RAM 16 G.B), besides two high-quality laptops to facilitate our work with the required software.

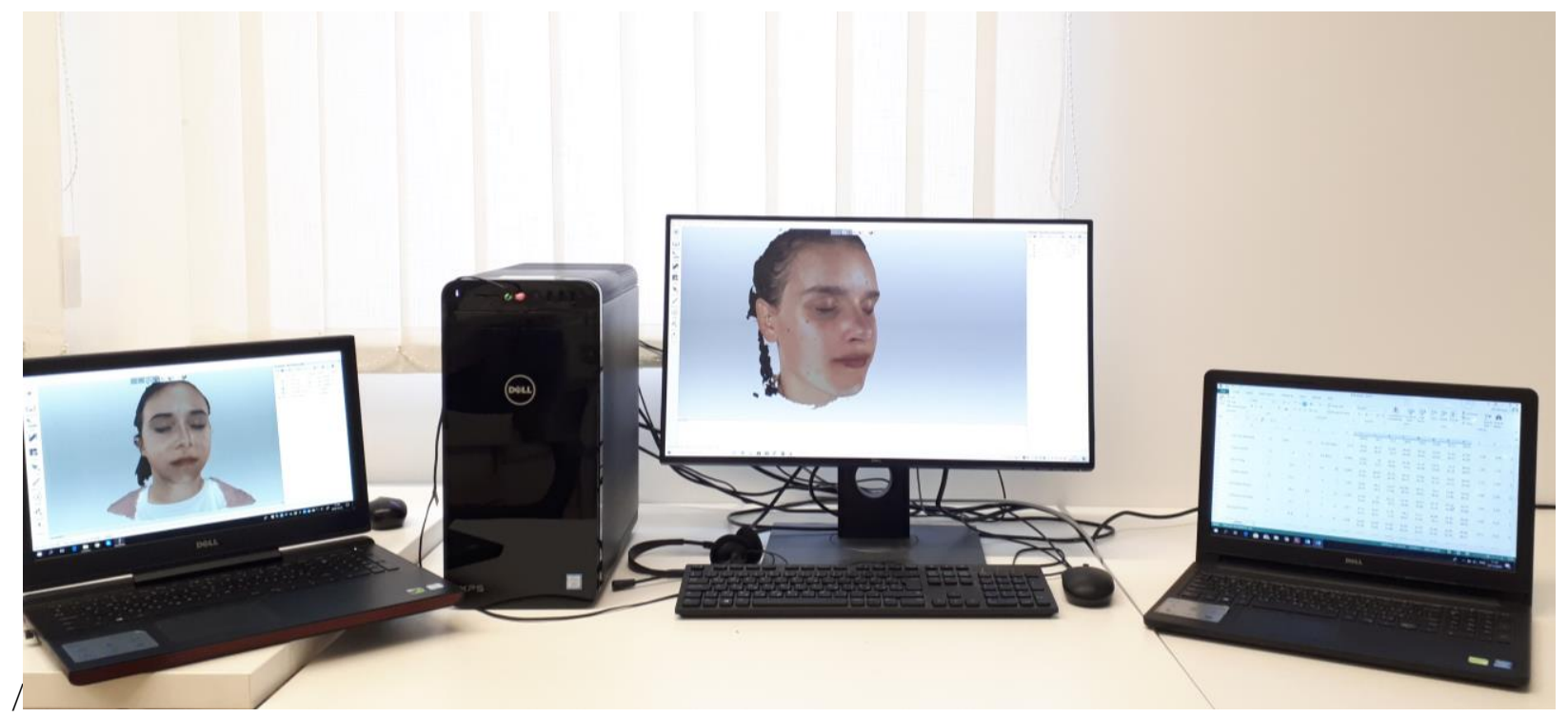

Fig.12. Computer workgroup (Craniofacial unit, Department of Oral and Maxillofacial Surgery, University of Szeged) 


\section{First prospective clinical study}

\section{Evaluation of the Soft Tissue Changes after Rapid Maxillary Expansion Using a handheld Three Dimensional Scanner}

\subsection{Introduction}

Rapid maxillary expansion (RME) is routinely used by orthodontists to eliminate skeletal maxillary transversal deficiency; it is used particularly in patients with a posterior crossbite, moderate crowding, and sleep apnea disorders (10,67-69), to achieve the apical opening of the maxillary base along the midpalatal suture.

The approach relies on the forces generated employing the RME appliances, which can mechanically separate the maxillary segments at the mid-palatal suture $(10,69,70)$. By this treatment, the following can be achieved: correction of the skeletal transversal deficiency and gain of space in the dental arch (71), improved smile through reducing the buccal corridors (72), and expansion of the airway (73).

It is very important to understand the impacts of expansion with RME on the facial soft tissue morphology to be able to determine the impediments of the treatment. It is in the patients' best interest that such changes are understood (74). Still, the area is surprisingly under-researched and several questions are unclarified.

Until recently, changes in the soft tissue envelope and the underlying skeletal structures following RME had been examined through two-dimensional (2D) imaging techniques, mostly lateral cephalometric images, anteroposterior graphs, and photogrammetric analyses (75-77). However, these methods suffer from superimposition and magnification problems, which can be avoided using three-dimensional (3D) imaging.

Out of the three-dimensional imaging methods, cone-beam computed tomography (CBCT) is becoming increasingly popular. However, soft tissues are poorly represented using this technique(78).

Therefore, non-contact optical scanning devices were introduced as 3D imaging techniques for soft tissue visualization like laser surface scanning and stereophotogrammetry [14]. These noninvasive approaches allow images to be captured at short intervals without exposing the patient to 
the radiation, which makes them an appealing option (79). However, these devices are often bulky and also rather expensive, which are deterring factors (80).

By using handheld 3D structured-light scanners, texture and color information of the face can be promptly obtained in high resolution without radiation. Further advantages include short scan time, portability, ease of operation, and reasonable cost (81).

Jung et al. found that the accuracy of structured light systems compares to that of direct anthropometric measurements and concluded that it is a reliable approach for facial soft tissue assessment (82).

Most of the previous studies which utilized 3D facial scanners to evaluate soft tissue changes following RME have examined deviations at specific points and calculated linear and angular measurements $(83,84)$. However, it is more accurate to predict changes within the whole complex structures on a 3D basis rather than only between specified points. Having recognized that, our study aimed to adopt a comprehensive examination of soft tissue in various morphological regions of the face after 6 months of retention following RME, based on structured-light scanning.

\subsection{Materials and Methods}

\subsubsection{Study sample}

This study was approved by the Human Investigation Review Board, the University of Szeged, Albert Szent-Györgyi Clinical Centre (No. 151/2019-SZTE). Informed consent was obtained from the parents of all patients who agreed to participate in this study.

Patients in need of upper arch expansion were recruited from among the patients of the Craniofacial Unit, Department of Oral and Maxillofacial Surgery, Albert Szent-Györgyi Clinical Center, University of Szeged, Hungary. The inclusion criteria included maxillary transverse deficiency, assessed both clinically and radiographically, associated with either unilateral or bilateral posterior crossbite and/or dental crowding. Exclusion criteria included the history of trauma or previous orthodontic treatment and patients with physical and psychological limitations and/or craniofacial anomalies.

The sample size was calculated based on the findings of Kim et al. [20], and the analysis was performed with G*Power software (Franz Faul, Universität Kiel, Germany) Version 3.1.9.4, based on the assumption of the Wilcoxon rank test. A sample size of 23 patients was predicted to provide $80 \%$ of the power with a $5 \%$ error of probability. 28 patients were eligible, but one of them had had orthodontic treatment before and two of them had poor oral hygiene, so a total of 25 patients 
(13 females and 12 males) with a mean age of 11.6 years (range: 8.1-14.4 years) were enrolled in our study. The 3D facial images were acquired immediately before the appliance was cemented $\left(\mathrm{T}_{0}\right)$ and at the end of the 6-month retention phase $\left(\mathrm{T}_{1}\right)$, using a structured-light $3 \mathrm{D}$ handheld scanner (Artec Eva ${ }^{\mathrm{TM}}$; Artec Group, Luxembourg). A 6-month retention period was chosen to control for growth, which could have interfered with the results in the case of a longer period.

The proposed scanner uses structured light scanning technology to accurately capture in a pointand-shoot manner up to 16 frames per second and each frame is a 3D image. These frames are aligned automatically in real-time while providing high resolution (up to $0.1 \mathrm{~mm}$ ). All images were taken with the head in a natural head position, teeth in centric occlusion, and lips in repose (85). To reach the natural head balance, subjects were seated in a back-supported and vertically adjustable chair. They were asked to turn their heads forward and backward with decreasing amplitude until they reached a relaxed position (86). Then they were told to look straight ahead to a point on the wall in front of them at eye level.

\subsubsection{Clinical Protocol}

Following upper and lower alginate impressions, a Hyrax-type expander was constructed with 4 bands, palatal stainless steel bars of 1.0-mm diameter, and a jackscrew (Forestadent, Pforzheim, Germany) with stainless steel extensions soldered to the palatal surfaces of each pair of bands. The activation of the jackscrew was for each quarter turn equivalent to $0.25 \mathrm{~mm}$ (Fig.13, 14).
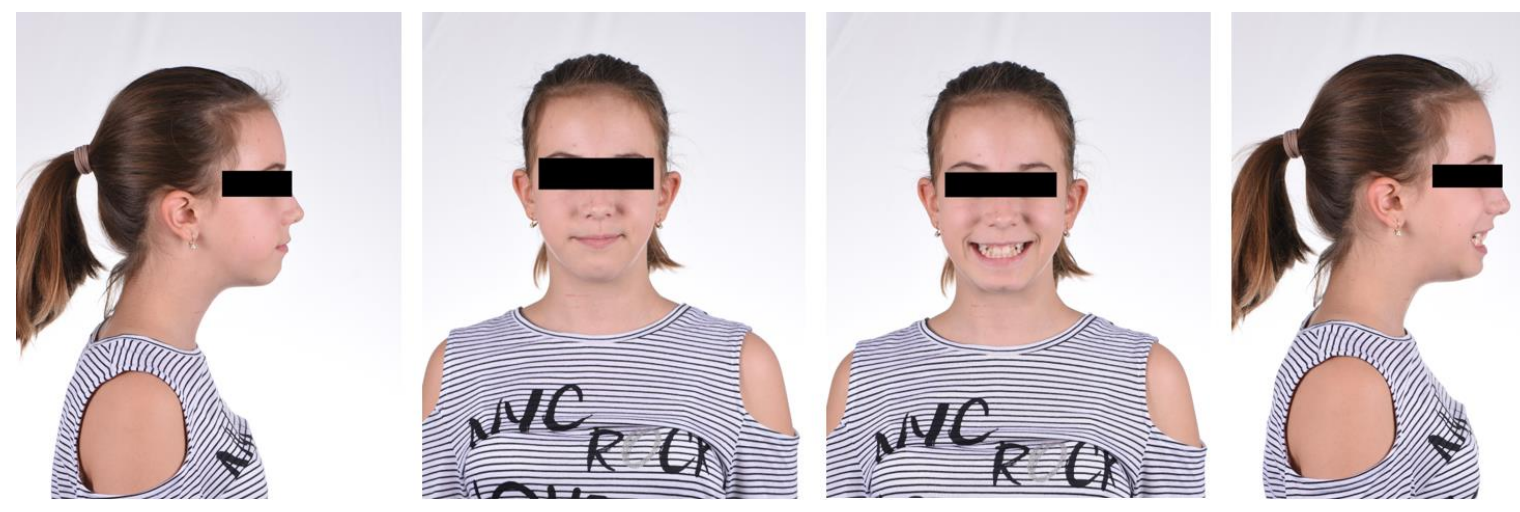


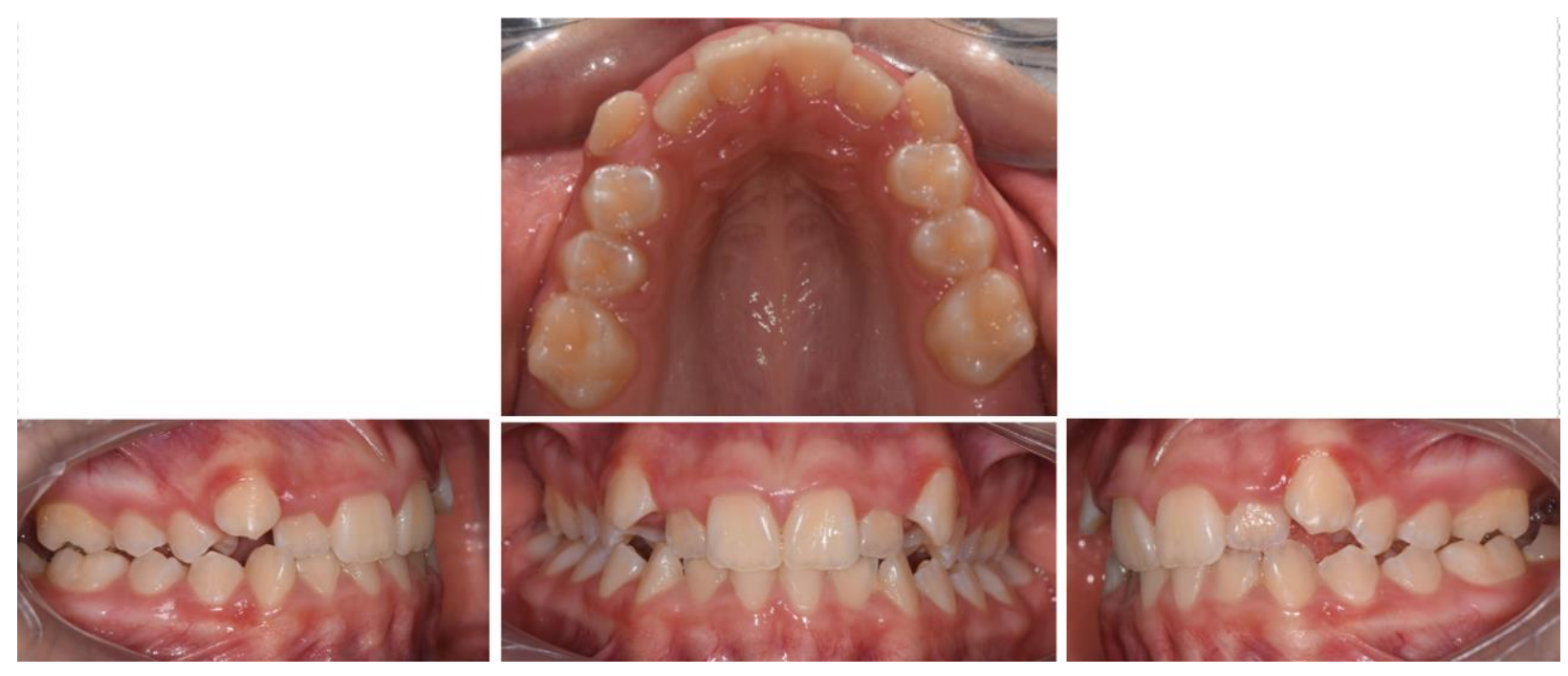

Fig. 13. Extra-oral and intraoral photographs of one patient who needed treatment using RME (To pre-treatment)
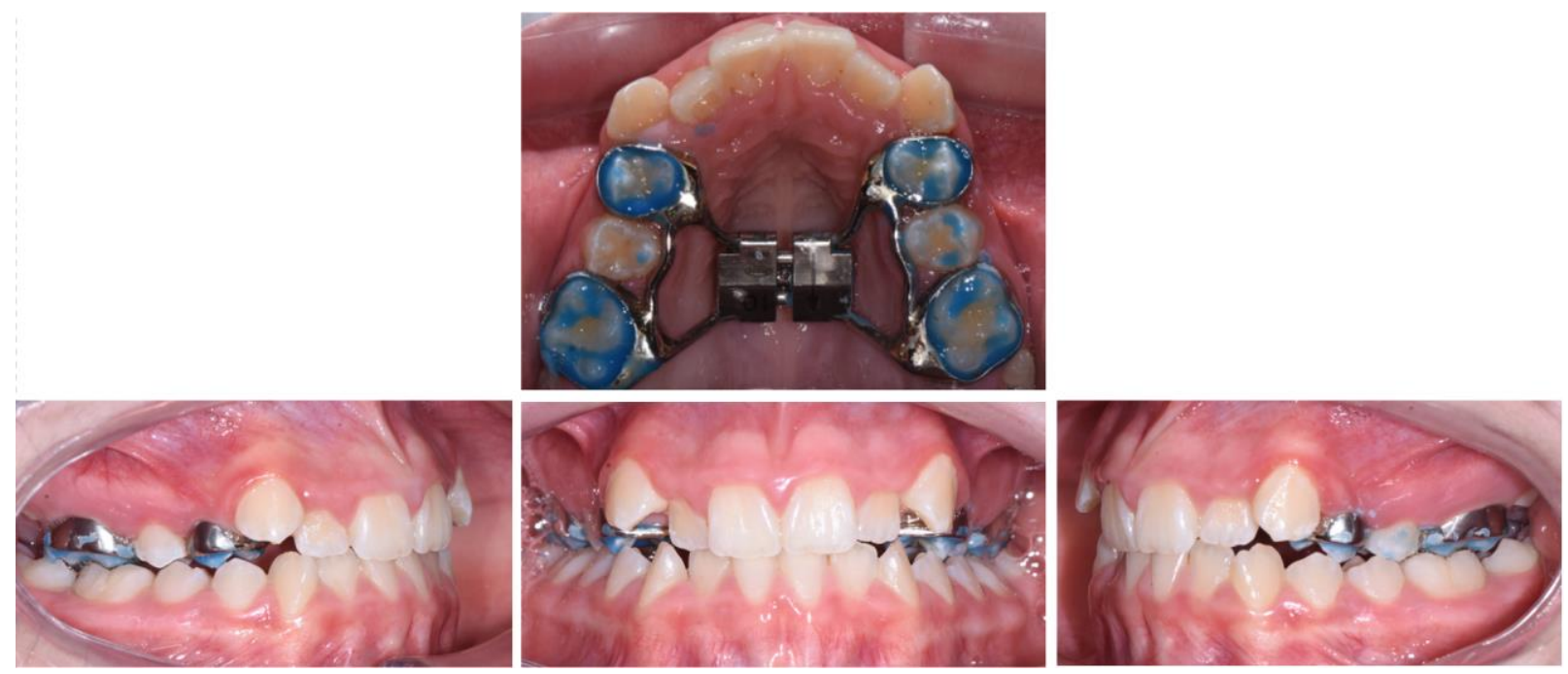

Fig. 14. Intraoral photographs of the patient at the time of the RME appliance cementation

The parents were instructed to activate the screw 2 turns per day $(0.5 \mathrm{~mm})$ and the patients were recalled on a weekly basis of the expansion period (2 to 3 weeks). The expansion was stopped when the palatal cusp of the upper molars was touching the buccal cusp of the lower molars (87). Then the appliance was kept in for the retention period (6 months), and the jackscrews were blocked with composite, to prevent relapse (Fig.15). 


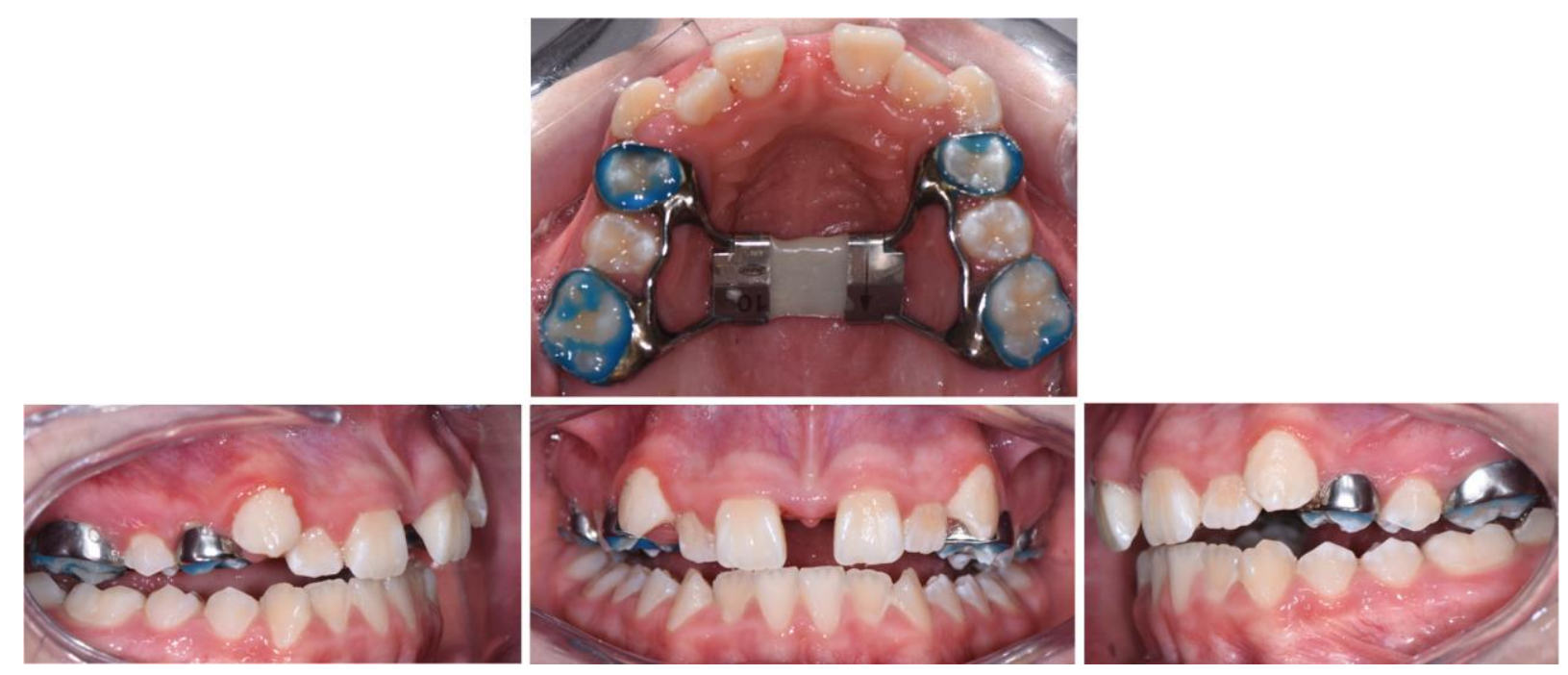

Fig. 15. Intra-oral photographs after the expander was blocked for retention
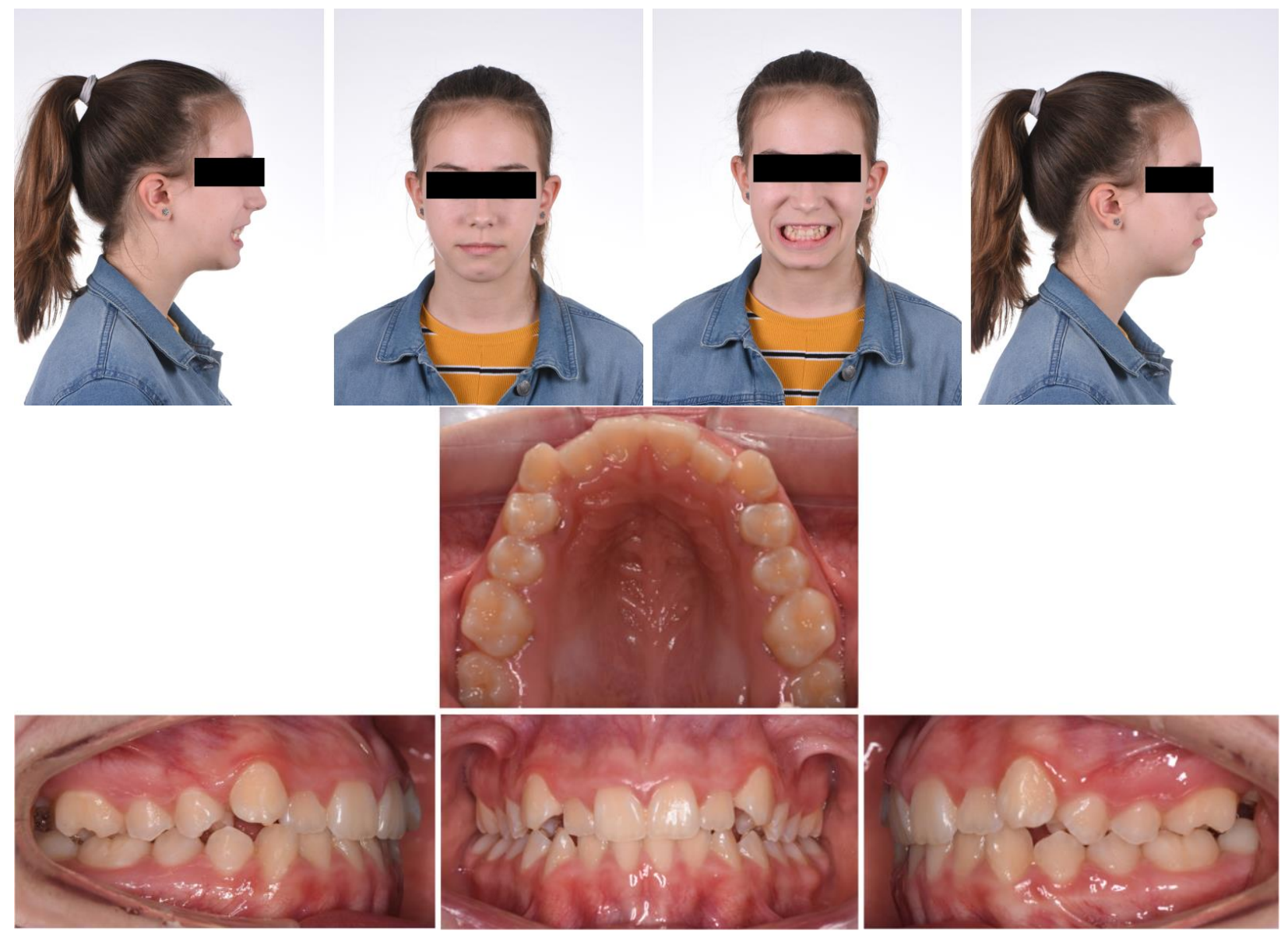

Fig. 16. Extra-oral and intraoral photographs of the patient after removal of the RME appliance ( $T_{1}$ post-treatment)

The expansion amount of the Hyrax jackscrew was measured for each patient. Dental cast models were also made before expander cementation and after the retention period. The distance between 
the mesial buccal cusp of the right and left upper first molar was measured before and after the expansion and the difference was calculated.

After removal of the Hyrax appliance (Fig.16), we continued the treatment for all our patients using a fixed appliance (self-ligating multibracket appliance, Roth prescription) (Fig.17).

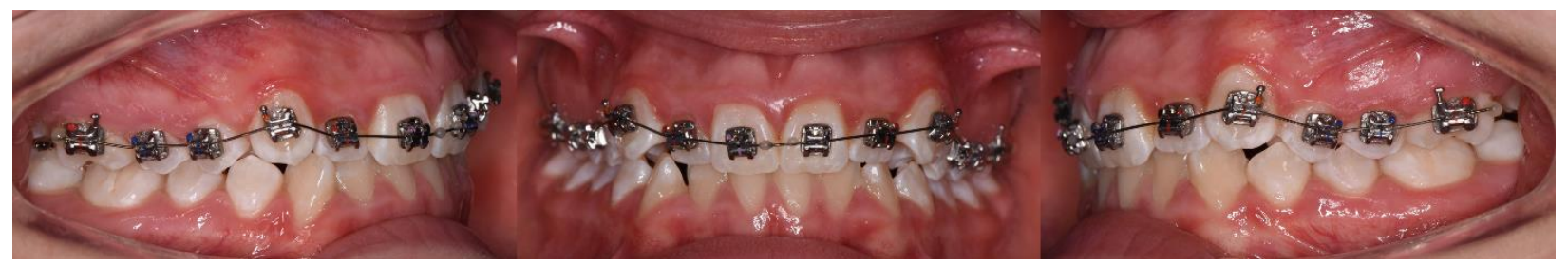

Fig. 17. Intraoral photographs for the orthodontic treatment with a fixed appliance

\subsubsection{Data processing and measurements}

18 landmarks ( 5 bilateral and 8 unilateral: Table 1, Fig. 18.) were defined according to the literature $(88,89)$. 4 linear and 3 angular measurements were performed directly on the 3D facial images using Artec Studio V.12 (Fig.19, 20.)
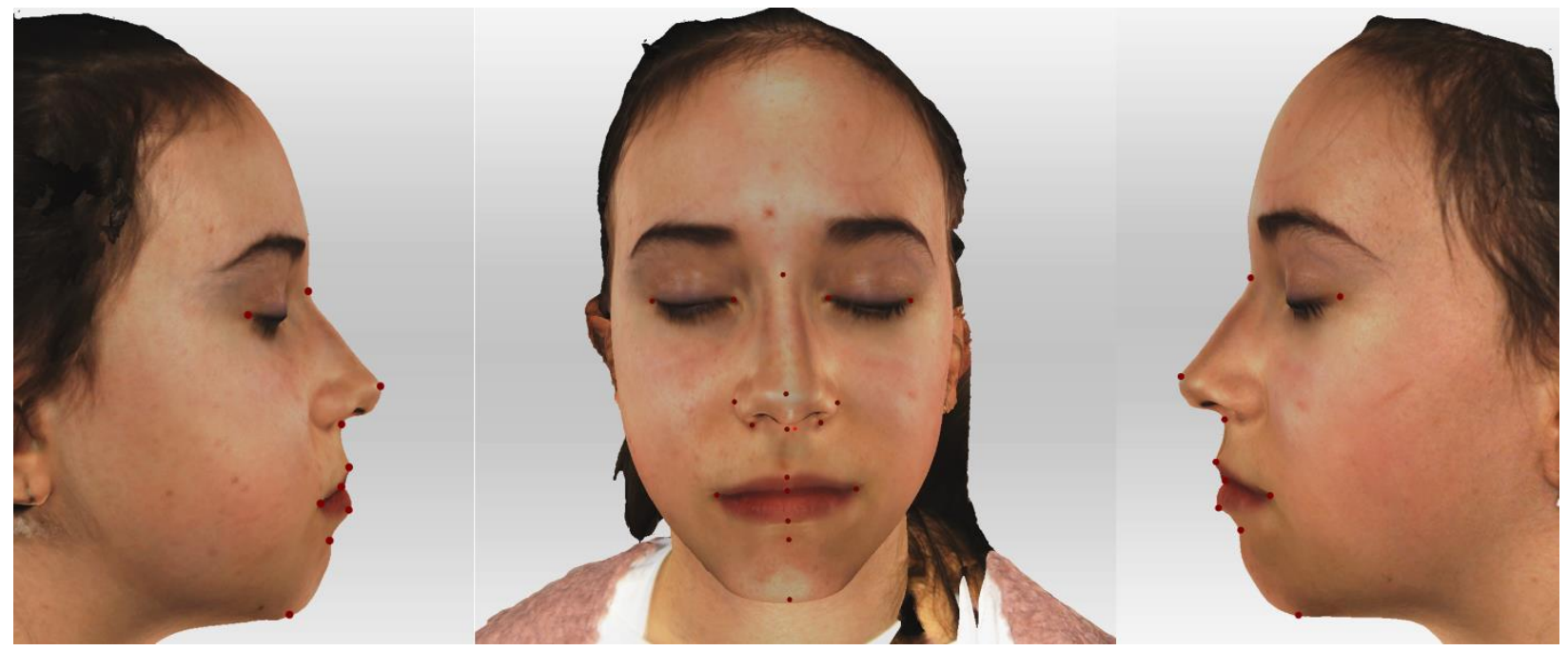

Fig. 18. Landmarks used in our study located on the 3D-facial images (frontal and lateral views) 

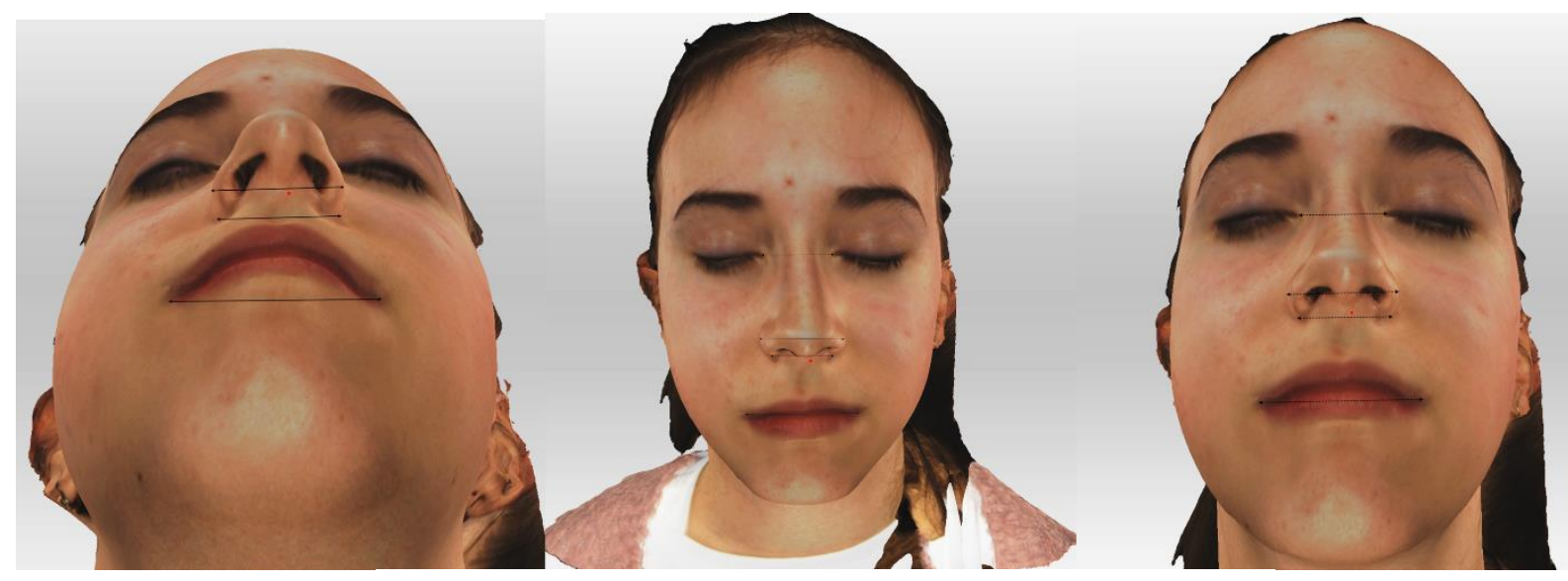

Fig. 19. Linear measurements used in our study
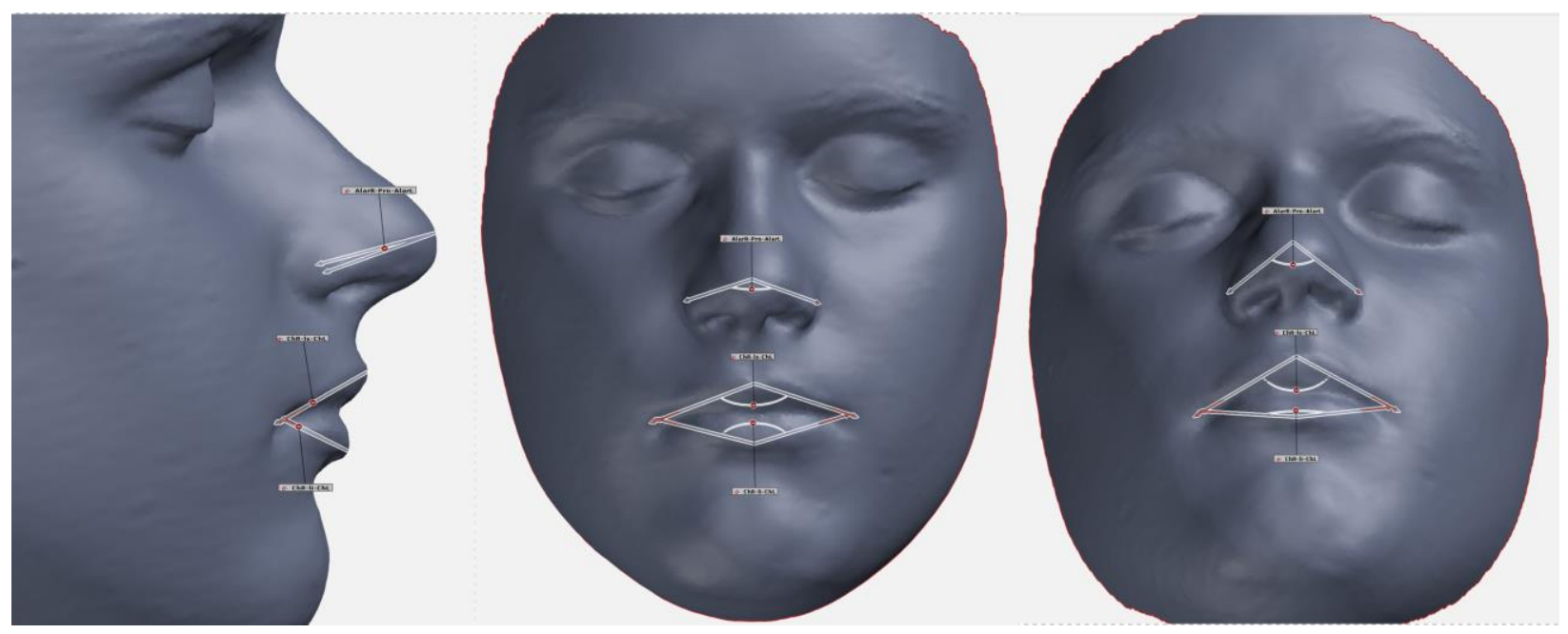

Fig. 20. Angular measurements used in our study

For the 3D deviation analysis, the 3D facial images were transferred into reverse engineering software (GOM Inspect Evaluation Software, Capture 3D, Inc, Santa Ana, CA) and polygon meshes were created in stereolithography (STL) format. The hair, ears, and the below-neck region were removed. The images obtained at the $\mathrm{T}_{0}$ time point were aligned with the images taken at $\mathrm{T}_{1}$ using the best-fit method, as described by Dindaroglu et al.(90) (Fig. 21). 

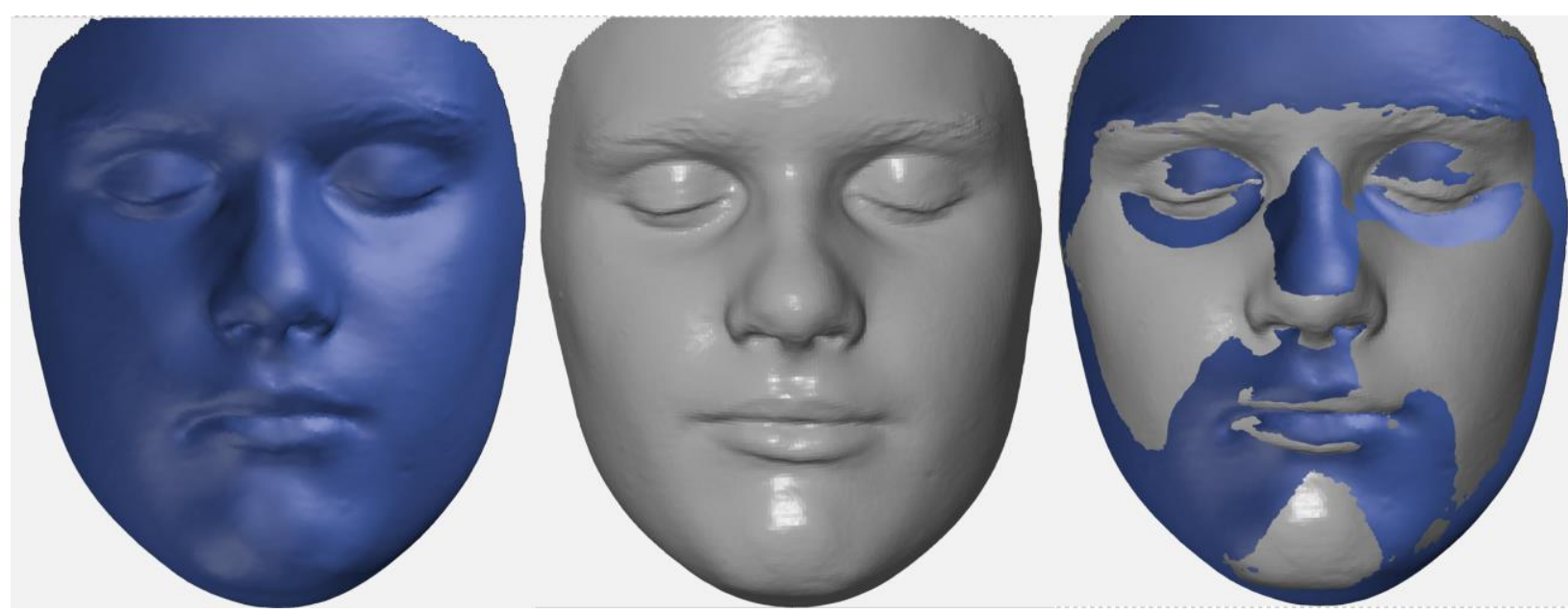

Fig. 21. The best-fit method used in our study to align the $\mathbf{T}_{0}$ and $\mathbf{T}_{1}$ meshes.

Negative values indicate that $T_{1}$ images were located behind the $T_{0}$ images (blue shades), whereas positive values indicate that $T_{1}$ images were located in front of the $T_{0}$ images (red shades). To create morphological regions, eight lines passing through different points specified on the face were determined and a 3D deviation analysis was made in six morphological regions (90) (Table 2, Fig. 22).
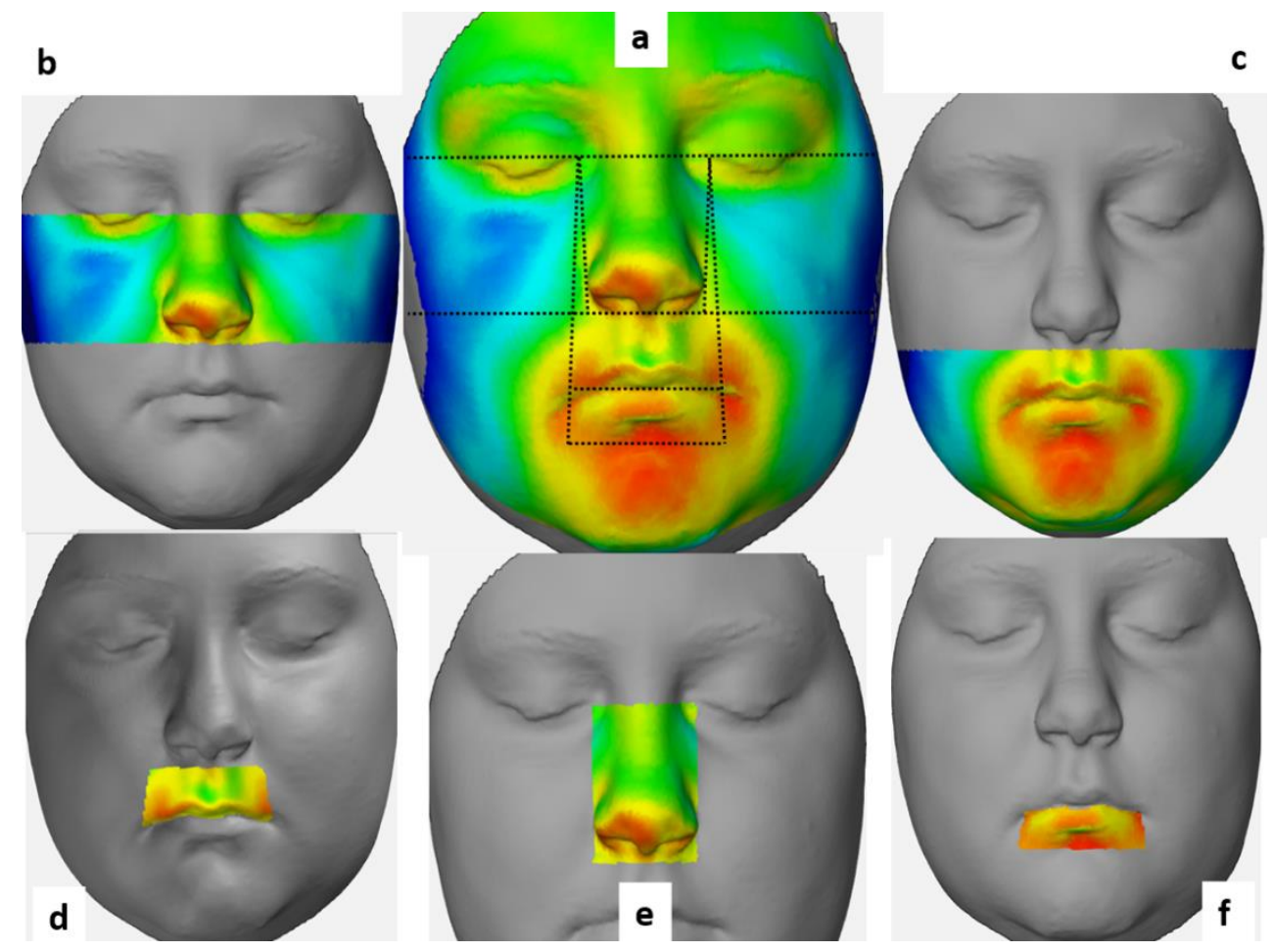

Fig.22 The morphological regions and their reference lines used in our study: a Total face region with the reference lines used; b Upper face region; c Lower face region; d Upper lip region; e Nose region; f Lower lip region 
We also calculated the deviation magnitude for specific facial landmarks directly on the 3D inspected meshes (Fig. 23).
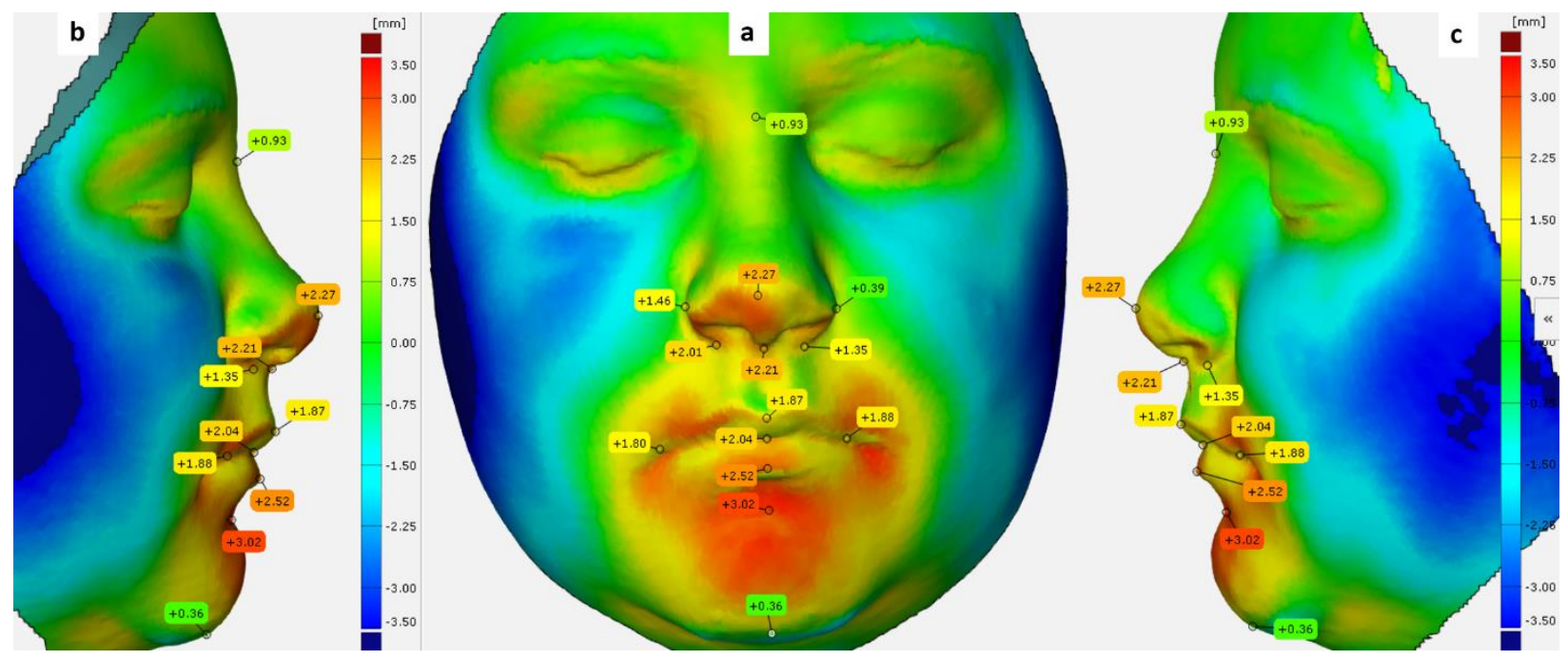

Fig.23 Deviation labels for the facial soft tissue landmarks used in our study: a Frontal view; b and c Lateral views

Table 1. Definition of facial landmarks used in our study.

\begin{tabular}{|c|c|c|}
\hline \multicolumn{2}{|l|}{ Landmark } & Definition \\
\hline Exocanthion & Ex* & The point at the outer commissure of the eye fissure \\
\hline Endocanthion & End* & The point at the inner commissure of the eye fissure \\
\hline Sellion & Se & $\begin{array}{l}\text { The most posterior point of the frontonasal soft tissue contour in the midline of the base of the } \\
\text { nasal root. }\end{array}$ \\
\hline Alare & $\mathbf{A l} *$ & The most lateral point on each alar contour (on the base view). \\
\hline Pronasale & Prn & $\begin{array}{l}\text { The most anterior midpoint of the nasal tip (on the right and left profile view). If a bifid nose is } \\
\text { present, the more protruding tip is chosen to determine Pronasale }\end{array}$ \\
\hline $\begin{array}{l}\text { Alar curvature } \\
\text { point }\end{array}$ & Ac* & The point is located at the facial insertion of each alar base. (on the submental view) \\
\hline Subnasale & Sn & Midpoint on the nasolabial soft tissue contour between the Columella crest and the upper lip \\
\hline Labiale superius & Ls & The midpoint of the vermilion line of the upper lip (on the submental view). \\
\hline Stomion & Stm & The midpoint of the horizontal labial fissure. \\
\hline Chelion & Ch* & The point is located at each labial commissure (on the frontal view). \\
\hline Labiale inferius & Li & The midpoint of the vermilion line of the lower lip (on the right profile view). \\
\hline Sublabiale & Sl & $\begin{array}{l}\text { The most posterior midpoint on the Labiomental soft tissue contour defines the border between } \\
\text { the lower lip and the chin. }\end{array}$ \\
\hline Soft tissue Menton & $\mathbf{M e}^{\prime}$ & $\begin{array}{l}\text { The most inferior midpoint on the soft tissue contour of the chin located at the level of the 3-D } \\
\text { cephalometric hard tissue Menton landmark }\end{array}$ \\
\hline
\end{tabular}


Table 2. Definition of morphological regions used for the 3D deviation analyses

\begin{tabular}{|c|c|}
\hline Region & Definition \\
\hline Total face & The facial region designated while creating masks prior to alignment \\
\hline Upper face & $\begin{array}{l}\text { The region between the line passing through the right and left Exocanthion points and the line passing through } \\
\text { the Subnasal point parallel to that line. }\end{array}$ \\
\hline Lower face & $\begin{array}{l}\text { The region between the line passing through the Subnasal point and the line passing through the Menton point } \\
\text { parallel to that line. }\end{array}$ \\
\hline Upper lip & $\begin{array}{l}\text { The region between the lines passing through the right and left Endocanthion points and the right and left } \\
\text { Cheilion points, and the line passing through the Subnasal point }\end{array}$ \\
\hline Lower lip & $\begin{array}{l}\text { The region between the lines passing through the right and left Endocanthion points and the right and left } \\
\text { Cheilion points, and the line passing through Sublabiale point parallel to other lines. }\end{array}$ \\
\hline Nose & $\begin{array}{l}\text { The region between the lines passing through the right and left Endocanthion points that are tangent to the } \\
\text { nasal wings and the line passing through the Subnasal point }\end{array}$ \\
\hline
\end{tabular}

\subsection{Statistical Analysis}

Normal distribution of the data was established with the Shapiro-Wilk and Kolmogorov-Smirnov tests. To determine the method's reliability, $\mathrm{T}_{0}$ and $\mathrm{T}_{1}$ images of 10 randomly selected patients were re-aligned and the measurements were recalculated one month later by the same investigator. Intra-examiner reliability was assessed to evaluate the reliability of the measurements in the same image and by the same investigator using the Intraclass Correlation Coefficient (ICC). The random errors were calculated according to Dahlberg's formula $\left(D=\sqrt{ } \sum \mathrm{d} 2 / 2 \mathrm{~N}\right)(91)$, where $D$ is the error variance and $\mathrm{d}$ is the difference between the first and second measures. $\mathrm{N}$ is the sample size, which was re-measured. The systematic errors were also evaluated by comparing the first and second measurements using the dependent t-test. The (T0) and (T1) linear and angular measurements were compared. Significant differences at the level of $5 \%$ of significance were tested using a Wilcoxon signed-rank test. Besides, for each patient, 3D deviation analysis was performed to calculate not only the maximum positive and negative deviation, but also the mean deviation for the facial meshes. Then, the Pearson correlation coefficient was calculated to determine the correlation between the expansion amount (expressed as the amount of jackscrew activation and resulting width difference of the upper arch) and the facial soft tissue changes. All statistical analyses were performed in SPSS 24.0 (IBM, Armonk, NY, USA).

\subsection{Results}

All parameters were normally distributed, according to the Shapiro-Wilk and KolmogorovSmirnov tests. No significant errors were found when repeating the measurements. The ICC values 
between the two sets of measurements were in a high range of (0.821-0.979). The amount of random error was small enough (less than $0.5 \mathrm{~mm} /{ }^{\circ}$ ), and no systematic errors were found between the measurements obtained on the two different occasions ( $p \geq 0.05$ ).

The mean value of the jackscrew activation after RME was $(7.75 \mathrm{~mm})$ and the mean of the upper arch width difference calculated on the dental casts was $(5.46 \mathrm{~mm})$. Statistically significant changes of the soft tissue variables were found after RME using the Wilcoxon rank test (Table 3).

The mean linear changes of the nasal width and the nasal base width after RME were $1.02 \mathrm{~mm}$ and $1.21 \mathrm{~mm}$, respectively, and $2.62 \mathrm{~mm}$ for the mouth width. While we also found significant angular changes after RME, the nasal tip angle increased by $3.2^{\circ}$, while the upper and lower lip angle has increased by $3.47^{\circ}$ and $3.78^{\circ}$, respectively as seen in (Table 3 ).

Table 3. Descriptive statistics of the pretreatment $\left(T_{0}\right)$ and posttreatment $\left(T_{1}\right)$ measurements

\begin{tabular}{|c|c|c|c|c|c|c|c|}
\hline & & \multicolumn{2}{|l|}{$\mathbf{T}_{\mathbf{0}}$} & \multicolumn{2}{|l|}{$\mathbf{T}_{1}$} & \multirow[b]{2}{*}{$\Delta=\mathbf{T}_{1-} \mathbf{T}_{0}$} & \multirow[b]{2}{*}{$\mathbf{P}$} \\
\hline & & Mean & SD & Mean & SD & & \\
\hline \multicolumn{7}{|c|}{ Linear measurements (mm) } & \\
\hline Intercanthal width & $\left(E n_{R}-E n_{L}\right)$ & 30.93 & 2.42 & 31.58 & 2.4 & 0.65 & NS \\
\hline Nasal width & (Alar R.-Alar.L) & 31.98 & 2.83 & 33.09 & 3.27 & $1.02 *$ & $0.023 *$ \\
\hline Nasal base width & $\left(A c_{R}-A c_{L}\right)$ & 30.26 & 2.67 & 31.48 & 2.85 & $1.21 *$ & $0.018^{*}$ \\
\hline Mouth width & $\left(\mathrm{ch}_{\mathrm{R}}-\mathrm{ch}_{\mathrm{L}}\right)$ & 43.28 & 3.8 & 45.9 & 3.7 & $2.62 *$ & $0.01 *$ \\
\hline \multicolumn{7}{|c|}{ Angular measurements $\left({ }^{\circ}\right)$} & \\
\hline Nasal tip angle & 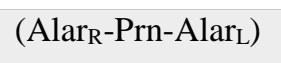 & 85.82 & 6.13 & 89.03 & 6.2 & $3.2 *$ & $0.05^{*}$ \\
\hline Upper lip angle & $\left(\mathrm{Ch}_{\mathrm{R}}-\mathrm{ls}-\mathrm{Ch}_{\mathrm{L}}\right)$ & 110.66 & 4.3 & 114.13 & 5.7 & $3.47 *$ & $0.023 *$ \\
\hline Lower lip angle & $\left(\mathrm{Ch}_{\mathrm{R}}-\mathrm{li}-\mathrm{Ch}_{\mathrm{L}}\right)$ & 122.16 & 6.1 & 125.94 & 6.34 & $3.78 *$ & $0.047 *$ \\
\hline
\end{tabular}

We also calculated the descriptive statistics of the maximum positive and negative deviation limits of the meshes, as shown in (Table 4). The mean of the maximum positive and negative deviation found in the total face was $(3.09,-2.93 \mathrm{~mm})$ respectively, $(2.16,2.81 \mathrm{~mm})$ both for the upper and lower face as positive deviation, and $(-1.9,-2.87 \mathrm{~mm})$ for the negative ones, we also found $(2.16$, $1.37 \mathrm{~mm})$ as a positive deviation of both the upper and lower lip regions, and $(-1.5,-2.02 \mathrm{~mm})$ as the negative ones. While the mean of the maximum positive and negative deviation found in the nasal region were $(2.04,-1.25 \mathrm{~mm})$ respectively. 
Table 4. Descriptive statistics of the maximum positive and negative deviation in the morphological regions

\begin{tabular}{|l|r|r|r|l|l|l|l|l|}
\hline Morphological region & \multicolumn{4}{|c|}{ Maximum positive deviation limits (mm) } & \multicolumn{3}{|c|}{ Maximum negative deviation limits (mm) } \\
\hline & Minimum & Maximum & Mean & SD & Minimum & Maximum & Mean & SD \\
\hline Total face & 1.72 & 5.43 & 3.09 & 0.92 & -5.88 & -1.93 & -2.93 & 0.85 \\
\hline Upper face & 0.97 & 3.9 & 2.16 & 0.77 & -3.5 & -0.89 & -1.9 & 0.79 \\
\hline Lower face & 1.47 & 5.22 & 2.81 & 0.87 & -5.88 & -1.34 & -2.78 & 0.89 \\
\hline Nose & 0.68 & 3.9 & 2.04 & 0.71 & -3.49 & -0.47 & -1.25 & 0.67 \\
\hline Upper lip & 0.64 & 5.06 & 2.16 & 0.97 & -5.69 & 0.11 & -1.5 & 1.03 \\
\hline Lower lip & -0.63 & 5.22 & 1.37 & 1.16 & -4.68 & 0.53 & -2.02 & 1.67 \\
\hline
\end{tabular}

Similarly, the mean, minimum and maximum limits of the mean values were calculated in (Table $5)$. While soft tissue changes were observed in the nasal and upper lip regions $(0.55,0.53 \mathrm{~mm})$ respectively, the changes observed in the total face region, as well as the upper and lower lip regions were very small and almost neglected.

Table 5. Descriptive statistics of the mean deviation in the morphological region

\begin{tabular}{|l|l|l|l|l|}
\hline Morphological region & Minimum & Maximum & Mean & SD \\
\hline Total face & -0.25 & 0.12 & -0.02 & 0.08 \\
\hline Upper face & -0.99 & 0.65 & 0.06 & 0.3 \\
\hline Lower face & -0.54 & 0.32 & -0.02 & 0.16 \\
\hline Nose & -0.1 & 0.96 & 0.55 & 0.26 \\
\hline Upper lip & -0.87 & 1.79 & 0.53 & 0.67 \\
\hline Lower lip & -2.54 & 2.19 & -0.04 & 1.24 \\
\hline
\end{tabular}

Changes were also observed at the level of the facial landmarks as seen in Table 6. The deviation found at the level of the right and left Alar points were $(0.72 \pm 0.45,0.46 \pm 0.59 \mathrm{~mm})$ respectively, we also found changes at the level of Pronasal and Subnasal points $(0.44 \pm 0.66,0.66 \pm 0.64 \mathrm{~mm})$, and for the right and left Cheilion landmarks $(0.46 \pm 1.621,0.66 \pm 1.98 \mathrm{~mm})$ respectively.

Table 6. Deviation analysis of the facial soft tissue landmarks

\begin{tabular}{|lcll}
\hline landmark & & Deviation mean(mm) & SD \\
\hline Endocanthion (right) & End $_{\mathrm{r}}$ & 0.28 & 0.39 \\
\hline Endocanthion (left) & End $_{1}$ & 0.25 & 0.55 \\
\hline Sellion & $\mathrm{Se}$ & -0.03 & 0.41 \\
\hline Alar point (right) & $\mathrm{Alar}_{\mathrm{r}}$ & 0.72 & 0.45 \\
\hline Alar point (left) & Alar $_{1}$ & 0.46 & 0.59 \\
\hline
\end{tabular}




\begin{tabular}{|lc|l|l|}
\hline Pronasal & prn & 0.44 & 0.66 \\
\hline Subnasal & $\mathrm{Sn}$ & 0.66 & 0.64 \\
\hline Cheilion (right) & $\mathrm{Ch}_{\mathrm{r}}$ & 0.46 & 1.62 \\
\hline Cheilion (left ) & $\mathrm{Ch}_{1}$ & 0.66 & 1.98 \\
\hline Labiale Superius & $\mathrm{Ls}$ & 0.23 & 1.36 \\
\hline Labiale Inferius & $\mathrm{Li}$ & 0.2 & 1.37 \\
\hline Stomion & $\mathrm{Sto}$ & -0.11 & 1.71 \\
\hline Sublabiale & $\mathrm{Sl}$ & -0.43 & 1.31 \\
\hline Soft tissue menton & $\mathrm{me}^{\prime}$ & 0.02 & 0.89
\end{tabular}

Moderate positive and negative correlations were found between the expansion amount and our variables using the Pearson correlation coefficient, but they did not reach the level of significance, except for the mouth width difference, which showed a significant moderate positive correlation with the jackscrew activation at the level of 5\% of significance as seen in the (Fig.24).

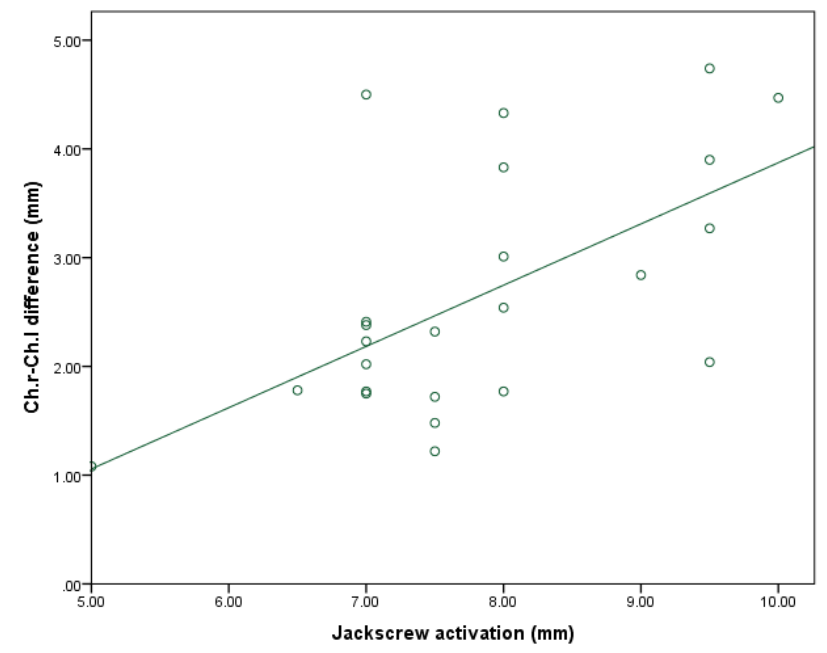

Fig. 24. Scatter plot for the correlation between the mouth width difference and the jackscrew activation amount

\subsection{Discussion}

Assessment of the soft tissue changes after RME is a critical step during our orthodontic treatment. Various strategies, including laser scanners, stereophotogrammetry, and structured light scanners have recently been introduced for 3D soft tissue evaluation. It was found that the accuracy of the structured light scanner $(0.57 \pm 0.07 \mathrm{~mm})$, and seemed to be the best in the midface region (92). Jung et al. concluded that the accuracy of the structured light system is comparable to the direct anthropometric measurements. Furthermore, if the face of the subject was scanned from a couple 
of angles at the same time in less than 1 second, more reliable 3D datasets are expected (82). Lee et al. investigated the reliability of 34 facial landmarks using a 3D handheld structured-light scanner (Artec Eva) and they observed constellations of landmarks that showed excessive reliability in each condition in terms of head posture and image resolution.

The effects of the sex and age of patients were not evaluated in our study because of the relatively small sample size. Previous studies found that the stage of maturation (based on the maturation of the cervical vertebrae) and sex had no significant effect on the soft tissue changes brought about by $\operatorname{RME}(93,94)$.

Our findings were based on subjects who were in the active growth phase with an average age of (11 years and 8 months). It has been presumed that growth might not cause large interference with the parameters evaluated during the observational period of up to 6-7 months (95). In our study, records were taken before treatment and after the appliance was removed following 6 months of retention, to dispose of the immediate positional changes of the lips, cheeks, chin, and mandible resulting from adapting to the bulk of the expander (75). We could not perform a longer evaluation because RME was usually followed by multibracket therapy.

To evaluate soft tissue changes, we calculated linear and angular measurements between two or three points in a specific region of the face, but since such results reflect the variations that have occurred at only those points, we also performed regional deviation analyses for various morphological regions of the face and the facial landmarks.

\subsubsection{Facial Soft tissue changes}

Intercantal width increased by a mean of $0.65 \mathrm{~mm}$ after RME expansion. However, this increase did not reach a statistically significant level. Generally, forces generated with the aid of RME can also affect circummaxillary sutures, along with the fronto-maxillary, naso-maxillary, and frontonasal ones (96-98). The aforementioned findings could explain the 3D deviations observed around the eye. Soft tissue changes were also observed around the eye area after RME (99). Baysal et al. suggested that the significant increases that they found in the intercanthal distance were the result of normal growth and development (49). Dindaroglu et al. added that, even if 3D facial images are captured rapidly, apparent 3D changes might occur in soft tissues around the eye because of the movement of the eyelids (90).

One of the most frequently examined anatomical regions in connection with RME is the nose, given the close anatomical relationship between the maxilla and the nasal area (90). 
We found a statistically significant increase in the nasal width $(1.02 \mathrm{~mm}, \mathrm{p}<0.05)$, as well as in the nasal base width $(1.21 \mathrm{~mm}, \mathrm{p}<0.05)$. We also found a significant increase in nasal angle $\left(3.2^{\circ}\right.$, $\mathrm{p}<0.05)$.

Berger et al. observed a $1.6 \mathrm{~mm}$ increase in nasal width, along with an increase in skeletal nasal width and about $1 \mathrm{~mm}$ increase in nasal length (75). Altorkat and colleagues also found that RME produces pyramidal expansion, with the greatest transverse expansion at the anterior nasal spine landmark (ANS) (84). However, the authors suggested that these changes may be neither symmetrical nor homogeneous when the anatomical relationship between the nose and maxilla is considered.

Other studies also identified a $(1.34 \mathrm{~mm})$ increase in the mean alar width after RME, which is following our findings (100). Johnson et al. used direct measurements with an average of $7 \mathrm{~mm}$ of appliance expansion and found less than $(1.5 \mathrm{~mm})$ change in nasal base and alar cartilage width, neither of which was clinically significant (93).

Increases were also observed in all transverse linear measurements in the nasal area including the nasal base width, alar cartridge width, nasal tip retraction, and flattening of the nasal tip following RME. However, it was reported that these changes were very small and variable (84). On the other hand, Silva Filho OG et al. used 2D photographs and concluded that RME did not cause changes in nasal morphology (101). These observations markedly differ from our findings, and the reason for this difference most likely lies in the different scanning methods.

In our study, we found a statically significant increase $(2.62 \mathrm{~mm}, \mathrm{p}<0.05)$ of mouth width after RME, probably as a result of the transverse expansion of the maxillary halves. We also found statically significant increases in the upper and lower lip angle (3.45 and 3.78 ${ }^{\circ}$, respectively).

Our results correspond to the results of Altındi S et al. who also found a statistically significant increase in mouth width(83). A recent CBCT study by Kim et al. demonstrated similar changes in the mouth width after RME (99). On the contrary, the study of Baysal et al. found no statistically significant change in this respect (49), but this lack of significance might well be put down to the small sample size (17 subjects).

Dindaroglu $\mathrm{F}$ et al. considered that although significant changes were found in their linear and angular measurements, changes measured only in these dimensions may not reflect the actual soft tissue changes properly (90). Therefore, volumetric analyses can provide the possibility to gain 
more information on the effects of treatment in facial regions. A region was characterized by the mean value of all points of measurement within the given region.

We found significant facial soft tissue changes in both the nose and the upper lip regions $(0.55 \pm 0.26,0.53 \pm 0.67 \mathrm{~mm}$ respectively), and we also noticed high positive and negative deviation limits in the other facial morphological regions of the face, but the mean deviation for these regions changed only to a negligible extent.

Similarly, the positive and negative deviations were less than $2 \mathrm{~mm}$ in all morphological regions in the face in the study of Dindaroglu F et al. (90), they also found that the mean maximum positive and negative deviation limits for the nasal area were $(0.77 \pm 0.34$ and $-0.94 \pm 0.41 \mathrm{~mm})$ respectively, and when all the points forming the nose region are considered, the mean deviation was $(0.41 \pm 0.21 \mathrm{~mm})$, which is similar to our results.

Regarding the upper lip region, the mean positive and negative change in their study was $(0.87 \pm$ $0.38,-0.57 \pm 0.14 \mathrm{~mm}$ ) respectively, while the greatest mean deviation noted was $1.44 \mathrm{~mm}(90)$. The mean of the maximum positive deviation for the total face was $(3.09 \pm 0.92 \mathrm{~mm})$ in our study. It was $(2.16 \pm 0.77,2.81 \pm 0.87 \mathrm{~mm})$ for the upper and lower face regions, respectively, while the mean of the maximum negative deviation was $(-2.93 \pm 0.85 \mathrm{~mm})$ for the total face, and $(-1.9 \pm 0.79$, $-2.78 \pm 0.89 \mathrm{~mm}$ ) for the upper and lower face regions, respectively.

Ong et al. conducted a 3D deviation analysis and reported a mean maximum deviation of (1.2 \pm 0.4 and $1.0 \pm 0.3 \mathrm{~mm}$ ) in the right and left maxilla respectively, which were very close to our results (87).

Although the greatest mean deviation limits noted in our study patients in the lower lip region was (2.19 and $2.54 \mathrm{~mm}$; positive and negative, respectively) the mean deviation for the whole sample in the lower lip region changed only to a negligible extent $(-0.04 \pm 1.24 \mathrm{~mm})$.

For a deeper understanding of the soft tissue deviations, we also calculated these deviations on specific facial landmarks directly after the surface comparisons and found the greatest deviation at the right Alar point $(0.72 \pm 0.45 \mathrm{~mm})$. The left Alar point changed by $(0.46 \pm 0.59 \mathrm{~mm})$, and we also found change at the subnasal point $(0.66 \pm 0.64 \mathrm{~mm})$.

Kim et al. evaluated the deviations at different points in various nasal regions and detected a mean deviation of less than $1 \mathrm{~mm}$ for all of the points, except for the ones in the subnasal region $(2.21 \pm$ $1.23 \mathrm{~mm}$ ) (99). They also found that the position of the left lip commissure changed by $(0.65 \mathrm{~mm})$, whereas the position of the right lip commissure changed by a mean of $(1.20 \mathrm{~mm})(99)$. We found 
that the position of the left and the right lip commissure has changed $(0.66$ and $0.46 \mathrm{~mm})$ in our study, respectively. We also found positive deviation at the Pronasal point $(0.44 \mathrm{~mm})$ and negative deviation at the sublabial point $(-0.43 \mathrm{~mm})$. Kim et al. (99) found a positive change of $(0.43 \pm 1.24$ $\mathrm{mm})$ at the nasion point, which did not change in our study.

Although we found positive and negative correlations between the amount of expansion and most of the facial soft tissue variables, these correlations did not reach a significant level. Only the mouth width showed a moderately significant positive correlation with the jackscrew activation amount $(\mathrm{p}<0.05)$.

\subsubsection{Limitations}

A major limitation of this study is the small sample size, which prevented us from considering the effect of sex, among other factors, and it is also a limitation that prevents strong conclusions. Another relative limitation is the absence of a control group. However, based on the literature, we had reason to assume that, with a short observation period, it was not likely that normal growth would interfere with the results.

\subsection{Conclusion}

Significant changes in the nasal region and the upper lip region were found after RME and six months of retention, and a significant positive correlation between mouth width and the amount of expansion was also observed.

The outcomes show that rapid expansion causes significant soft tissue changes on the surface of the face. While our results are a good starting point, further investigations with larger sample sizes and suitable controls are necessary to allow generalizable statements about soft tissue responses after RME, especially in the long run 


\section{Second prospective clinical study:}

\section{Post-operative facial soft tissue changes after bimaxillary surgery using 3D- handheld structured-light scanner}

\subsection{Introduction}

Needless to say, deficiencies associated with malocclusion and craniofacial deformities are usually compound with cognitive difficulties and psychiatric disorders. It is therefore important to consider soft tissue adaptation and soft tissue contours, as well as the normal skeletal relationships and functional occlusion during treatment planning (102-104), especially in patients with skeletal discrepancies and soft tissue imbalances, where the orthognathic surgery can be the key (46).

Since it provides more favorable results for the esthetic facial proportion, bimaxillary surgery has been increasingly used, especially in patients with mandibular prognathism (105).

Research into soft tissue changes after orthognathic surgery has largely been hampered by a lack of suitable tools for evaluating changes in all three dimensions. These drawbacks can be tackled with the use of three-dimensional imaging techniques, such as cone-beam computed tomography (CBCT), stereophotogrammetry, and structured-light scanning (26). However, cone-beam computed tomography (CBCT) provides 3D information about deep skeletal structures and superficial skin, but it also has disadvantages due to the low resolution of the soft tissue with large slice gaps and the long scanning time $(106,107)$. Using a structured light scanning system, texture and color information of the face can be readily obtained in high resolution without additional radiation hazards, together with some advantages such as the short scanning time along with the flexible portability and operability (81). To our knowledge, there are only a few studies that evaluated soft tissue changes after orthognathic surgery of skeletal class III patients using the 3Dfacial scanner, some of them have examined deviations at specific points or calculated linear and angular measurements $(24,108)$. However, it's more inclusive to anticipate the facial regions on a 3D-basis assessment. Therefore, the purpose of our prospective study was to perform an extensive evaluation of the short-term soft tissue changes in various morphological regions of the face after bimaxillary surgery of skeletal class III patients using a 3D handheld structured-light scanner. 


\subsection{Materials and Methods}

\subsubsection{Subjects}

This study was approved by the Human Investigation Review Board, the University of Szeged, Albert Szent-Györgyi Clinical Centre (No. 151/2019-SZTE). Informed consent was obtained from all patients who agreed to participate in this study.

Patients were recruited from the Craniofacial Unit, Department of Oral and Maxillofacial Surgery, Albert Szent-Györgyi Clinical Center, University of Szeged, Hungary.

Those patients came to our department under a functional or aesthetic compliment, with skeletal class III malocclusion as the main disorder of their craniofacial deformities, which included one of the following: anteroposterior skeletal discrepancy, cleft lip and palate, facial asymmetry, and craniofacial syndromes. All of them had Caucasian ethnic background, with no further anticipated growth, and went to receive full comprehensive orthodontic-orthognathic treatment including the pre-surgical orthodontic treatment, planning for the surgical stage, the orthognathic surgery, and the post-surgical orthodontic treatment.

Our sample consisted of 12 patients ( 6 males and 6 females), with a mean age of ( $22 \pm 2.17$ years, range 19.6-24.5) requiring bimaxillary osteotomy as the second step in our comprehensive treatment.

The sample size was determined based on the findings of a previous study by Koerich and colleagues (109). The extent of skeletal movement achieved using the treatment plan was $(3.87 \pm 1.6 \mathrm{~mm})$ for the maxillary advancement, and $(3.46 \pm 1.34 \mathrm{~mm})$ for the mandibular setback. No additional surgical procedures such as genioplasty, rhinoplasty, or infraorbital augmentations were performed in conjunction with the osteotomies or postoperatively.

The 3D facial images were acquired one week before surgery $\left(\mathrm{T}_{0}\right)$ and 6 months after surgery $\left(\mathrm{T}_{1}\right)$ using a 3D handheld structured-light scanner (Artec Eva ${ }^{\mathrm{TM}}$; Artec Group, Luxembourg). All images were taken with the head in a natural head position, teeth in centric occlusion, lips in repose, and slightly closed eyes(85). To reach the natural head balance, subjects were seated in a backsupported and vertically adjustable chair, they were asked to turn their heads forward and backward with decreasing amplitude until they reached a relaxed position (86), then they were told to look straight ahead to a point on the wall in front of them at eye level. 


\subsubsection{Clinical Protocol}

\subsubsection{Pre-surgical orthodontic treatment}

For each patient, a medical and dental history, intraoral, extra-oral photographs, and dental casts were taken (Fig. 25). We performed a comprehensive diagnostic analysis including posterior transverse dimension, vertical and sagittal skeletal and dental relationship, mandibular functional shift, lip/incisor relationships, temporomandibular joint function, and facial midline (110).
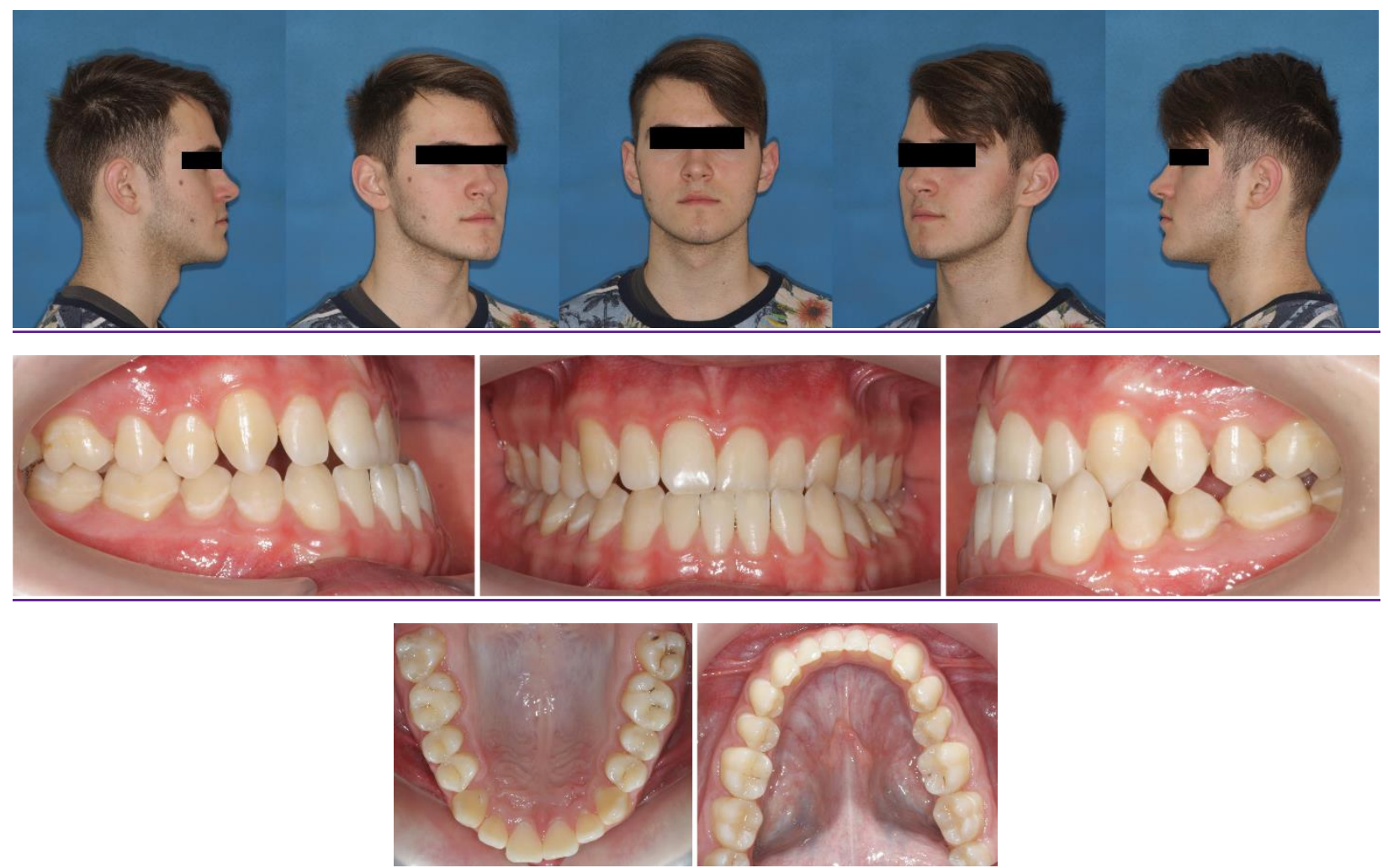

Fig. 25. Extra-oral and intraoral photographs of one patient included in our study (T0 pre-treatment)

Then we started the pre-surgical orthodontic treatment (Fig. 26), the overriding goal was to decompensate the lower and upper incisors, which can be accomplished in many different ways depending on the initial deformity, relieve the crowding to align the arches individually, and achieve compatibility of the arches or arch segments and finally to establish the proper anteroposterior and vertical position of the incisors (110). 

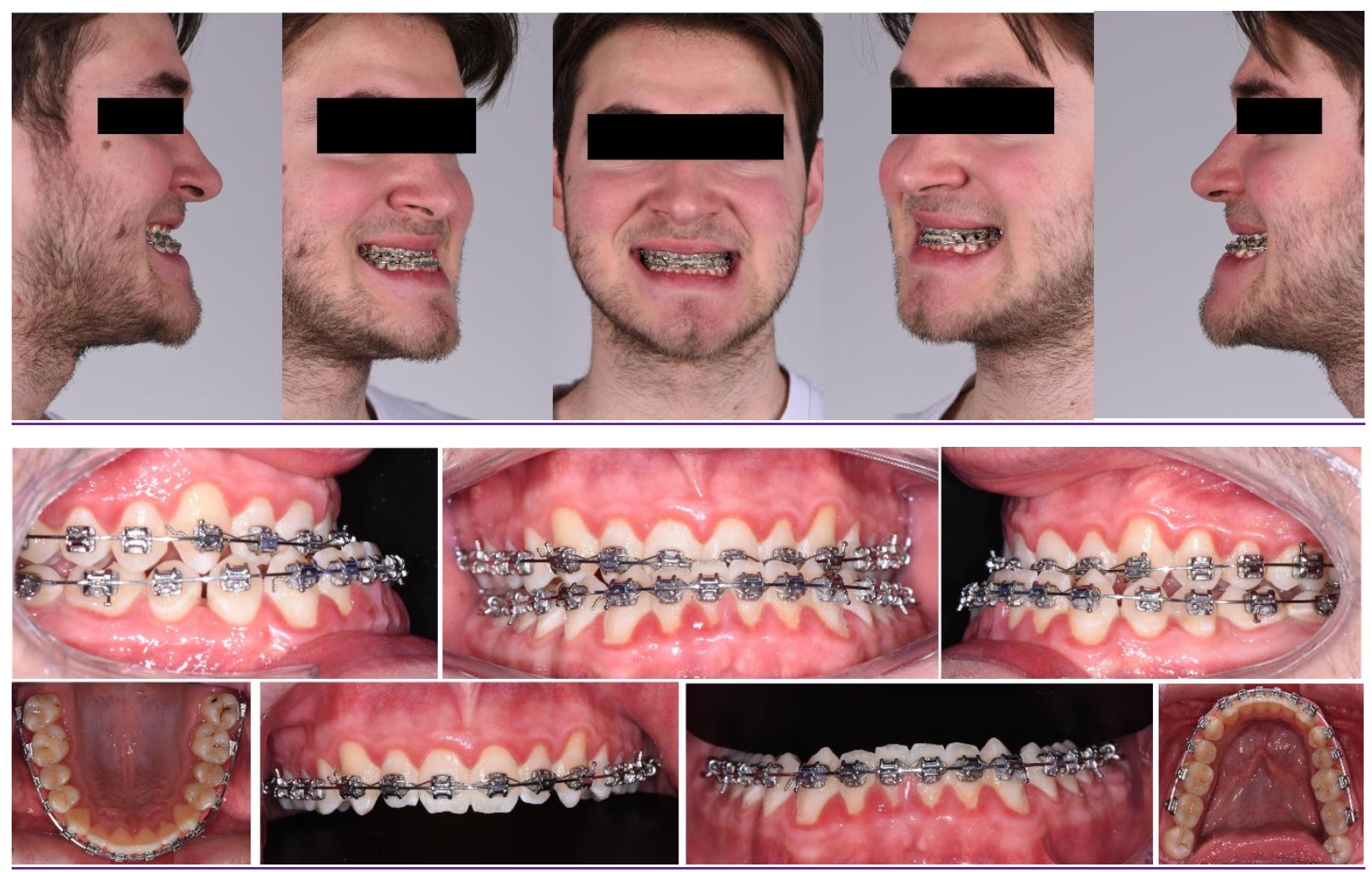

Fig. 26. Extra-oral and intraoral photographs of the pre-surgical orthodontic treatment

\subsubsection{Surgical Planning}

The limits of skeletal movement for every patient were defined based on their unique characteristics, a balanced harmonious skeletal and facial appearance was always our goal. We used the traditional surgical planning using semi-adjustable dental articulator (SAM 2P, SchulArtikulator-München, SAM Präzisionstechnik, Gauting, Germany) and the corresponding facebow transfer, panoramic x-rays, lateral cephalograms, and facial photogrammetry. We also used the 3D technique for surgical planning using (Blender software V.2.80) after merging CBCT images with the intraoral scans and obtaining a 3D virtual patient to fabricate the 3D- printed splint using 3D printers (Fig. 27).
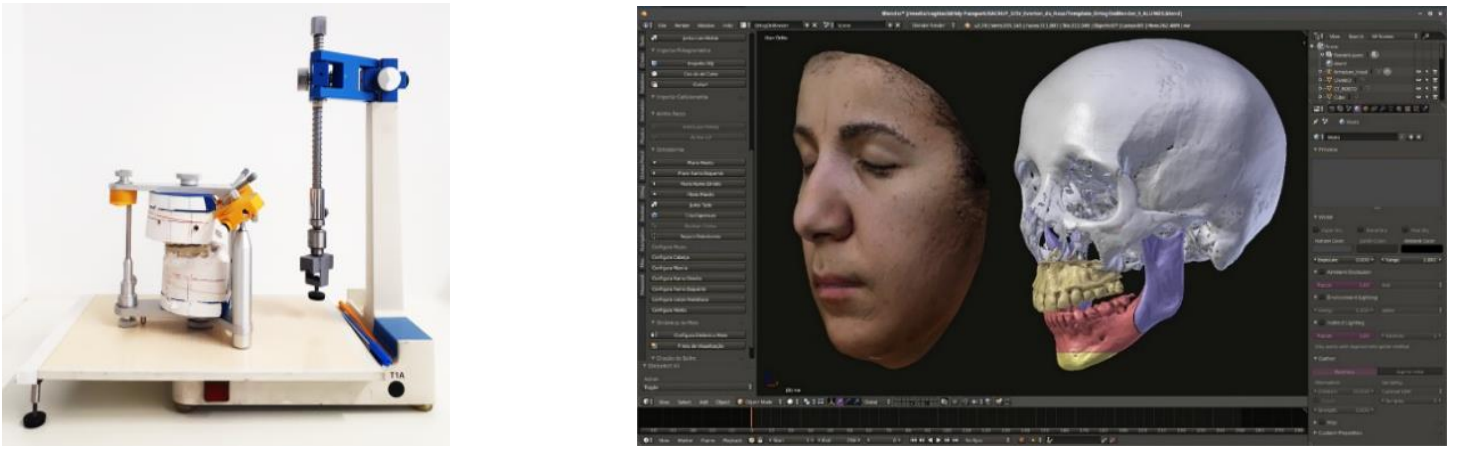

Fig. 27. Traditional and virtual techniques used for orthognathic surgery planning (Craniofacial unit, Department of Oral and Maxillofacial Surgery, University of Szeged) 


\subsubsection{Surgical procedures}

\section{Maxillary advancement through Le Fort I. Osteotomy}

An incision through the mucosa, subcutaneous tissue, and periosteum was made, with a specific design of this incision which can provide adequate access and enable the mucosa to be carefully closed at the end.

Then the submucosal tissue and the periosteum were elevated off the underlying bone, with special care in retraction to prevent temporary neuropraxia of surrounding nerves. The osteotomy cut was made according to Obwegeser(111), above the apices of the maxillary teeth and underneath the infraorbital nerve, with an angle around $15-20^{\circ}$ to the maxillary occlusal plane and extends from the pterygomaxillary fissure to the pyriform fossa to achieve full mobilization of the maxilla. Then the mobile maxilla was fixed in a previously planned position, with the aid of the surgical splint. Mini plates and screws were placed and used to fix the maxilla in the new position (112).

\section{Mandibular setback through Bilateral sagittal split set-back osteotomy (BSSO)}

Following the incision, a subperiosteal dissection took place buccally which proceeded inferiorly in front of the antegonial notch, exposing the inferior border of the mandible, it proceeded upward against the external oblique ridge as high up as the coronoid process, the lingual (medial) subperiosteal dissection proceeded superior to inferior along the lingual aspect of the ramus, until the lingual is reached. The vertical section of the osteotomy was done according to Obwegeser/Dal Ponte (113). Then, splitting of the mandible was carried out, a segment of bone was removed from the proximal segment of the buccal osteotomy to set-back the body of the mandible.

The proper movement of the mandible was achieved with the help of the fabricated surgical splint. In the end, all patients underwent semi-rigid internal fixation of the maxilla and the mandible with functional mini-plates and mini-screws, and a surgical wafer was placed for approximately 5-6 weeks after surgery, intermaxillary elastics were performed to stabilize the occlusion after the removal of the surgical wafers (112).

\subsubsection{Post-operative Orthodontics}

The two primary goals of the postoperative orthodontic treatment were to stabilize the skeletal movements and to detail and finish the dental occlusion (110). Inter-arch elastics were used in this period to refine any minor skeletal movements that need to occur and counterbalance the soft tissue pull that may lead to relapse, then we finished out treatment with the proper type of retention (Fig. 28,29). 

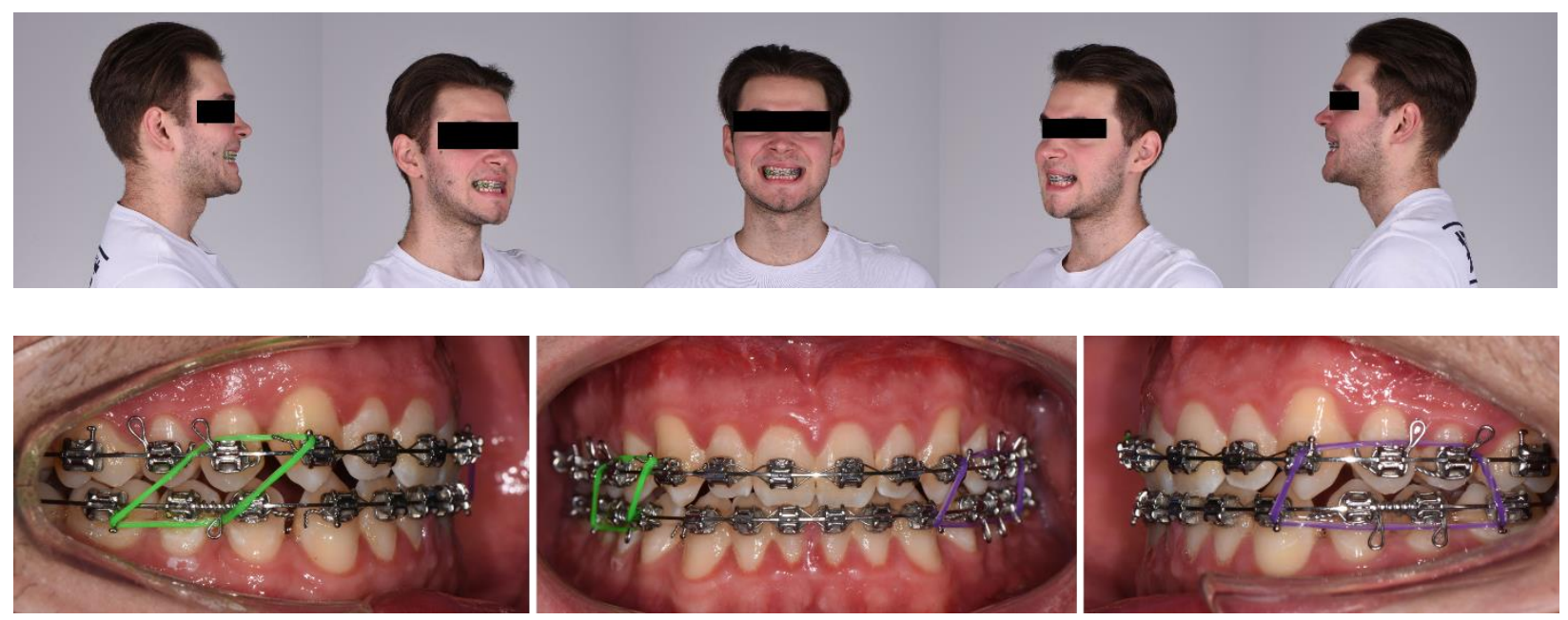

Fig. 28: Extra-oral and intraoral photographs of the post-surgical orthodontic treatment (T1)
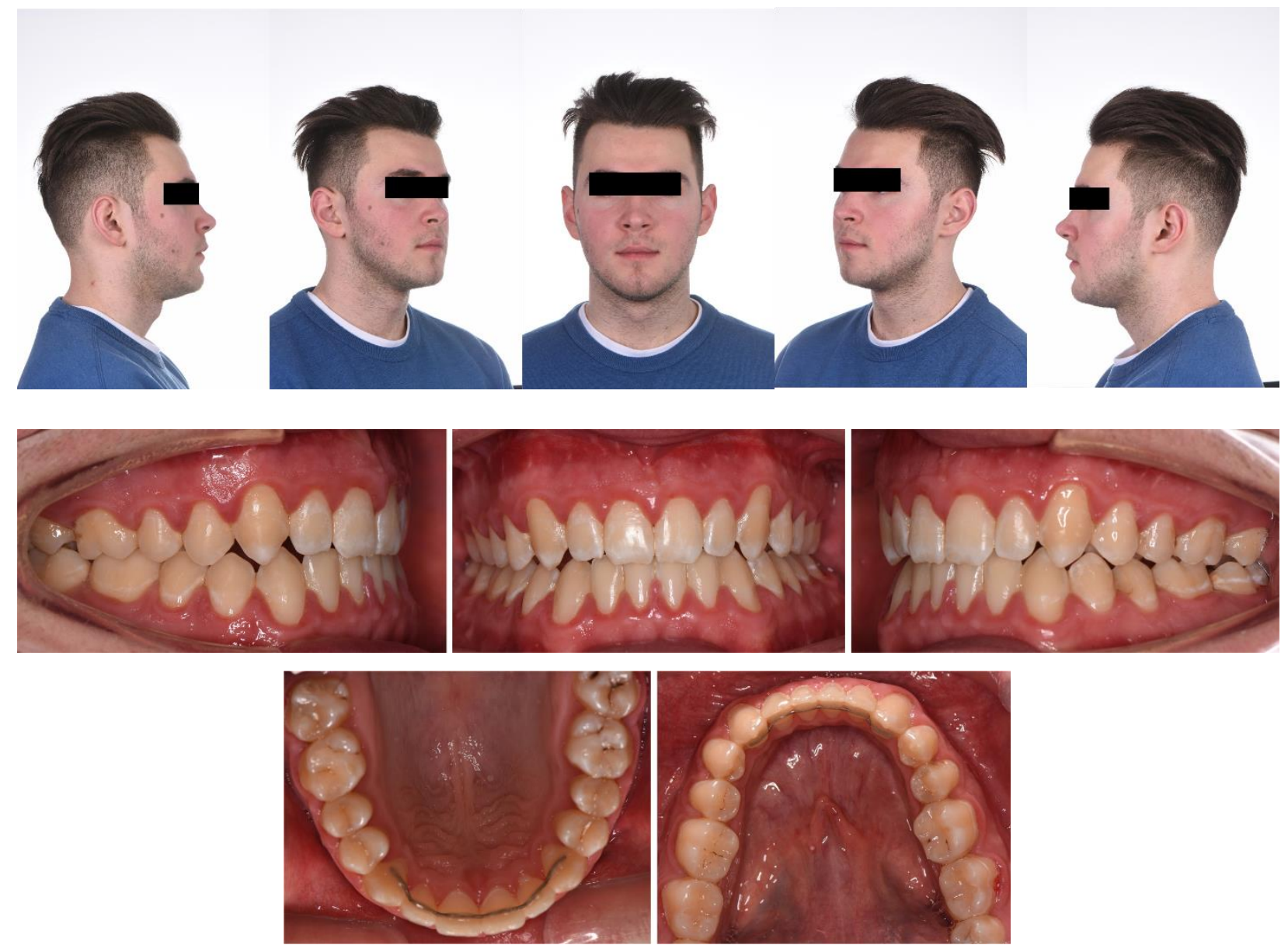

Fig. 29 Extra-oral and intraoral photographs after finishing the treatment with the proper type of retention 


\subsubsection{Data processing and measurements}

In total 20 landmarks, (5 bilateral and 10 unilateral) (Table 7, Fig. 30) were located according to the literature $(88,89), 13$ linear and 6 angular measurements were measured directly on the 3D facial images using Artec Studio V.12 software (Fig. 31, 32).
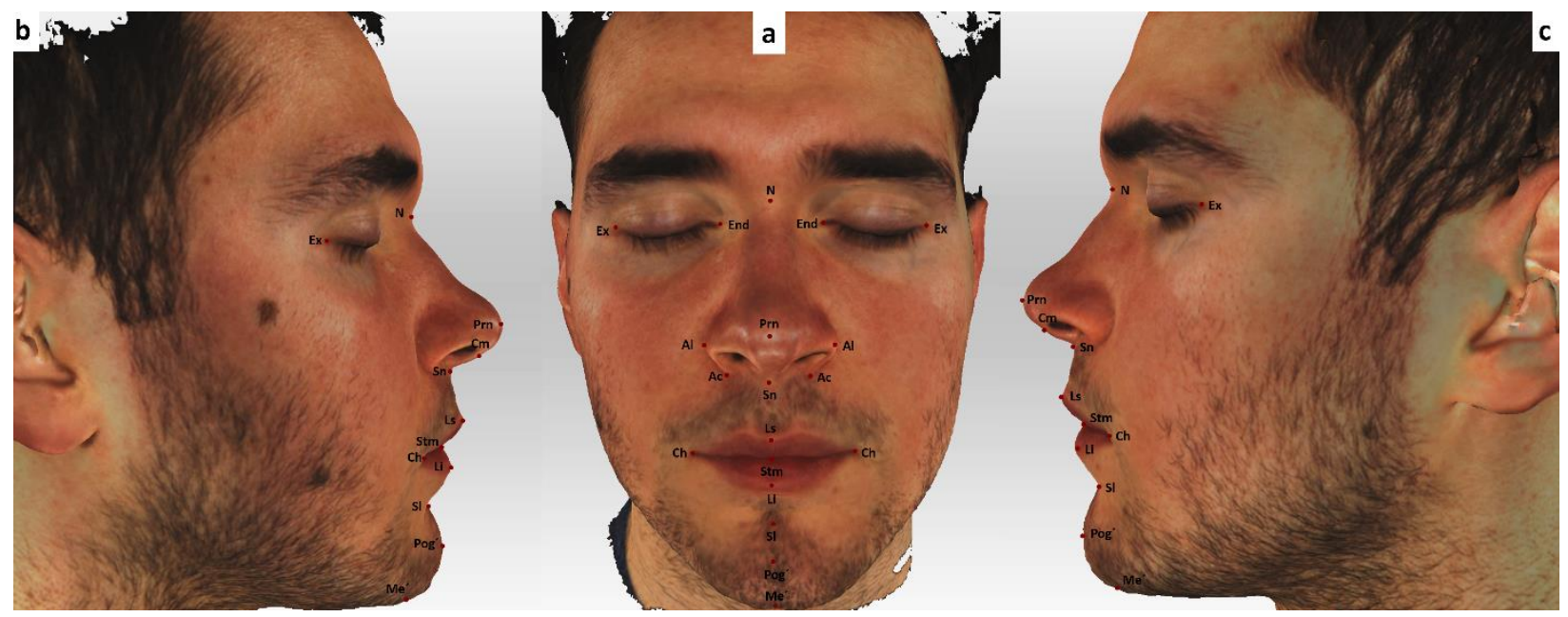

Fig. 30. Landmarks used in our study located directly on the 3D-facial images (a) Frontal view. (b) and (c) Lateral views
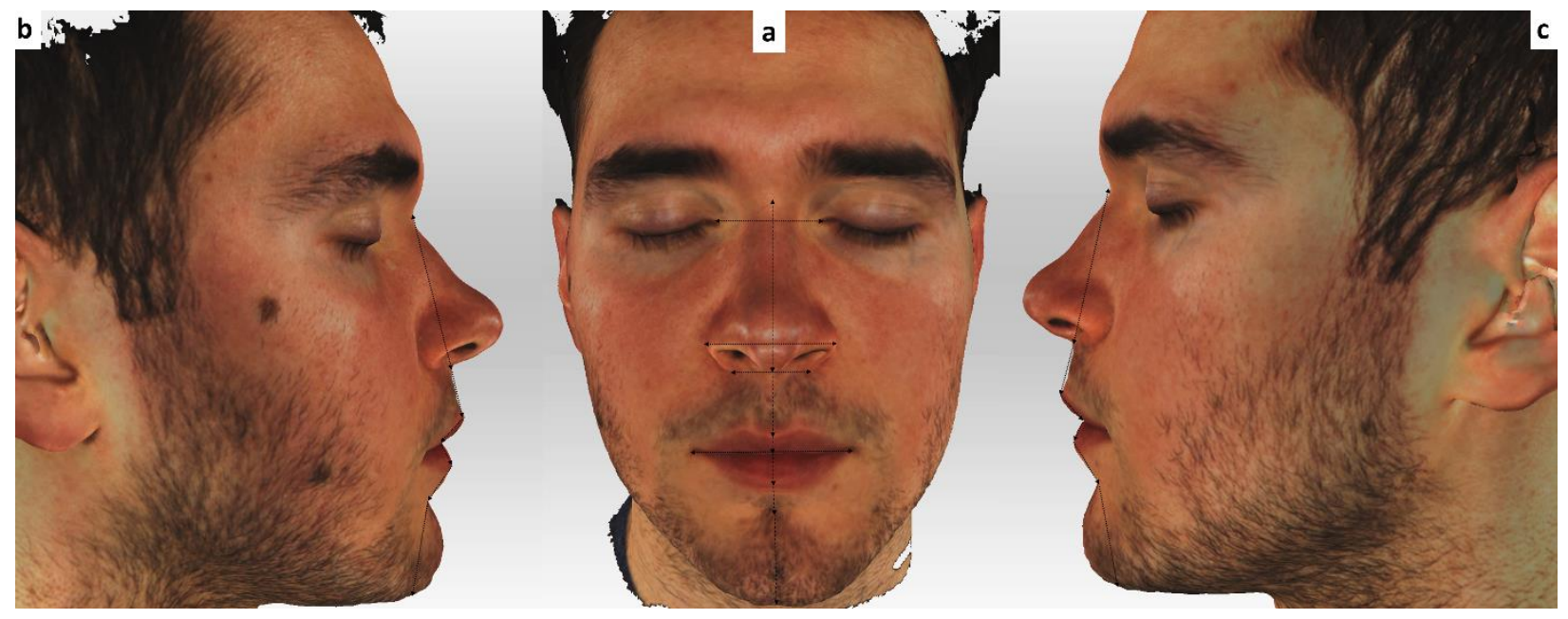

Fig. 31. Linear measurements used in our study (a) Frontal view. (b) and (c) Lateral views 

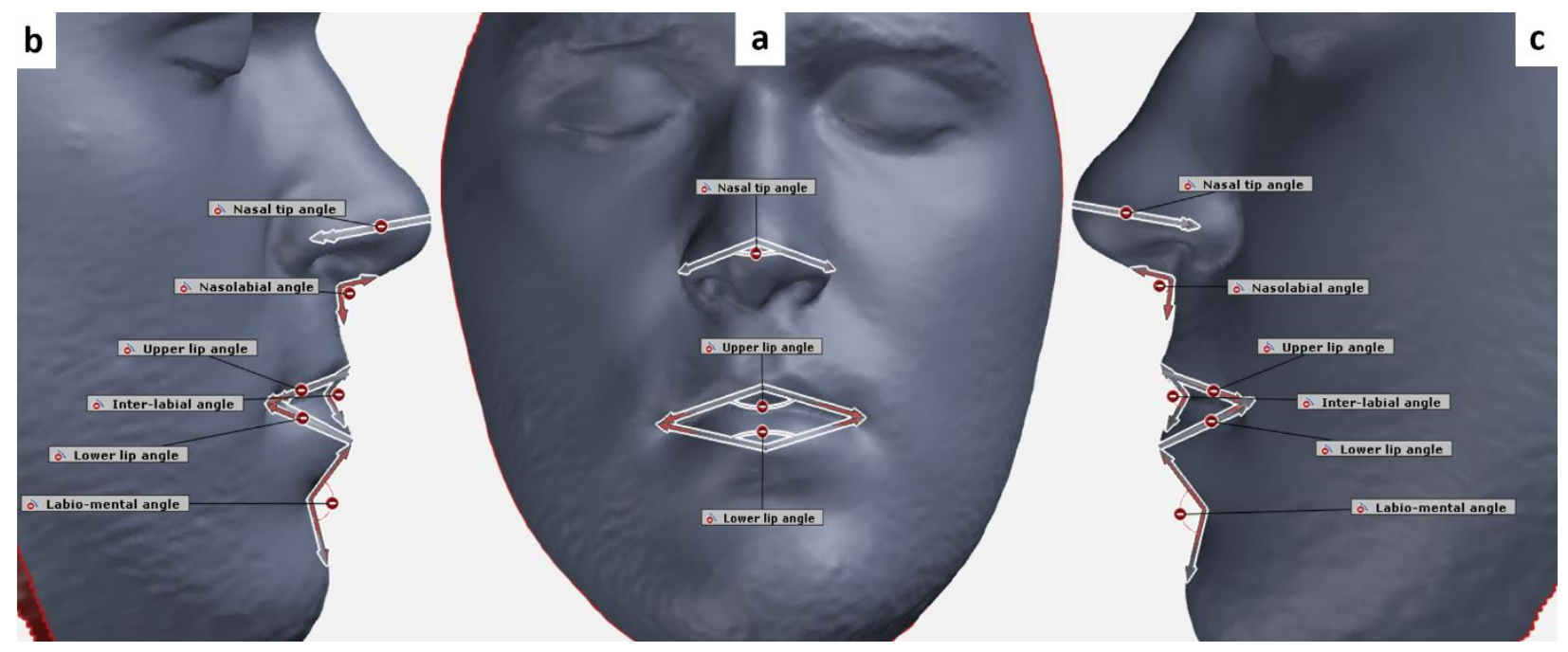

Fig. 32. Angular measurements used in our study, (a) Frontal view. (b) and (c) Lateral views.

For the 3D deviation analysis, the 3D facial images were transferred into reverse engineering software (GOM Inspect Evaluation Software, Capture 3D, Inc, Santa Ana, CA) and polygon meshes were created in stereolithography (STL) format. The hair, ears, and the below-neck region were removed. The images obtained at the $\mathrm{T}_{0}$ time point were aligned with the images taken at $\mathrm{T}_{1}$ using the best-fit method (Fig. 33).
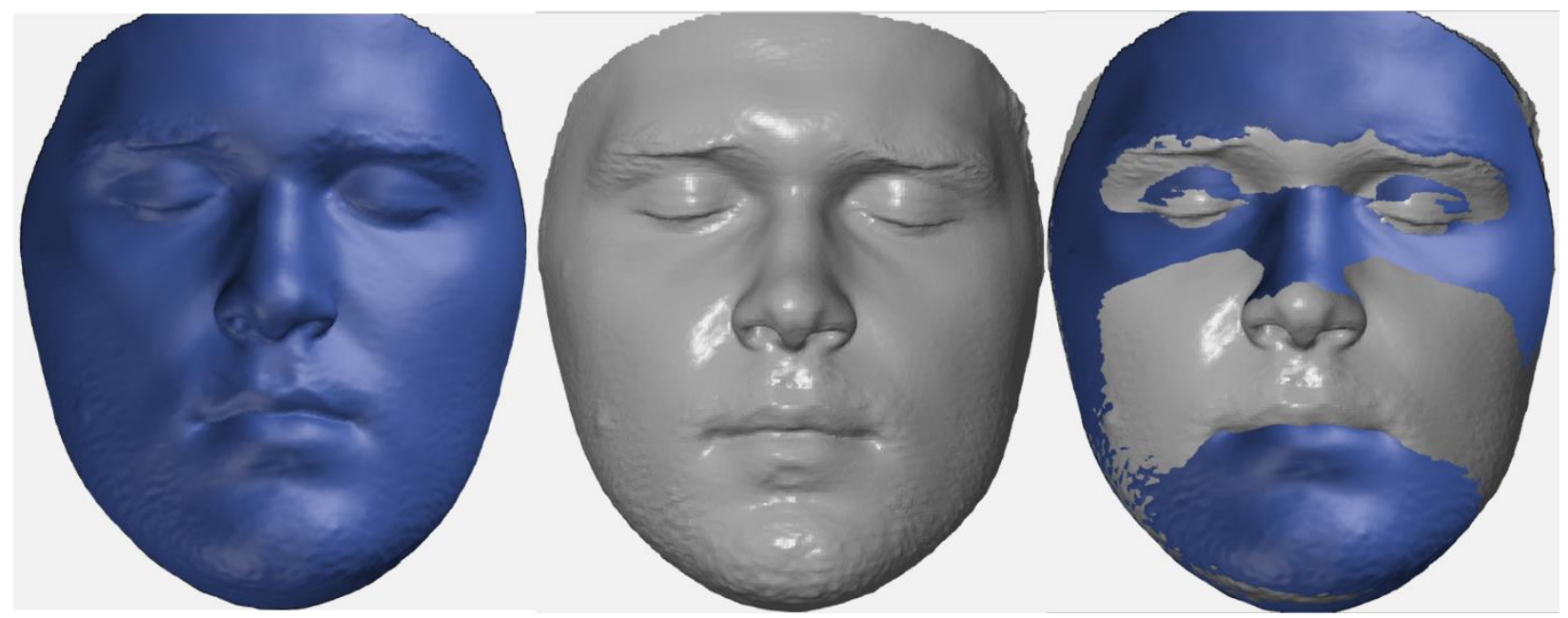

Fig. 33. The best fit method used to align the $T_{0}$ and $T_{1}$ meshes

Negative values indicate that $\mathrm{T}_{1}$ images are located behind the $\mathrm{T}_{0}$ images (blue shades), whereas positive values indicate that $\mathrm{T}_{1}$ images are located in front of the $\mathrm{T}_{0}$ images (red shades). To create morphological regions, reference lines passing through different points specified on the face were 
determined and a 3D deviation analysis was made in seven morphological regions (90) (Tab.8, Fig. 34).

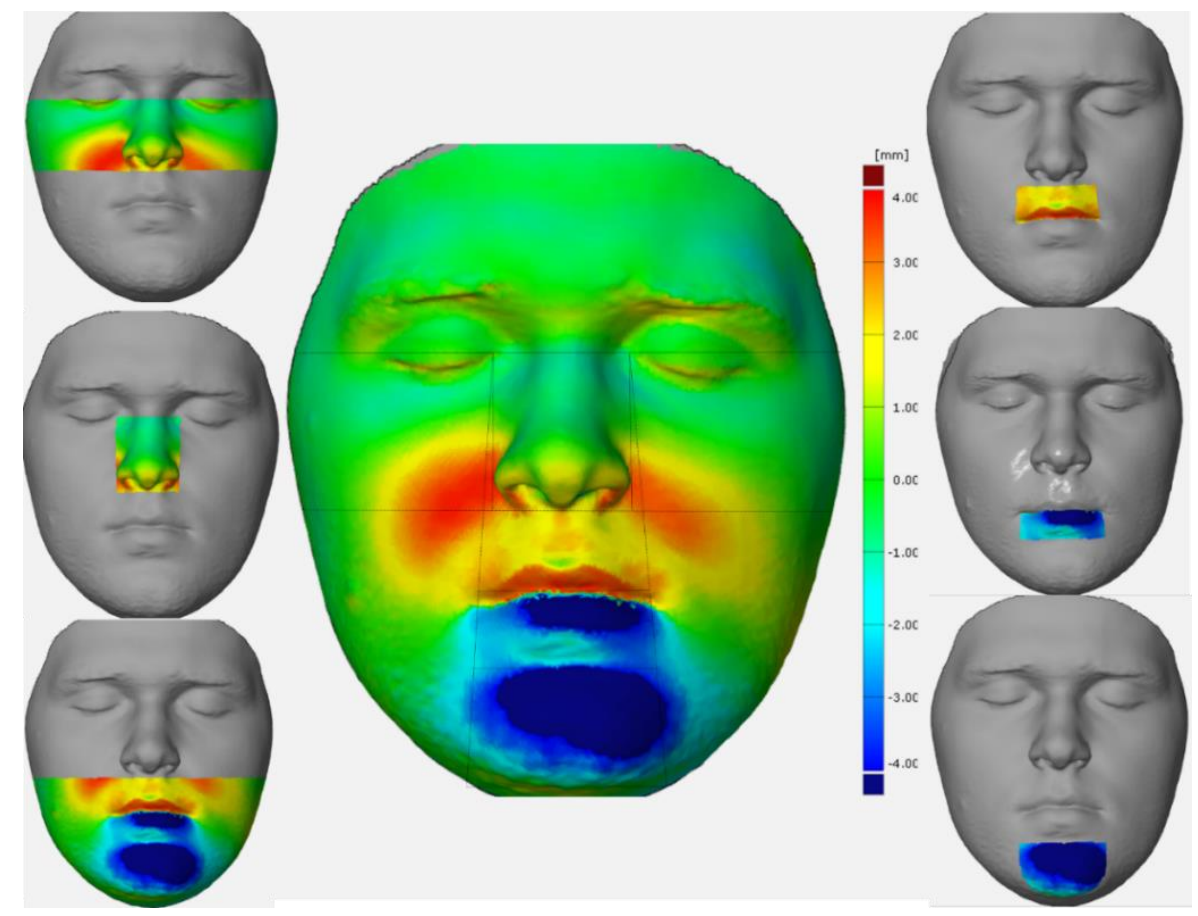

Fig. 34. The morphological regions and their reference lines used for the deviation analysis

We also calculated the deviation labels for the facial soft tissue landmarks directly on the 3D inspected meshes (Fig.35).

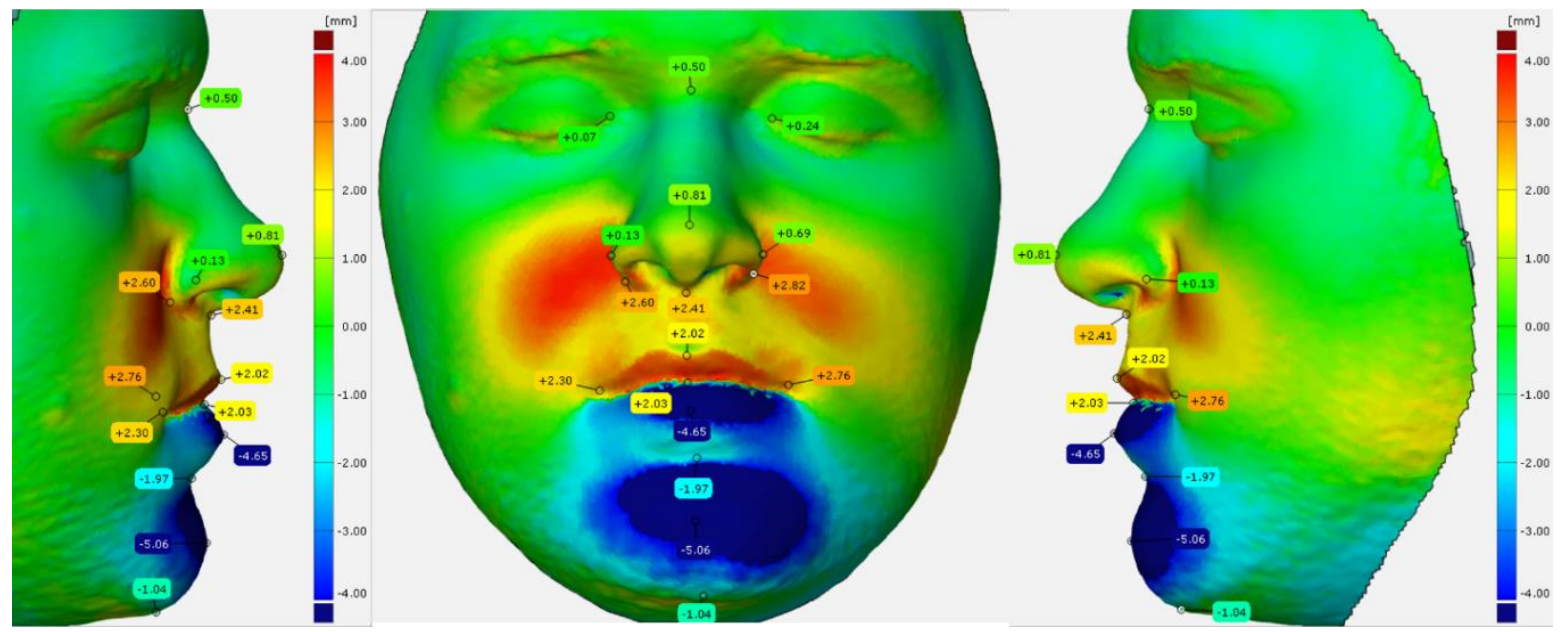

Fig. 35. Deviation analysis used for specific landmarks in our study 
Table 7 Definition of facial landmarks used in our study.

\begin{tabular}{|c|c|c|}
\hline Landmark & & Definition \\
\hline Exocanthion & $(\mathrm{Ex})^{*}$ & The Point at the outer commissure of the eye fissure \\
\hline Endocanthion & (End)* & The point at the inner commissure of the eye fissure \\
\hline Soft tissue nasion & $(\mathrm{N})$ & Midpoint on the soft tissue contour of the nasal root's base \\
\hline Alare & $(\mathrm{Al})^{*}$ & The most lateral point on each alar contour (on the base view). \\
\hline Pronasale & $(\operatorname{Prn})$ & $\begin{array}{l}\text { The most anterior midpoint of the nasal tip (on the right and left profile view). If a bifid nose is } \\
\text { present, the more protruding tip is chosen to determine Pronasale (L.G. Farkas). }\end{array}$ \\
\hline Alar curvature po & nt $(\mathrm{Ac})^{*}$ & The point which located at the facial insertion of each alar base. (on the submental view) \\
\hline Subnasale & $(\mathrm{Sn})$ & Midpoint on the nasolabial soft tissue contour between the Columella crest and the upper lip \\
\hline Columella & $(\mathrm{Cm})$ & The midpoint of the Columella crest at the level of the nostril top points \\
\hline Labiale Superius & (Ls) & The midpoint of the vermilion line of the upper lip (on the submental view). \\
\hline Stomion & $(\mathrm{Stm})$ & The midpoint of the horizontal labial fissure. \\
\hline Chelion & $(\mathrm{Ch})^{*}$ & The point which located at each labial commissure (on the frontal view). \\
\hline Labiale Inferius & (Li) & The midpoint of the vermilion line of the lower lip (on the right profile view). \\
\hline Sublabiale & $(\mathrm{Sl})$ & $\begin{array}{l}\text { The most posterior midpoint on the Labiomental soft tissue contour defines the border between } \\
\text { the lower lip and the chin. }\end{array}$ \\
\hline Soft tissue pogonic & n (Pog') & The most anterior midpoint of the chin \\
\hline Menton & $\left(\mathrm{Me}^{\prime}\right)$ & $\begin{array}{l}\text { The most inferior midpoint on the soft tissue contour of the chin located at the level of the } 3-\mathrm{D} \\
\text { cephalometric hard tissue Menton landmark }\end{array}$ \\
\hline
\end{tabular}

Table 8 Definition of the morphological regions used for the 3D deviation analyses

\begin{tabular}{l|l|l|l|l}
\hline Region & Definition \\
Total face & The facial region designated while creating masks before alignment \\
Upper face & $\begin{array}{l}\text { The region between the line passing through the right and left Exocanthion points and the line passing through } \\
\text { the Subnasal point parallel to that line. }\end{array}$ \\
\hline Lower face & $\begin{array}{l}\text { The region between the line passing through the Subnasal point and the line passing through the Menton point } \\
\text { parallel to that line. }\end{array}$ \\
\hline Upper lip & $\begin{array}{l}\text { The region between the lines passing through the right and left Endocanthion points and the right and left } \\
\text { Cheilion points, and the line passing through the Subnasal point }\end{array}$ \\
\hline Lower lip & $\begin{array}{l}\text { The region between the lines passing through the right and left Endocanthion points and the right and left } \\
\text { Cheilion points, and the line passing through the supramental point parallel to other lines. }\end{array}$ \\
\hline Nose & $\begin{array}{l}\text { The region between the lines passing through the right and left Endocanthion points that are tangent to the nasal } \\
\text { wings and the line passing through the Subnasal point }\end{array}$ \\
\hline Chin & $\begin{array}{l}\text { The region formed between four reference lines: the two lines passing through the right and left Endocanthion } \\
\text { points, the right and left cheilion points respectively, and the horizontal lines passing through Sublabiale and } \\
\text { Menton points respectively. }\end{array}$
\end{tabular}




\subsection{Statistical Analysis}

Normal distribution of the data was set up through the Shapiro-Wilk and Kolmogorov-Smirnov tests. To determine the method's reliability, T0 and T1 images of the patients were re-aligned then the measurements were recalculated a month later by the same investigator. Intra-examiner reliability was evaluated utilizing the intraclass correlation coefficient (ICC). The random errors were calculated according to Dahlberg's formula $\left(D=\sqrt{ } \sum \mathrm{d} 2 / 2 \mathrm{~N}\right)(91)$, where $D$ is the error variance and $\mathrm{d}$ is the difference between the first and second measure, $\mathrm{N}$ is the sample size which was re-measured. The systematic errors were also assessed by the dependent t-test. The (T0) and (T1) linear and angular measurements were compared. Significant differences at the level of $5 \%$ significance were tested utilizing the Wilcoxon signed-rank test. Also, for every patient, a 3D deviation analysis was performed to calculate not only the maximum positive and negative deviation but also, the mean deviation amounts for the facial meshes. The deviation magnitude for specific facial landmarks was as well calculated straight on the 3D assessed meshes. All statistical analyses were performed using the Statistical Package for Social Sciences software (SPSS Inc. v 24; Armonk, NY, USA).

\subsection{Results}

All parameters were normally distributed, according to Shapiro-Wilk test and the Kolmogorov-Smirnov test. The ICC values between the two sets of measurements were high (range 0.816-0.924). The amount of random error was small enough (less than $0.5 \mathrm{~mm} /{ }^{\circ}$ ), and no systematic errors were found between the measurements obtained on the two different occasions $(\mathrm{p} \geq 0.05)$.

We found statistically significant increases in the nasal and nasal base width, the upper lip height, and a decrease in the lower lip height after bimaxillary surgery (Table.9) which also shows descriptive statistics of the pretreatment $\left(\mathrm{T}_{0}\right)$ and post-treatment $\left(\mathrm{T}_{1}\right)$ variables.

Table 9 Descriptive statistics of the pretreatment $\left(T_{0}\right)$ and posttreatment $\left(T_{1}\right)$ linear measurements

\begin{tabular}{|c|c|c|c|c|c|c|}
\hline \multirow[t]{2}{*}{ Measurement } & & \multicolumn{2}{|l|}{$\mathbf{T}_{\mathbf{0}}$} & \multicolumn{2}{|l|}{$\mathbf{T}_{1}$} & \multirow{2}{*}{$\begin{array}{l}\Delta=\mathbf{T}_{\mathbf{1}}-\mathbf{T}_{\mathbf{0}} \\
(\mathrm{mm})\end{array}$} \\
\hline & & $\operatorname{Mean}(\mathrm{mm})$ & SD & $\operatorname{Mean}(\mathrm{mm})$ & SD & \\
\hline Intercanthal width & $E n_{R}-E n_{L}$ & 33.87 & 1.05 & 33.92 & 2.02 & 0.05 \\
\hline Nasal width & Alar. $_{\mathrm{R}}$-Alar.L & 36.44 & 3.38 & 38.75 & 3.32 & $2.31 *$ \\
\hline Nasal base width & $A c_{R}-A c_{L}$ & 32.92 & 3.2 & 34.94 & 1.49 & $2.02 *$ \\
\hline Mouth width & $\mathrm{ch}_{\mathrm{R}}-\mathrm{ch}_{\mathrm{L}}$ & 48.88 & 4.14 & 50.47 & 3.46 & 1.59 \\
\hline Nose high & $\mathrm{N}-\mathrm{sn}$ & 50.13 & 4.46 & 50.2 & 4.9 & 0.07 \\
\hline
\end{tabular}




\begin{tabular}{|l|l|l|l|l|l|l|}
\hline Upper lip height & Sn-Ls & 12.3 & 2.97 & 13.77 & 2.8 & $1.47^{*}$ \\
\hline Upper lip vermilion height & Ls-Stm & 6.71 & 1.2 & 9.02 & 4.4 & $2.31^{*}$ \\
\hline Total upper lip height & Sn-Stm & 18.89 & 2.88 & 22.7 & 3.18 & $3.8^{*}$ \\
\hline Lower lip vermilion height & Stm-Li & 9.66 & 0.46 & 8.36 & 1.26 & -1.3 \\
\hline Lower lip height & Li-Sl & 15.56 & 3.7 & 13.66 & 3.18 & $-1.9^{*}$ \\
\hline lips vermilion height & Ls-Li & 16.37 & 1.47 & 17.38 & 1.62 & 1.01 \\
\hline Chin height & Stm-Me' & 53.24 & 5.61 & 48.49 & 4.28 & -4.75 \\
\hline Lower anterior facial height & Sn-Me' & 72.14 & 4.7 & 73.54 & 4.18 & 1.4 \\
\hline
\end{tabular}

*Significant changes at the level of $5 \%$ of significance $(\alpha=0.05)$

Statistically significant increases in the nasal tip angle, the lower lip angle, and a decrease in the Inter-labial angle were noticed after bimaxillary surgery, as seen in (Table 10).

Table 10 Descriptive statistics of the pretreatment $\left(T_{0}\right)$ and posttreatment $\left(T_{1}\right)$ angular measurements

\begin{tabular}{|c|c|c|c|c|c|c|}
\hline \multicolumn{2}{|l|}{ Measurement } & \multicolumn{2}{|c|}{$\mathbf{T}_{\mathbf{0}}$} & \multicolumn{2}{|c|}{$\mathbf{T}_{1}$} & \multirow{2}{*}{$\begin{array}{l}\Delta=T_{1}-T_{0} \\
\operatorname{Mean}\left({ }^{\circ}\right)\end{array}$} \\
\hline & & $\operatorname{Mean}\left({ }^{\circ}\right)$ & SD & $\operatorname{Mean}\left({ }^{\circ}\right)$ & SD & \\
\hline Nasal tip angle & Alar $_{R}-\operatorname{Prn}-$ Alar $_{L}$ & 81.26 & 7.5 & 88.62 & 8.5 & $7.36^{*}$ \\
\hline Upper lip angle & $\mathrm{Ch}_{\mathrm{R}}-1 \mathrm{~s}-\mathrm{Ch}_{\mathrm{L}}$ & 119.7 & 6.2 & 115.38 & 6.9 & -4.32 \\
\hline Lower lip angle & $\mathrm{Ch}_{\mathrm{R}}-\mathrm{li}-\mathrm{Ch}_{\mathrm{L}}$ & 116 & 4.8 & 126.46 & 4.56 & $10.46^{*}$ \\
\hline Inter-labial angle & Ls-Stm-Li & 134.33 & 8.5 & 125.52 & 8.67 & $-8.81 *$ \\
\hline Nasolabial angle & $\mathrm{Cm}-\mathrm{Sn}-\mathrm{Ls}$ & 82.68 & 9.14 & 94.25 & 6.22 & 11.57 \\
\hline Labio-mental angle & Li-Sm- Pog' & 145.91 & 10.8 & 140.59 & 8.19 & -5.32 \\
\hline
\end{tabular}

*Significant changes at the level of $5 \%$ of significance $(\alpha=0.05)$ based on the Wilcoxon signed-rank test

We found facial soft tissue changes in both the upper face and lower face regions with a mean of $(0.77,0.67 \mathrm{~mm})$ respectively, while the mean deviation at the nasal region was $(1.03 \mathrm{~mm})$, the highest magnitude of the soft tissue changes was found in the upper lip region with a mean deviation $(3.25 \mathrm{~mm})$. In regards to the Lower lip and Chin regions, noticed soft tissue decreases with a mean of deviation $(-1.21 \mathrm{~mm},-1.66 \mathrm{~mm})$ were reported respectively.

Descriptive statistics of the maximum positive and negative deviation limits, and also of the mean limits of the meshes are seen in (Table 11, 12). 
Table 11 Descriptive statistics of the maximum positive and negative deviation limits of the meshes

\begin{tabular}{|l|r|r|r|r|l|l|l|l|}
\hline Morphological region & \multicolumn{4}{|c}{ Maximum positive deviation limits $(\mathbf{m m})$} & \multicolumn{4}{c|}{ Maximum negative deviation limits (mm) } \\
\hline & Minimum & Maximum & Mean & SD & Minimum & Maximum & Mean & SD \\
\hline Total face & 5.84 & 5.96 & 5.9 & 0.08 & -5.04 & -4.74 & -4.89 & 0.21 \\
\hline Upper face & 5.68 & 5.98 & 5.87 & 0.16 & -4.74 & -3.04 & -3.98 & 0.86 \\
\hline Lower face & 5.62 & 5.84 & 5.7 & 0.15 & -5.04 & -2.53 & -3.83 & 1.25 \\
\hline Nose & 5.6 & 5.98 & 5.84 & 0.21 & -4.74 & -3.94 & -4.49 & 0.7 \\
\hline Upper lip & 5.62 & 5.84 & 5.71 & 0.11 & -2.94 & -2.4 & -2.67 & 0.27 \\
\hline Lower lip & 2.31 & 2.44 & 2.37 & 0.09 & -5.04 & -3.47 & -4.25 & 1.11 \\
\hline Chin & 0.46 & 1.48 & 0.97 & 0.72 & -3.94 & -3.38 & -3.66 & 0.39 \\
\hline
\end{tabular}

Table 12 Descriptive statistics of the mean limits of the meshes

\begin{tabular}{|l|l|l|l|l|}
\hline Morphological regions & Minimum & Maximum & Mean & SD \\
\hline Total face & 0.34 & 0.7 & 0.52 & 0.25 \\
\hline Upper face & 0.29 & 1.31 & 0.77 & 0.51 \\
\hline Lower face & 0.4 & 0.95 & 0.67 & 0.38 \\
\hline Nose & 0.89 & 1.17 & 1.03 & 0.14 \\
\hline Upper lip & 3.03 & 3.38 & 3.25 & 0.19 \\
\hline Lower lip & -1.48 & -0.95 & -1.21 & 0.37 \\
\hline Chin & -1.73 & -1.59 & -1.66 & 0.09 \\
\hline
\end{tabular}

Soft tissue changes were also observed in several facial landmarks after calculating the deviation in the soft tissue at the level of these landmarks as seen in (Table 13).

Table 13 Deviation labels of the facial soft tissue landmarks

\begin{tabular}{|l|l|l|l|}
\hline landmark & & Deviation mean(mm) & SD \\
\hline Endocanthion (right) & $\mathrm{End}_{\mathrm{r}}$ & -0.4 & 1.09 \\
\hline Endocanthion (left) & $\mathrm{End}_{1}$ & -0.1 & 1.03 \\
\hline Soft tissue nasion & $\mathrm{N}$ & -0.23 & 0.78 \\
\hline Alar point (right) & $\mathrm{Alar}_{\mathrm{r}}$ & 1.26 & 0.92 \\
\hline Alar point (left) & $\mathrm{Alar}_{1}$ & 0.85 & 0.99 \\
\hline Alar curvature (right) & $\mathrm{Ac}_{\mathrm{r}}$ & 1.36 & 0.69 \\
\hline Alar curvature (left) & $\mathrm{Ac}_{1}$ & 1.14 & 0.83 \\
\hline Pronasal & $\mathrm{prn}$ & 1.93 & 0.12 \\
\hline
\end{tabular}




\begin{tabular}{|l|l|l|l|}
\hline subnasal & $\mathrm{sn}$ & 3.03 & 2.32 \\
\hline Chelion (right) & $\mathrm{Ch}_{\mathrm{r}}$ & 0.63 & 0.78 \\
\hline Chelion (left ) & $\mathrm{Ch}_{1}$ & 0.57 & 0.44 \\
\hline Labiale superius & $\mathrm{ls}$ & 3.12 & 1.23 \\
\hline Labiale inferius & $\mathrm{li}$ & -3 & 1.77 \\
\hline Stomion & sto & 2.58 & 1.28 \\
\hline Sublabiale & $\mathrm{Sl}$ & -2 & 1.22 \\
\hline Soft tissue pogonion & $\mathrm{Pog}^{\prime}$ & -2.5 & 1.94 \\
\hline Soft tissue menton & $\mathrm{me}^{\prime}$ & -1.3 & 1.76 \\
\hline
\end{tabular}

\subsection{Discussion}

Facial soft tissue is dynamic, elastic, and easily affected by other factors. These may be general causes such as weight change, swelling, and aging, or related to the patient's head position and movement (114), or to the treatment itself and the underlying hard tissue changes, as well as soft tissue response to the tonicity of the surrounding muscles and tissue thickness $(46,114,115)$. That is why $2 \mathrm{D}$ facial images and cephalometric examination were found to be inadequate tools for soft tissue assessment after surgical procedures.

With the advances in 3D technology, it has recently become possible to standardize the registration of images and reduce errors in head orientation $(114,116)$. Some studies suggested that the flaws associated with setting reference landmarks on facial scanning images were sub-millimeter and found that facial soft tissue landmarks were of moderate to high reliability and reproducibility (49, 117).

To keep the malocclusion type and surgeon-related factors out of inclinations, the subjects were limited to those with skeletal class III, and all operations were performed by one surgeon (J.P.). We couldn't perform further analyses considering gender because of the small sample size in our study. However, C.-M. Chen and colleagues found no sex-related differences in soft tissue changes in patients with mandibular prognathism after orthognathic surgery (118). Whereas Mubarak and colleagues reported that females demonstrated higher percentages of soft tissue movement than did males (119). Further studies with larger sample size and the sex-related effects of bimaxillary surgery on the soft tissue are essential.

The timing of the soft tissue analysis is very critical. A period lasting 6 months after bimaxillary surgery was chosen as the $T_{1}$ stage since sufficient facial soft tissue stabilization is required to 
occur during this time, any subsequent modifications, such as post-operative swelling, soft tissue remodeling, and relocation should be minor enough to be insignificant $(29,30)$. Kau et al. suggested that the largest decline in swelling occurred within 1 month and the facial morphology recovered to about 90 percent within 3 months of surgery (120). Proffit and colleagues explained that postoperative changes do not show a normal distribution and that few patients exhibit considerable changes. The quantification and visualization of specific patient changes will then be relevant (121). Similarly, Oh and co-workers reported important changes in soft tissue 2 to 6 months after surgery and found that 6 months after surgery will be ideal for improved assessment (115).

\subsubsection{Soft tissue changes}

We found a statistically significant increase in the nasal width and widening of the alar bases after bimaxillary osteotomies $(2.31 \mathrm{~mm}$ and $2.02 \mathrm{~mm} \mathrm{p}$ <0.05) respectively. We can explain these increases by the remodeling and relocation of the surrounding muscles which may contribute to the post-operative soft tissue changes around the alar region (115). Our results commit to the results of Baik and colleagues who found $2.0 \mathrm{~mm}$ of nasal width increase after maxillary advancement and mandibular setback (24). Similarly, an increase was also reported in the alar width after bimaxillary surgery in class III patients using a 3D laser scanner and 3D facial morphometry $(122,123)$. Liebregts and colleagues found an increase of $(0.24 \mathrm{~mm})$ in the alar width for every $1 \mathrm{~mm}$ of maxillary advancement (124). While Altman and Oeltjen noted that all Le Fort I osteotomies cause widening of the alar bases because of the retraction of perioral muscles around the maxilla which results in detachment from their insertions during maxillary surgery(125). No significant changes neither in the intercanthal width nor in the mouth width were found in our study, and that was also noted in the study of Baik and colleagues, who found no significant changes neither in the mouth and philtrum width, and concluded that the increase in the lip length in some parts of the upper lip was produced by stretching the soft tissues (24).

Tiwari and colleagues found no significant changes in the lip width in patients who underwent maxillary advancement and mandibular setback which commit with our results (126). Similar results were reported by Lim and colleagues, who didn't find significant transverse changes of the landmarks of the lips, this might be due to their selection criteria, where they included patients with less than $3 \mathrm{~mm}$ of chin deviation (108). While Kim and colleagues reported a significant 
decrease in lip width after mandibular setback surgery (MSS), and it was explained by a decrease in soft tissue tension in the lower lip area after MSS (127).

On the other hand, predicting the impact of bimaxillary surgery on the vertical relationship of the jaws was extremely relevant. In this regard, we found significant increases in both the upper lip height and the upper lip vermilion height $(1.47$ and $2.31 \mathrm{~mm})$ respectively, thus the total upper lip height was significantly increased $(3.8 \mathrm{~mm})$. We can explain these increases by the relocation of the orbicularis oris muscle and soft tissue tension in the upper lip region.

Marsan and co-workers found elongation in the upper lip $(1.2 \pm 1.6 \mathrm{~mm})$ after bimaxillary surgery in Turkish female Class III patients and were correlated with the decrease in ANS-Gn distance, which contribute to our results (128).

In our study, we found a statistically significant decrease in the lower lip height ( $\mathrm{Li}-\mathrm{Sl} ; 1.9 \mathrm{~mm}$, $\mathrm{p}<0.05)$, decreases in the lower lip vermilion height, and also in the chin height $(-1.3 \mathrm{~mm},-4.75 \mathrm{~mm})$ respectively, without recording a significant level. The upward and backward movement of the mandible may play a role in these changes. Similarly, Marsan and colleagues reported a decrease in the lower lip height $(4 \mathrm{~mm})$ after bimaxillary surgery in Turkish female Class III patients, which contributes to our results. While the findings of Kim and colleagues suggest that the lower lip could be under the influence of the muscle rather than the bone(129), and this might be related to the inherent differences in the soft tissue between lip and chin(130).

As a result of the previous vertical measurements in our study, the lower anterior facial height was increased by $(1.4 \mathrm{~mm})$, without recording a significant level. On the other hand, Enacar and colleagues didn't report an increase in the vertical proportions of the face following single- or double-jaw surgery (131). However, some previous findings suggested that the measurement error appeared to be greater in the vertical changes, and it was difficult to predict the correlation in the vertical plane $(132,133)$.

In regards to our angular measurements, we found a statistically significant increase in the Nasal tip angle $\left(7.36^{\circ}, p<0.05\right)$, which could be affected by the lateral movements of the alar landmarks and the increase in the nasal and nasal base width, due to the relocation of the nasalis muscle after surgery.

Nasolabial angle is utilized to know the protrusion and retrusion of the maxilla concerning the upper lip. It likewise helps in diagnosing the nasal tip projection. We found an increase in the 
Nasolabial angle $\left(11.57^{\circ}\right)$ without reaching a significant level. However, this change can be produced by stretching the soft tissues in this area.

We also noticed a decrease in the Inter-labial angle $\left(-8.81^{\circ}, \mathrm{p}<0.05\right)$, which also can be explained by the relocation of the orbicularis oris muscle, the upper and lower lips after bimaxillary osteotomies, which cause movements of the Ls, Li landmarks. While the significant increase found in the Lower lip angle after bimaxillary surgery $\left(10.46^{\circ}\right)$ could refer to the movement of the $/ \mathrm{Li} /$ point.

In regards to the Labio-mental angle, which is usually influenced by the location of lower lip, chin, and tendency of mandibular incisor teeth. An acute angle might be an impression of the dentoalveolar protrusion or an over-grown chin and in contrast, while the obtuse one could be a result of dentoalveolar reclination or an undergrown chin(50). We can interpret the decrease found in our study in the Labio-mental angle after surgery by the backward and upward movement of the lower lip.

Al-Gunaid and colleagues found in their study which evaluated the hard and soft tissue changes after bimaxillary surgery in skeletal class III patients, an increase in the nasolabial angle, a decrease in the labio-mental angle, and improvement of the dentofacial aesthetics, they also reported that the soft tissue facial profiles and the posture of the lips were improved(134)

In the study of Marsan and colleagues, a gradual advancement at the nasal tip, a significant increase in the nasolabial angle, and a decrease in the labio-mental angle were reported (128).

For better analysis of the facial changes by involving the whole facial regions in our post-operative study instead of being admired to just some linear and angular measurements, we calculated the deviation analysis on the facial meshes in seven morphological regions of the face.

Baik et al. also suggested dividing the entire face into several regions, then measuring the amounts of soft-tissue changes with the percentage ratios relative to the movement of hard tissues for the different facial parts(24).

Although the high positive and negative deviation limits observed in the total face region in our study, the mean deviation of all landmarks forming this region didn't exceed $(0.52 \pm 0.25 \mathrm{~mm})$, this small magnitude can be explained by the multidirectional soft tissue changes in the facial parts forming the overall facial envelope.

previous studies reported more soft-tissue movement in the central parts than in the lateral parts with maxillary advancement and mandibular setback(135). 
We found facial soft tissue changes in both the upper face and lower face regions with a mean of $(0.77,0.67 \mathrm{~mm})$ respectively, while the mean deviation at the nasal region was $(1.03 \mathrm{~mm})$.

Gjorup and co-workers found that no changes appeared in the cheeks, and they took into consideration that the influence of the muscles and soft tissue tension decreased as the distance from the area where the hard tissue changes increased (136)

The highest magnitude of the soft tissue changes was found in the upper lip region with a mean deviation $(3.25 \mathrm{~mm})$ and high positive and negative deviation peaks $(5.71,-2.67 \mathrm{~mm})$ respectively. In regards to the Lower lip and Chin regions, we noticed soft tissue decreases with a mean of deviation $(-1.21 \mathrm{~mm},-1.66 \mathrm{~mm})$ respectively.

Baik et al. suggested that the semicircular shapes of the maxilla and the mandible correspond to the fewer changes in the sub-commissural region, a lateral part, than in the labio-mental or chin region, a central part(24).

For a better overview of the facial changes, we calculated the deviation on the facial landmarks after the surface comparison. The magnitude of deviation at the level of bilateral Alar points (1.26, $0.85 \mathrm{~mm}$ ) for the right and left respectively, emphasizes the lateral and anterior movement that we previously mentioned. A similar movement can be anticipated at the level of bilateral Alar curvature landmarks $(1.36,1.14 \mathrm{~mm})$, indicating soft tissue changes in the nasal region, along with the deviation noticed at the level of Pronasal and Subnasal (1.93 and 3.83mm) respectively. Regarded the upper lip area, a valuable positive deviation $(3.44 \mathrm{~mm})$ was found at the level of Labiale Superius point, indicating the anterior moment of this point after bimaxillary surgery. While deviations at the level of ( Labiale Inferius, Soft tissue pogonion, and Soft tissue Menton; $3,-2.5,-1.3 \mathrm{~mm}$ ) respectively, were reported in our study, which may indicate a posterior movement of the soft tissue in both the lower lip and chin regions after bimaxillary osteotomies, and confirm our previous results in the linear and angular measurements.

Even though the sample size is small, which is one of the limitations, our study is giving relevant and important information regarding three-dimensional soft tissue changes. It would be a great advancement for the clinical research and the analysis to be performed, considering gender, with larger sample size. 


\subsection{Conclusion}

In our present comprehensive 3D-evaluation, we succeeded to quantify and visualize the postoperative soft tissue changes after 6 months of bimaxillary surgery. Bearing in mind the limitations of the small sample size, the middle third of the face, especially the nose and upper lip will be influenced by bimaxillary surgery compared to the other facial structures. This must be taken into account in the course of treatment planning and that patients must be informed accordingly. Further investigations with larger sample size and appropriate controls are necessary for a more accurate evaluation of soft tissue responses after bimaxillary surgery. 


\section{Conclusion of the research}

- 3D handheld structured- light scanner seems to be an effective method in maxillofacial orthopedics, especially for prediction of the soft tissue changes during the conservative and surgical correction of the craniofacial anomalies.

- Statistically significant soft tissue changes were found in various morphological regions of the face during our orthodontic and surgical treatment of the craniofacial deformities in all 3D planes of space, especially in the middle third of the face, the nose and upper lip regions.

\section{Recommendation}

- Further investigations with larger sample size and appropriate controls are necessary for a more accurate evaluation of the facial soft tissue changes during the orthodontic and surgical treatment.

- More studies are necessary to predict the correlation between the hard and soft tissue changes after merging CBCT scans, intraoral and facial 3D scans to visualize a 3D virtual patient.

- Further studies seem to be necessary to inspect the accuracy of 3D handheld structuredlight scanner in maxillofacial orthopedics.

- Further studies are recommended for soft tissue evaluation using other types of 3D scanning methods, taking into consideration the facial expression and the jaw motion during our treatment. 


\section{Dedication and acknowledgments}

\section{Dedication}

I would like to dedicate this dissertation to my family for their unconditional love and support. You have provided me with every means to succeed and have been the foundation that has allowed me to progress and achieve my goals while keeping myself emotionally and physically grounded. I could not be where I am today without all of you.

\section{Acknowledgments}

Undertaking this Ph.D. has been a truly life-changing experience for me and it would not have been possible to do without the support and guidance that I received from many people.

First, I would like to express my most sincere gratitude and appreciation to the head of my department, oral and maxillofacial surgery, Prof. Dr. Dr. József Piffkó for his guidance, patience, and encouragement throughout the development of the project, without your wisdom, I couldn't complete my thesis.

My deepest gratitude also goes to my supervisor, the godfather of my research, Assoc. Prof. Dr. Emil Segatto, not only for his bright ideas, which influenced the whole project but also for his persistent demand for perfection which led to the quality of this project. I am greatly appreciative of your supervision, your valuable insight throughout this project's creation and development and for all the efforts and time you spent during my Ph.D. period.

No words can express my thanks and appreciation to my second mother here in Szeged, Prof. Dr. Nagy Katalin, the president of the Hungarian dental association and the head of the department of oral surgery, who made it possible for me, I can't forget your call when I needed help, that moment has changed my life. Thank you for all that you did for me.

My biggest thanks and sincere also go to the opponents and commission members, who spend a lot of time and effort to review my dissertation, to reach the highest scientific level.

Lastly, I would like to acknowledge the quarterly brainstorm group that consisted of my colleagues and to express my special thanks to my colleague, Dr. László Hegedús, who spent so much time assisting my work, I wish you the best of luck in all your future endeavors.

There are many more people I would like to thank, but time, space, and modesty compel me to stop here. Thank you all,

\section{Ali ...}




\section{References}

1. Ahlin JH. Maxillofacial Orthopedics: Xulon Press; 20034 December

2. AAOMS Wp, Committee on Government Affairs. Craniofacial Anomalies. American Association of Oral and Maxillofacial Surgeons2018.

3. Proffit WR, Fields HW, Larson B, Sarver DM. Contemporary Orthodontics. 6th Edition ed. 201806 Oct 2018.

4. Zarante I, Lopez MA, Caro A, Garcia-Reyes JC, Ospina JC. Impact and risk factors of craniofacial malformations in a Colombian population. International journal of pediatric otorhinolaryngology. 2009;73(10):1434-7.

5. Silva-Giraldo X, Porras-Hurtado GL. Characterization of congenital craniofacial anomalies in a specialized hospital of Risaralda, Colombia. 2010-2014. Revista de la Facultad de Medicina. 2018;66(2):223-7.

6. Czeizel AE. First 25 years of the Hungarian congenital abnormality registry. Teratology. 1997;55(5):299-305.

7. McNamaraa JA. Maxillary transverse deficiency. American Journal of Orthodontics and Dentofacial Orthopedics. 2000;117(5):567-70.

8. Bishara SE. Textbook of Orthodontics 1ed: Elsevier Science; ; 2001.

9. Vig Kw Fau - Turvey TA, Turvey TA. Orthodontic-surgical interaction in the management of cleft lip and palate. Clin Plast, Surg. 1985 Oct;12(4):735-48.

10. Haas AJ. THE TREATMENT OF MAXILLARY DEFICIENCY BY OPENING THE MIDPALATAL SUTURE. The Angle orthodontist. 1965;35:200-17.

11. AAOMS Cp. Criteria for Orthognathic Surgery. American Association of Oral and Maxillofacial Surgeons. 2017.

12. Hambleton RS. The soft-tissue covering of the skeletal face as related to orthodontic problems. American journal of orthodontics. 1964;50(6):405-20.

13. Holdaway RA. A soft-tissue cephalometric analysis and its use in orthodontic treatment planning. Part I. Am, J Orthod. 1983 Jul. 84(1):1-28.

14. Burstone CJ. Lip posture and its significance in treatment planning. Am, J Orthod. 1967. Apr. 53(4):262-84.

15. Macgregor FC. Social and psychological implications of dentofacial disfigurement. Angle, Orthod 1970 Jul. 40(3):231-3.

16. Rustemeyer J, Gregersen J. Quality of Life in orthognathic surgery patients: post-surgical improvements in aesthetics and self-confidence. Journal of cranio-maxillo-facial surgery : official publication of the European Association for Cranio-Maxillo-Facial Surgery. 2012;40(5):400-4.

17. Ackerman JL, Proffit Wr Fau - Sarver DM, Sarver DM. The emerging soft tissue paradigm in orthodontic diagnosis and treatment planning. Clin Orthod Res. 1999 May;2(2):49-52.

18. Angle EH. Treatment of malocclusion of the teeth : Angle's system. Philadelphia: White Dental Manufacturing Co.; 1907.

19. Burstone CJ. Integumental Contour And Extension Patterns. The Angle orthodontist. 1959;29(2):93-104.

20. Burstone CJ. The integumental profile. American Journal of Orthodontics and Dentofacial Orthopedics. 1958;44(1):1-25.

21. Nanda RS, Ghosh J. Facial soft tissue harmony and growthin orthodontic treatment. Seminars in Orthodontics. 1995;1(2):67-81.

22. Proffit WR. The soft tissue paradigm in orthodontic diagnosis and treatment planning: a new view for a new century. J Esthet Dent. 2000;12(1):46-9. 
23. Bianchi A, Muyldermans L, Di Martino M, Lancellotti L, Amadori S, Sarti A, et al. Facial soft tissue esthetic predictions: validation in craniomaxillofacial surgery with cone beam computed tomography data. Journal of oral and maxillofacial surgery : official journal of the American Association of Oral and Maxillofacial Surgeons. 2010;68(7):1471-9.

24. Baik HS, Kim SY. Facial soft-tissue changes in skeletal Class III orthognathic surgery patients analyzed with 3-dimensional laser scanning. American journal of orthodontics and dentofacial orthopedics: official publication of the American Association of Orthodontists, its constituent societies, and the American Board of Orthodontics. 2010;138(2):167-78.

25. Arnett GW, Jelic Js Fau - Kim J, Kim J Fau - Cummings DR, Cummings Dr Fau - Beress A, Beress A Fau Worley CM, Jr., Worley Cm Jr Fau - Chung B, et al. Soft tissue cephalometric analysis: diagnosis and treatment planning of dentofacial deformity. Am J Orthod Dentofacial Orthop. 1999 Sep;116(3):239-53.

26. Gill DS, Lloyd T, East C, Naini FB. The Facial Soft Tissue Effects of Orthognathic Surgery. Facial plastic surgery : FPS. 2017;33(5):519-25.

27. Ryckman MS, Harrison S, Oliver D, Sander C, Boryor AA, Hohmann AA, et al. Soft-tissue changes after maxillomandibular advancement surgery assessed with cone-beam computed tomography. American journal of orthodontics and dentofacial orthopedics : official publication of the American Association of Orthodontists, its constituent societies, and the American Board of Orthodontics. 2010;137(4 Suppl):S86-93.

28. Sarver DM. Esthetic orthodontics and orthognathic surgery. St. Louis: Mosby; 1998. 281 p.

29. Day CJ, Robert T. Three-dimensional assessment of the facial soft tissue changes that occur postoperatively in orthognathic patients. World journal of orthodontics. 2006;7(1):15-26.

30. Kau CH, Cronin AJ, Richmond S. A three-dimensional evaluation of postoperative swelling following orthognathic surgery at 6 months. Plastic and reconstructive surgery. 2007;119(7):2192-9.

31. van der Vlis M, Dentino KM, Vervloet B, Padwa BL. Postoperative swelling after orthognathic surgery: a prospective volumetric analysis. Journal of oral and maxillofacial surgery : official journal of the American Association of Oral and Maxillofacial Surgeons. 2014;72(11):2241-7.

32. Erten O, Yilmaz BN. Three-Dimensional Imaging in Orthodontics. Turkish journal of orthodontics. 2018;31(3):86-94.

33. Da Silveira AC, Daw JI Jr Fau - Kusnoto B, Kusnoto B Fau - Evans C, Evans C Fau - Cohen M, Cohen M. Craniofacial applications of three-dimensional laser surface scanning. 2003 (1049-2275 (Print)).

34. Sarver DM, McNamara JA. The face as the determinant of treatment choice. CRANIOFACIAL GROWTH SERIES. 2001;38:36.

35. Park YC Fau - Burstone CJ, Burstone CJ. Soft-tissue profile--fallacies of hard-tissue standards in treatment planning. American journal of orthodontics and dentofacial orthopedics : official publication of the American Association of Orthodontists, its constituent societies, and the American Board of Orthodontics. 1986 Jul;90(1).

36. Honrado CP, Larrabee WF, Jr. Update in three-dimensional imaging in facial plastic surgery. Curr Opin Otolaryngol Head Neck Surg. 2004 Aug;12(4):327-31.

37. Jacobson A, Jacobson RL. Radiographic Cephalometry: From Basics to 3-d Imaging. 2nd edition ed: Quintessence Pub Co. 2006 August 30, 2006.

38. Palomo JM, Yang C-Y, Hans MG. Clinical Application of Three-Dimensional Craniofacial Imaging in Orthodontics. J Med Sci 2005;25(6):9.

39. Mozzo P, Procacci C, Tacconi A, Tinazzi Martini P, Bergamo Andreis IA. A new volumetric CT machine for dental imaging based on the cone-beam technique: preliminary results. European Radiology. 1998;8(9):1558-64.

40. Kapila SD, Nervina JM. CBCT in orthodontics: assessment of treatment outcomes and indications for its use. Dento maxillo facial radiology. 2015;44(1):20140282. 
41. Mossaz J, Kloukos D, Pandis N, Suter VG, Katsaros C, Bornstein MM. Morphologic characteristics, location, and associated complications of maxillary and mandibular supernumerary teeth as evaluated using cone beam computed tomography. European journal of orthodontics. 2014;36(6):708-18.

42. Garib DG, Yatabe MS, Ozawa TO, Filho OG. Alveolar bone morphology in patients with bilateral complete cleft lip and palate in the mixed dentition: cone beam computed tomography evaluation. The Cleft palate-craniofacial journal : official publication of the American Cleft Palate-Craniofacial Association. 2012;49(2):208-14.

43. Goracci C, Franchi L, Vichi A, Ferrari M. Accuracy, reliability, and efficiency of intraoral scanners for full-arch impressions: a systematic review of the clinical evidence. European journal of orthodontics. 2016;38(4):422-8.

44. Currier F, Currier GF. Craniofacial 3D Imaging: Current Concepts in Orthodontics and Oral and Maxillofacial Surgery. Springer Nature Switzerland AG: Springer International Publishing; 2019. X, 252 p.

45. Yu Z, Mu X, Feng S, Han J, Chang T. Flip-registration procedure of three-dimensional laser surface scanning images on quantitative evaluation of facial asymmetries. The Journal of craniofacial surgery. 2009;20(1):157-60.

46. Soncul M, Bamber MA. Evaluation of facial soft tissue changes with optical surface scan after surgical correction of Class III deformities. Journal of oral and maxillofacial surgery : official journal of the American Association of Oral and Maxillofacial Surgeons. 2004;62(11):1331-40.

47. Langdon(ED) JD, Patel(ED) MF, Ord(ED) R, Brennan(ED) PA. Operative Oral and Maxillofacial Surgery. CRC P, editor. Boca Raton2017.

48. de Menezes M, Rosati R, Ferrario VF, Sforza C. Accuracy and reproducibility of a 3-dimensional stereophotogrammetric imaging system. Journal of oral and maxillofacial surgery : official journal of the American Association of Oral and Maxillofacial Surgeons. 2010;68(9):2129-35.

49. Baysal A, Ozturk MA, Sahan AO, Uysal T. Facial soft-tissue changes after rapid maxillary expansion analyzed with 3-dimensional stereophotogrammetry: A randomized, controlled clinical trial. Angle Orthod. 2016;86(6):934-42.

50. Kim YK, Lee NK, Moon SW, Jang MJ, Kim HS, Yun PY. Evaluation of soft tissue changes around the lips after bracket debonding using three-dimensional stereophotogrammetry. The Angle orthodontist. 2015;85(5):833-40.

51. Plooij JM, Swennen GR, Rangel FA, Maal TJ, Schutyser FA, Bronkhorst EM, et al. Evaluation of reproducibility and reliability of 3D soft tissue analysis using 3D stereophotogrammetry. International journal of oral and maxillofacial surgery. 2009;38(3):267-73.

52. Hajeer MY, Millett DT, Ayoub AF, Siebert JP. Applications of 3D imaging in orthodontics: part I. Journal of orthodontics. 2004;31(1):62-70.

53. Ayoub AF, Siebert P, Moos KF, Wray D, Urquhart C, Niblett TB. A vision-based three-dimensional capture system for maxillofacial assessment and surgical planning. The British journal of oral \& maxillofacial surgery. 1998;36(5):353-7.

54. Kuijpers MAR, Chiu Y-T, Nada RM, Carels CEL, Fudalej PS. Three-dimensional imaging methods for quantitative analysis of facial soft tissues and skeletal morphology in patients with orofacial clefts: a systematic review. PloS one. 2014;9(4):e93442-e.

55. Wong JY, Oh AK, Ohta E, Hunt AT, Rogers GF, Mulliken JB, et al. Validity and reliability of craniofacial anthropometric measurement of 3D digital photogrammetric images. The Cleft palate-craniofacial journal : official publication of the American Cleft Palate-Craniofacial Association. 2008;45(3):232-9.

56. Karatas $\mathrm{OH}$, Toy $\mathrm{E}$. Three-dimensional imaging techniques: A literature review. European journal of dentistry. 2014;8(1):132-40.

57. OH K, E T. Three-dimensional imaging techniques: A literature review. European journal of dentistry. 2014;8:8. 
58. Nguyen CX, Nissanov J Fau - Ozturk C, Ozturk C Fau - Nuveen MJ, Nuveen Mj Fau - Tuncay OC, Tuncay OC. Three-dimensional imaging of the craniofacial complex. Clin Orthod Res. 2000 Feb;3(1):46-50.

59. Chan B, Auyeung J, Rudan JF, Ellis RE, Kunz M. Intraoperative application of hand-held structured light scanning: a feasibility study. International journal of computer assisted radiology and surgery. 2016;11(6):1101-8.

60. Europe A. Artec Eva 2019 Available from: https://www.artec3d.com/portable-3d-scanners/artec-eva.

61. Hallac RR, Feng J, Kane AA, Seaward JR. Dynamic facial asymmetry in patients with repaired cleft lip using 4D imaging (video stereophotogrammetry). Journal of cranio-maxillo-facial surgery : official publication of the European Association for Cranio-Maxillo-Facial Surgery. 2017;45(1):8-12.

62. Joda T, Bragger $U$, Gallucci $G$. Systematic literature review of digital three-dimensional superimposition techniques to create virtual dental patients. The International journal of oral \& maxillofacial implants. 2015;30(2):330-7.

63. Xue Z, Wu L, Qiu T, Li Z, Wang X, Liu X. Three-Dimensional Dynamic Analysis of the Facial Movement Symmetry of Skeletal Class III Patients With Facial Asymmetry. Journal of oral and maxillofacial surgery : official journal of the American Association of Oral and Maxillofacial Surgeons. 2020 Feb;78(2):267-74.

64. Alagha MA, Ju X, Morley S, Ayoub A. Reproducibility of the dynamics of facial expressions in unilateral facial palsy. International journal of oral and maxillofacial surgery. 2018;47(2):268-75.

65. Europe A. 3D Software. 2019.

66. Metrology GPID. Software for 3D Measurement Data. 2019

67. Zeng J, Gao X. A prospective CBCT study of upper airway changes after rapid maxillary expansion. International journal of pediatric otorhinolaryngology. 2013;77(11):1805-10.

68. Haas AJ. Rapid Expansion Of The Maxillary Dental Arch And Nasal Cavity By Opening The Midpalatal Suture. The Angle orthodontist. 1961;31(2):73-90.

69. Wertz RA. Skeletal and dental changes accompanying rapid midpalatal suture opening. American journal of orthodontics. 1970;58(1):41-66.

70. Zimring JF, Isaacson RJ. FORCES PRODUCED BY RAPID MAXILLARY EXPANSION. 3. FORCES PRESENT DURING RETENTION. The Angle orthodontist. 1965;35:178-86.

71. Adkins MD, Nanda RS, Currier GF. Arch perimeter changes on rapid palatal expansion. American journal of orthodontics and dentofacial orthopedics : official publication of the American Association of Orthodontists, its constituent societies, and the American Board of Orthodontics. 1990;97(3):194-9.

72. Maulik C, Nanda R. Dynamic smile analysis in young adults. American journal of orthodontics and dentofacial orthopedics : official publication of the American Association of Orthodontists, its constituent societies, and the American Board of Orthodontics. 2007;132(3):307-15.

73. Smith T, Ghoneima A, Stewart K, Liu S, Eckert G, Halum S, et al. Three-dimensional computed tomography analysis of airway volume changes after rapid maxillary expansion. American journal of orthodontics and dentofacial orthopedics : official publication of the American Association of Orthodontists, its constituent societies, and the American Board of Orthodontics. 2012;141(5):618-26.

74. Abedini S, Elkenawy I, Kim E, Moon W. Three-dimensional soft tissue analysis of the face following micro-implant-supported maxillary skeletal expansion. Progress in orthodontics. 2018;19(1):46.

75. Berger JL, Pangrazio-Kulbersh V, Thomas BW, Kaczynski R. Photographic analysis of facial changes associated with maxillary expansion. American journal of orthodontics and dentofacial orthopedics: official publication of the American Association of Orthodontists, its constituent societies, and the American Board of Orthodontics. 1999;116(5):563-71.

76. Chung $\mathrm{CH}$, Font B. Skeletal and dental changes in the sagittal, vertical, and transverse dimensions after rapid palatal expansion. American journal of orthodontics and dentofacial orthopedics : official publication of the American Association of Orthodontists, its constituent societies, and the American Board of Orthodontics. 2004;126(5):569-75. 
77. da Silva Filho OG, Boas MC, Capelozza Filho L. Rapid maxillary expansion in the primary and mixed dentitions: a cephalometric evaluation. American journal of orthodontics and dentofacial orthopedics : official publication of the American Association of Orthodontists, its constituent societies, and the American Board of Orthodontics. 1991;100(2):171-9.

78. Littlefield TR, Kelly KM, Cherney JC, Beals SP, Pomatto JK. Development of a new three-dimensional cranial imaging system. The Journal of craniofacial surgery. 2004;15(1):175-81.

79. Brons S, van Beusichem ME, Bronkhorst EM, Draaisma J, Bergé SJ, Maal TJ, et al. Methods to quantify soft-tissue based facial growth and treatment outcomes in children: a systematic review. PloS one. 2012;7(8):e41898.

80. Straub J, Kading B, Mohammad A, Kerlin S. Characterization of a Large, Low-Cost 3D Scanner. Technologies. 2015;3(1):19-36.

81. Ma L, Xu T, Lin J. Validation of a three-dimensional facial scanning system based on structured light techniques. Computer methods and programs in biomedicine. 2009;94(3):290-8.

82. Jung J, Lee $\mathrm{CH}$, Lee JW, Choi BJ. Three dimensional evaluation of soft tissue after orthognathic surgery. Head Face Med. 2018;14(1):21.

83. Altindis S, Toy E, Basciftci FA. Effects of different rapid maxillary expansion appliances on facial soft tissues using three-dimensional imaging. The Angle orthodontist. 2016;86(4):590-8.

84. Altorkat Y, Khambay BS, McDonald JP, Cross DL, Brocklebank LM, Ju X. Immediate effects of rapid maxillary expansion on the naso-maxillary facial soft tissue using 3D stereophotogrammetry. The surgeon : journal of the Royal Colleges of Surgeons of Edinburgh and Ireland. 2016;14(2):63-8.

85. Solow B, Tallgren A. Natural Head Position in Standing Subjects. Acta Odontologica Scandinavica. 1971;29(5):591-607.

86. Weber DW, Fallis Dw Fau - Packer MD, Packer MD. Three-dimensional reproducibility of natural head position. American journal of orthodontics and dentofacial orthopedics : official publication of the American Association of Orthodontists, its constituent societies, and the American Board of Orthodontics. 2013 May;143(5):738-44.

87. Ong SC, Khambay BS, McDonald JP, Cross DL, Brocklebank LM, Ju X. The novel use of three-dimensional surface models to quantify and visualise the immediate changes of the mid-facial skeleton following rapid maxillary expansion. The surgeon : journal of the Royal Colleges of Surgeons of Edinburgh and Ireland. 2015;13(3):132-8.

88. LG F. Anthropometry of the head and face in medicine. Journal of Oral and Maxillofacial Surgery. 1981;40(6):394.

89. Swennen GRJ. 3-D Cephalometric Soft Tissue Landmarks Three-Dimensional Cephalometry: Springer; 2006. p. 183-226.

90. Dindaroglu F, Duran GS, Gorgulu S. Effects of rapid maxillary expansion on facial soft tissues : Deviation analysis on three-dimensional images. Journal of orofacial orthopedics = Fortschritte der Kieferorthopadie : Organ/official journal Deutsche Gesellschaft fur Kieferorthopadie. 2016;77(4):242-50.

91. G D. Statistical Methods for Medical and Biological Students. Br Med J. 1940;2(4158):358-9.

92. Zhao YJ, Xiong YX, Wang Y. Three-Dimensional Accuracy of Facial Scan for Facial Deformities in Clinics: A New Evaluation Method for Facial Scanner Accuracy. PloS one. 2017;12(1):e0169402.

93. Johnson BM, McNamara JA, Bandeen RL, Baccetti T. Changes in soft tissue nasal widths associated with rapid maxillary expansion in prepubertal and postpubertal subjects. The Angle orthodontist. 2010;80(6):995-1001.

94. Torun GS. Soft tissue changes in the orofacial region after rapid maxillary expansion : A cone beam computed tomography study. Journal of orofacial orthopedics = Fortschritte der Kieferorthopadie : Organ/official journal Deutsche Gesellschaft fur Kieferorthopadie. 2017;78(3):193-200. 
95. Huang J, Li CY, Jiang JH. Facial soft tissue changes after nonsurgical rapid maxillary expansion: a systematic review and meta-analysis. Head Face Med. 2018;14(1):6.

96. Bazargani F, Feldmann I, Bondemark L. Three-dimensional analysis of effects of rapid maxillary expansion on facial sutures and bones. The Angle orthodontist. 2013;83(6):1074-82.

97. Ghoneima A, Abdel-Fattah E, Hartsfield J, El-Bedwehi A, Kamel A, Kula K. Effects of rapid maxillary expansion on the cranial and circummaxillary sutures. American journal of orthodontics and dentofacial orthopedics : official publication of the American Association of Orthodontists, its constituent societies, and the American Board of Orthodontics. 2011;140(4):510-9.

98. Woller JL, Kim KB, Behrents RG, Buschang PH. An assessment of the maxilla after rapid maxillary expansion using cone beam computed tomography in growing children. Dental press journal of orthodontics. 2014;19(1):26-35.

99. Kim KB, Adams D, Araújo EA, Behrents RG. Evaluation of immediate soft tissue changes after rapid maxillary expansion. Dental press journal of orthodontics. 2012;17 (5).

100. Pangrazio-Kulbersh V, Wine P, Haughey M, Pajtas B, Kaczynski R. Cone beam computed tomography evaluation of changes in the naso-maxillary complex associated with two types of maxillary expanders. The Angle orthodontist. 2012;82(3):448-57.

101. Silva Filho OG, Lara TS, Ayub PV, Ohashi AS, Bertoz FA. Photographic assessment of nasal morphology following rapid maxillary expansion in children. Journal of applied oral science : revista FOB. 2011;19(5):535-43.

102. Garvill J, Garvill H, Kahnberg KE, Lundgren S. Psychological factors in orthognathic surgery. Journal of cranio-maxillo-facial surgery : official publication of the European Association for Cranio-MaxilloFacial Surgery. 1992;20(1):28-33.

103. Nurminen L, Pietila T, Vinkka-Puhakka H. Motivation for and satisfaction with orthodontic-surgical treatment: a retrospective study of 28 patients. European journal of orthodontics. 1999;21(1):79-87.

104. Ackerman JL, Proffit WR, Sarver DM. The emerging soft tissue paradigm in orthodontic diagnosis and treatment planning. Clinical Orthodontics and Research. 1999;2(2):49-52.

105. Bailey LT, Proffit WR, White RP, Jr. Trends in surgical treatment of Class III skeletal relationships. The International journal of adult orthodontics and orthognathic surgery. 1995;10(2):108-18.

106. Ayoub AF, Xiao Y, Khambay B, Siebert JP, Hadley D. Towards building a photo-realistic virtual human face for craniomaxillofacial diagnosis and treatment planning. International journal of oral and maxillofacial surgery. 2007;36(5):423-8.

107. Miracle AC, Mukherji SK. Conebeam CT of the head and neck, part 1: physical principles. AJNR American journal of neuroradiology. 2009;30(6):1088-95.

108. Lim YK, Chu EH, Lee DY, Yang IH, Baek SH. Three-dimensional evaluation of soft tissue change gradients after mandibular setback surgery in skeletal Class III malocclusion. The Angle orthodontist. 2010;80(5):896-903.

109. Koerich L, Brunetto DP, Ohira ETB. The effect of hard tissue surgical changes on soft tissue displacement: a pilot CBCT study. Dental press journal of orthodontics. 2017;22(5):39-46.

110. Wirthlin JO, Shetye PR. Orthodontist's Role in Orthognathic Surgery. Seminars in plastic surgery. 2013;27(3):137-44.

111. Obwegeser H. SURGERY OF THE MAXILLA FOR THE CORRECTION OF PROGNATHISM. 1965 Apr;75:365-74.

112. Naini FB, Gill DS. Orthognathic Surgery: Principles, Planning and Practice. 1 edition ed: WileyBlackwell; 2017 February 6, 2017. 936 p.

113. Dal Pont G. Retromolar osteotomy for the correction of prognathism. J Oral Surg Anesth Hosp Dent Serv. 1961 Jan;19(0095-9618 (Print)):42-7. 
114. Cevidanes LH, Motta A, Proffit WR, Ackerman JL, Styner M. Cranial base superimposition for 3dimensional evaluation of soft-tissue changes. American journal of orthodontics and dentofacial orthopedics : official publication of the American Association of Orthodontists, its constituent societies, and the American Board of Orthodontics. 2010;137(4 Suppl):S120-9.

115. Oh KM, Seo SK, Park JE, Sim HS, Cevidanes LH, Kim YJ, et al. Post-operative soft tissue changes in patients with mandibular prognathism after bimaxillary surgery. Journal of cranio-maxillo-facial surgery : official publication of the European Association for Cranio-Maxillo-Facial Surgery. 2013;41(3):204-11.

116. Almeida RC, Cevidanes LH, Carvalho FA, Motta AT, Almeida MA, Styner M, et al. Soft tissue response to mandibular advancement using 3D CBCT scanning. International journal of oral and maxillofacial surgery. 2011;40(4):353-9.

117. Othman SA, Ahmad R Fau - Mericant AF, Mericant Af Fau - Jamaludin M, Jamaludin M. Reproducibility of facial soft tissue landmarks on facial images captured on a 3D camera. Aust Orthod J. 2013 May;29(1):58-65.

118. Chen CM, Lai S, Lee HE, Chen KK, Hsu KJ. Soft-tissue profile changes after orthognathic surgery of mandibular prognathism. The Kaohsiung journal of medical sciences. 2012;28(4):216-9.

119. Mobarak KA, Krogstad O Fau - Espeland L, Espeland L Fau - Lyberg T, Lyberg T. Factors influencing the predictability of soft tissue profile changes following mandibular setback surgery. The Angle orthodontist. 2001;71(3):216-27.

120. Kau CH, Cronin A Fau - Durning P, Durning P Fau - Zhurov Al, Zhurov Ai Fau - Sandham A, Sandham A Fau - Richmond S, Richmond S. A new method for the 3D measurement of postoperative swelling following orthognathic surgery. Orthodontics \& craniofacial research. 2006 Feb;9(1):31-7.

121. Proffit WR, Turvey TA, Phillips $C$. The hierarchy of stability and predictability in orthognathic surgery with rigid fixation: an update and extension. Head Face Med. 2007;3:21.

122. Ferrario VF, Sforza C Fau - Schmitz JH, Schmitz Jh Fau - Santoro F, Santoro F. Three-dimensional facial morphometric assessment of soft tissue changes after orthognathic surgery. Oral Surg Oral Med Oral Pathol Oral Radiol Endod. 1999 Nov;88(5):549-56.

123. McCance AM, Moss Jp Fau - Wright WR, Wright Wr Fau - Linney AD, Linney Ad Fau - James DR, James DR. A three-dimensional soft tissue analysis of 16 skeletal class III patients following bimaxillary surgery. Br J Oral Maxillofac Surg. 1992 Aug;30(4).

124. Liebregts J, Xi T, Schreurs R, van Loon B, Berge S, Maal T. Three-dimensional virtual simulation of alar width changes following bimaxillary osteotomies. International journal of oral and maxillofacial surgery. 2016;45(10):1315-21.

125. Altman JI, Oeltjen JC. Nasal deformities associated with orthognathic surgery: analysis, prevention, and correction. J Craniofac Surg. 2007 Jul;18(4):734-9.

126. Tiwari R, Chakravarthi PS, Kattimani VS, Lingamaneni KP. A Perioral Soft Tissue evaluation after Orthognathic Surgery Using Three-Dimensional Computed Tomography Scan. Open Dent J.2018;12:366-76.

127. Kim M, Lee DY, Lim YK, Baek SH. Three-dimensional evaluation of soft tissue changes after mandibular setback surgery in class III malocclusion patients according to extent of mandibular setback, vertical skeletal pattern, and genioplasty. Oral surgery, oral medicine, oral pathology, oral radiology, and endodontics. 2010;109(5):e20-32.

128. Marsan G, Cura N, Emekli U. Soft and hard tissue changes after bimaxillary surgery in Turkish female Class III patients. Journal of cranio-maxillo-facial surgery : official publication of the European Association for Cranio-Maxillo-Facial Surgery. 2009;37(1):8-17.

129. Kim KA, Chang YJ, Lee SH, An HJ, Park KH. Three-dimensional soft tissue changes according to skeletal changes after mandibular setback surgery by using cone-beam computed tomography and a structured light scanner. Progress in orthodontics. 2019;20(1):25. 
130. Jung YJ, Kim Mj Fau - Baek S-H, Baek SH. Hard and soft tissue changes after correction of mandibular prognathism and facial asymmetry by mandibular setback surgery: three-dimensional analysis using computerized tomography. Oral surgery, oral medicine, oral pathology, oral radiology, and endodontics. 2009 Jun;107(6):763-71.e8.

131. Enacar A, Taner T Fau - Manav O, Manav O. Effects of single- or double-jaw surgery on vertical dimension in skeletal Class III patients. 2001(0742-1931 (Print)).

132. Koh CH, Chew MT. Predictability of soft tissue profile changes following bimaxillary surgery in skeletal class III Chinese patients. Journal of oral and maxillofacial surgery : official journal of the American Association of Oral and Maxillofacial Surgeons. 2004;62(12):1505-9.

133. Mansour S Fau - Burstone C, Burstone C Fau - Legan $\mathrm{H}$, Legan $\mathrm{H}$. An evaluation of soft-tissue changes resulting from Le Fort I maxillary surgery. American journal of orthodontics and dentofacial orthopedics : official publication of the American Association of Orthodontists, its constituent societies, and the American Board of Orthodontics. $1983 \mathrm{Jul} ; 84(1): 37-47$.

134. Al-Gunaid T, Yamaki M, Takagi R, Saito I. Soft and hard tissue changes after bimaxillary surgery in Japanese class III asymmetric patients. Journal of orthodontic science. 2012;1(3):69-76.

135. Kim NK, Lee C, Kang SH, Park JW, Kim MJ, Chang YI. A three-dimensional analysis of soft and hard tissue changes after a mandibular setback surgery. Computer methods and programs in biomedicine. 2006;83(3):178-87.

136. Gjorup H, Athanasiou AE. Soft-tissue and dentoskeletal profile changes associated with mandibular setback osteotomy. American journal of orthodontics and dentofacial orthopedics : official publication of the American Association of Orthodontists, its constituent societies, and the American Board of Orthodontics. 1991 Oct;100(4):312-23. 
APPENDIX 


\title{
Article \\ Evaluation of the Soft Tissue Changes after Rapid Maxillary Expansion Using a Handheld Three-Dimensional Scanner: A Prospective Study
}

\author{
Ali Alkhayer ${ }^{1}{ }^{\mathbb{D}}$, Roland Becsei ${ }^{1}$, László Hegedús ${ }^{1}$, László Párkányi ${ }^{2}$, József Piffkó ${ }^{3}$, Gábor Braunitzer ${ }^{4}$ \\ and Emil Segatto ${ }^{1, *}$ \\ 1 Craniofacial Unit, Department of Oral \& Maxillofacial Surgery, University of Szeged, Tisza Lajos krt. 97, \\ 6722 Szeged, Hungary; ali.alkhayer@hotmail.com (A.A.); becsei.roli@gmail.com (R.B.); \\ hlac929@gmail.com (L.H.) \\ 2 Department of Periodontology, Faculty of Dentistry, University of Szeged, Tisza Lajos krt. 64-66, \\ 6720 Szeged, Hungary; parkanyilaci@gmail.com \\ 3 Department of Oral \& Maxillofacial Surgery, Faculty of Medicine, University of Szeged, Kálvária Sugárút 57, \\ 6725 Szeged, Hungary; piffkojozsef@gmail.com \\ 4 DicomLAB Dental, Ltd., Szent-Györgyi Albert u. 2, 6726 Szeged, Hungary; braunitzergabor@gmail.com \\ * Correspondence: dr@segatto.hu; Tel.: +36-309969800
}

Citation: Alkhayer, A.; Becsei, R.; Hegedûs, L.; Párkányi, L.; Piffkó, J.; Braunitzer, G.; Segatto, E. Evaluation of the Soft Tissue Changes after Rapid Maxillary Expansion Using a Handheld Three-Dimensional Scanner: A Prospective Study. Int. J. Environ. Res. Public Health 2021, 18, 3379. https://doi.org/10.3390/ ijerph18073379

Academic Editors: Eitan Mijiritsky, Pietro Felice and Barbara Zavan

Received: 7 February 2021

Accepted: 22 March 2021

Published: 24 March 2021

Publisher's Note: MDPI stays neutra with regard to jurisdictional claims in published maps and institutional affiliations.

Copyright: (c) 2021 by the authors. Licensee MDPI, Basel, Switzerland. This article is an open access article distributed under the terms and conditions of the Creative Commons Attribution (CC BY) license (https:/ / creativecommons.org/licenses/by/ $4.0 /)$.

\begin{abstract}
Facial soft tissue esthetics is a priority in orthodontic treatment, and emerging of the digital technologies can offer new methods to help the orthodontist toward an esthetic outcome. This prospective study aimed to assess the soft tissue changes of the face after six month of retention following Rapid Maxillary Expansion (RME). The sample consisted of 25 patients (13 females, 12 males, mean age: 11.6 years) who presented with unilateral or bilateral posterior crossbite requiring RME, which was performed with a Hyrax expander. 3D facial images were obtained before treatment $\left(\mathrm{T}_{0}\right)$ and at the end of a six-month retention period after the treatment $\left(\mathrm{T}_{1}\right)$ using a structured-light 3D handheld scanner. Linear and angular measurements were performed and 3D deviation analyses were done for six morphological regions of the face. Significant changes in various areas of the nasal and the upper lip regions were observed. Based on the results of the study and within the limitations of the study, RME with a Hyrax expander results in significant morphological changes of the face after a six-month retention period.
\end{abstract}

Keywords: rapid maxillary expansion; malocclusion; facial soft tissue; three-dimensional imaging

\section{Introduction}

Rapid maxillary expansion (RME) is routinely used to eliminate skeletal maxillary transversal deficiency, particularly in patients with posterior crossbite, moderate crowding, and sleep apnea disorders [1-4], to achieve apical opening of the maxillary base along the mid-palatal suture.

The approach basically relies on the forces generated by means of the RME appliances, which can mechanically separate the maxillary segments at the mid-palatal suture [3-5]. By this treatment, the following can be achieved: correction of the skeletal transversal deficiency and gain of space in the dental arch [6], improved smile by reducing the buccal corridors [7] and expansion of the airway [8].

RME has an influence on the morphology of the soft tissues of the face as well. It is in the patients' best interest that such changes are understood [9]. Still, the area is surprisingly under-researched and several questions are unclarified.

Until recently, changes in the soft tissue envelope and the underlying skeletal structures following RME have been examined mainly through two-dimensional (2D) imaging techniques, mostly lateral cephalometric images, anteroposterior graphs, and photogram- 
metric analyses [10-12]. However, these methods suffer from superimposition and magnification problems, which can be avoided using three-dimensional (3D) imaging.

Of the three-dimensional imaging methods, cone-beam computed tomography (CBCT) is becoming increasingly popular. However, soft tissues are poorly represented using this technique [13].

Therefore, noncontact optical scanning devices were introduced as 3D imaging techniques for soft tissue visualization like laser surface scanning and stereophotogrammetry [14]. These non-invasive approaches are thought to allow images to be captured at short intervals without exposing the patient to the radiation, which makes them an appealing option [14]. However, these devices are often bulky and also rather expensive, which are clearly deterring factors [15].

By using a handheld 3D structured-light scanners, texture and color information of the face can be promptly obtained in high resolution without radiation. Further advantages include short scan time, portability, ease of operation, and reasonable cost [16]. Jung et al. found that the accuracy of structured light systems compares to that of direct anthropometric measurements and concluded that it is a reliable approach for a facial soft tissue assessment [17].

Most of the previous studies that utilized 3D facial scanners to evaluate soft tissue changes following RME have examined deviations at specific points and calculated linear and angular measurements $[18,19]$. However, it is more accurate to predict changes within the whole complex structures on a 3D basis rather than only between specified points. Having recognized that, the aim of our prospective study was to adopt a comprehensive examination of soft tissue in various morphological regions of the face after six months of retention following RME, based on structured-light scanning.

\section{Materials and Methods}

This prospective study was approved by the Human Investigation Review Board, University of Szeged, Albert Szent-Györgyi Clinical Centre (No. 151/2019-SZTE).

\subsection{Study Sample}

Patients in need of upper arch expansion were recruited from among the patients of the Craniofacial Unit, Department of Oral and Maxillofacial Surgery, Albert SzentGyörgyi Clinical Center, Szeged, Hungary, between January 2019 and January 2020. The inclusion criteria included maxillary transverse deficiency, assessed both clinically and radiographically, which is associated with either unilateral or bilateral posterior crossbite and/or dental crowding. Exclusion criteria included the history of trauma or previous orthodontic treatment, and patients with physical and psychological limitations and/or craniofacial anomalies.

The sample size was calculated based on the findings of Kim et al. [20], and the analysis was performed with $G^{*}$ Power software (Franz Faul, Universität Kiel, Germany) Version 3.1.9.4, based on the assumption of the Wilcoxon rank test. A sample size of 23 patients was predicted to provide $80 \%$ of power with a $5 \%$ error of probability. A total of 25 patients (13 females and 12 males) with a mean age of 11.6 years (range: 8.1-14.4 years) were enrolled in our study.

The 3D facial images were acquired immediately before the appliance was cemented $\left(T_{0}\right)$ and at the end of the 6-month retention phase $\left(T_{1}\right)$, using a structured-light 3D handheld scanner (Artec Eva ${ }^{\mathrm{TM}}$; Artec Group, Luxembourg). A 6-month retention period was chosen to control for growth, which could have interfered with the results in case of a longer period.

The proposed scanner uses structured light scanning technology to accurately capture in a point-and-shoot manner up to 16 frames per second and each frame is a 3D image. These frames are aligned automatically in real-time while providing high resolution (up to $0.5 \mathrm{~mm}$ ) and high accuracy (up to $0.1 \mathrm{~mm}$ ). All images were taken with the head in a natural head position and with a relaxed lip posture [21]. To reach the natural head balance, 
subjects were seated in a back-supported and vertically adjustable chair. They were asked to turn their heads forward and backward with decreasing amplitude until they reached a relaxed position [22]. Then they were told to look straight ahead to a point on the wall in front of them at eye level.

\subsection{Clinical Protocol}

Following upper and lower alginate impressions, a Hyrax-type expander was constructed with 4 bands, palatal stainless-steel bars of 1.0-mm diameter, and a jackscrew (Forestadent, Pforzheim, Germany) with stainless steel extensions soldered to the palatal surfaces of each pair of bands. The activation of the jackscrew was for each quarter turn equivalent to $0.25 \mathrm{~mm}$.

The parents were instructed to activate the screw 2 turns per day $(0.5 \mathrm{~mm})$ and the patients were recalled on a weekly basis of the expansion period ( 2 to 3 weeks). The expansion was stopped when the palatal cusp of the upper molars was touching the buccal cusp of the lower molars [23]. Then the appliance was kept in for the retention period (6 months), and the jackscrews were blocked with a composite to prevent relapse (Figure 1).
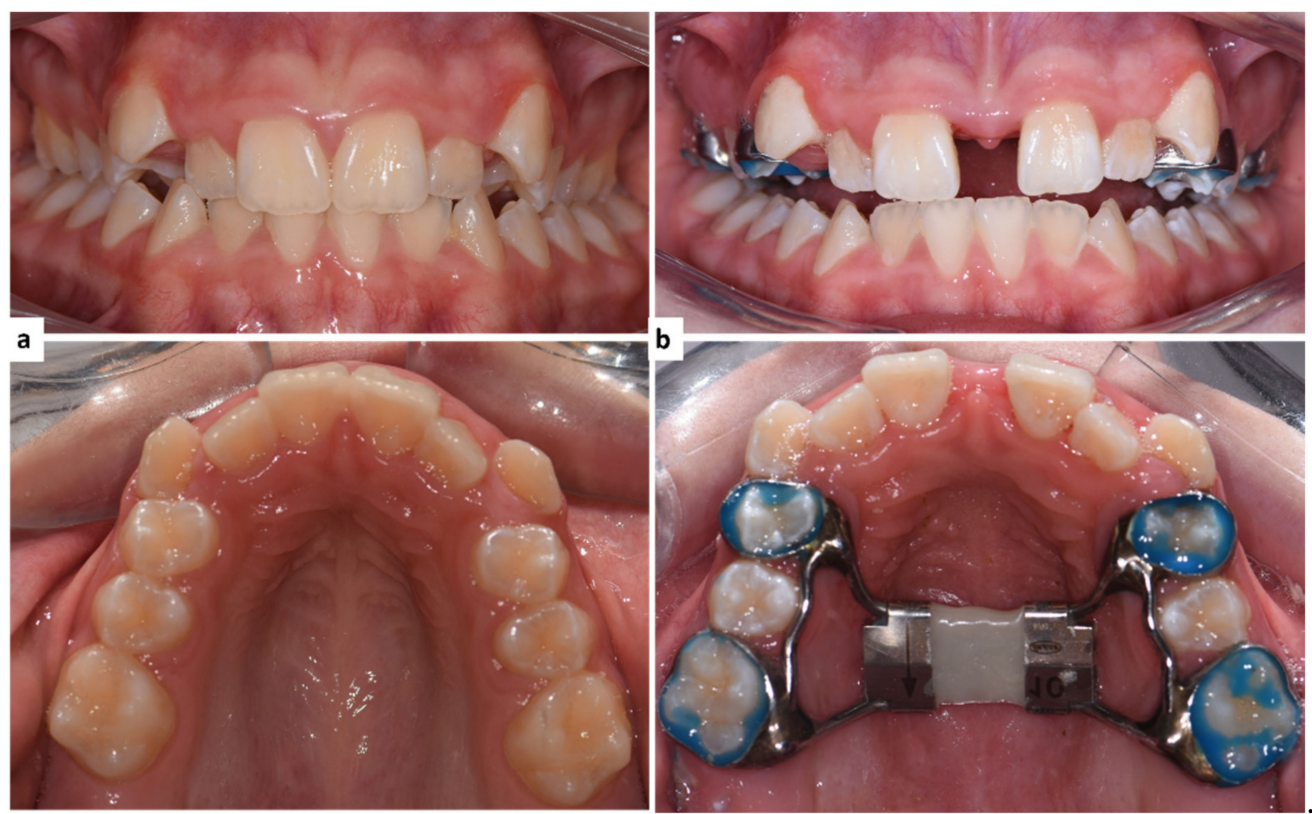

Figure 1. Intraoral photographs of a patient. (a) Before the cementation of the Hyrax expander. (b) After the expander was blocked for retention.

The expansion of the Hyrax jackscrew was measured for each patient. Dental cast models were also made prior to expander cementation and after the retention period. The distance between the mesial buccal cusp of the right and left upper first molar was measured before and after the expansion and the difference was calculated.

After removal of the Hyrax appliance, we continued the treatment for all our patients using a fixed appliance (self-ligating multibracket appliance, Roth prescription).

\subsection{Data Processing and Measurements}

In total, 18 landmarks (5 bilateral and 8 unilateral: Table 1, Figure 2) were defined according to the literature [24,25]. In addition, 4 linear and 3 angular measurements were performed directly on the 3D facial images using Artec Eva V.12 (Figures 3 and 4). 
Table 1. Definition of the facial landmarks used in our study.

\begin{tabular}{|c|c|c|}
\hline \multicolumn{2}{|c|}{ Landmark } & Definition \\
\hline Exocanthion & Ex* & Point at the outer commissure of the eye fissure \\
\hline Endocanthion & End * & Point at the inner commissure of the eye fissure \\
\hline Sellion & Se & $\begin{array}{c}\text { The most posterior point of the frontonasal soft tissue contour in the midline of the } \\
\text { base of the nasal root }\end{array}$ \\
\hline Alare & $\mathrm{Al}$ * & The most lateral point on each alar contour (on the base view) \\
\hline Pronasale & Prn & $\begin{array}{l}\text { The most anterior midpoint of the nasal tip (on the right and left profile view). If a } \\
\text { bifid nose is present, the more protruding tip is chosen to determine Pronasale }\end{array}$ \\
\hline alar curvature point & $\mathrm{Ac}^{*}$ & The point located at the facial insertion of each alar base. (on the submental view) \\
\hline Subnasale & Sn & $\begin{array}{l}\text { Midpoint on the nasolabial soft tissue contour between the Columella crest and } \\
\text { the upper lip }\end{array}$ \\
\hline Labiale superius & Ls & The midpoint of the vermilion line of the upper lip (on the submental view) \\
\hline Stomion & Stm & The midpoint of the horizontal labial fissure \\
\hline Chelion & $\mathrm{Ch}^{*}$ & The point located at each labial commissure (on the frontal view) \\
\hline Labiale inferius & $\mathrm{Li}$ & The midpoint of the vermilion line of the lower lip (on the right profile view) \\
\hline Sublabiale & $\mathrm{Sl}$ & $\begin{array}{l}\text { The most posterior midpoint on the Labiomental soft tissue contour that defines } \\
\text { the border between the lower lip and the chin }\end{array}$ \\
\hline Soft tissue Menton & $\mathrm{Me}^{\prime}$ & $\begin{array}{l}\text { The most inferior midpoint on the soft tissue contour of the chin located at the } \\
\text { level of the 3-D cephalometric hard tissue Menton landmark }\end{array}$ \\
\hline
\end{tabular}

* Indicates bilateral landmarks (right and left).
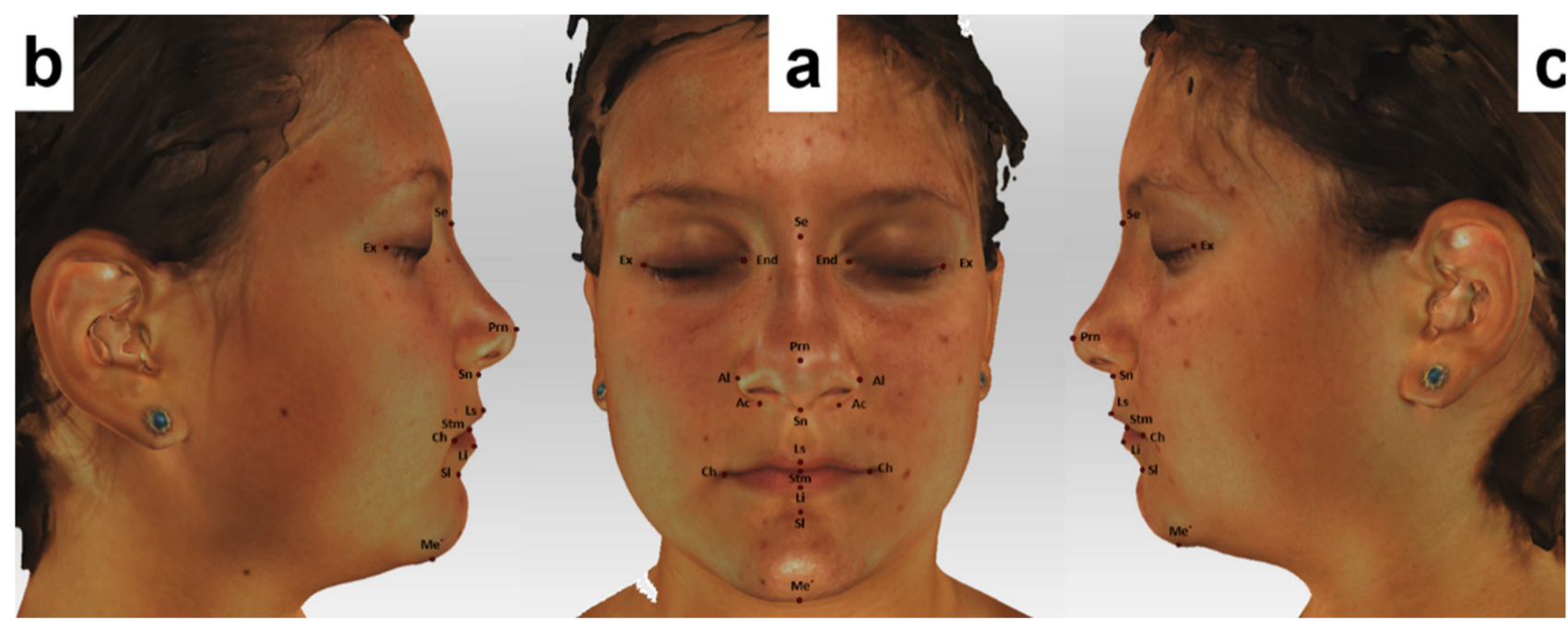

Figure 2. Landmarks used in our study located on the 3D-facial images. (a) Frontal view (b) and (c) lateral views.

For the 3D deviation analysis, the 3D facial images were transferred into a reverse engineering software (GOM Inspect Evaluation Software, Capture 3D, Inc, Santa Ana, CA, USA) and polygon meshes were created in a stereolithography (STL) format. The hair, ears, and the below-neck region were removed. The images obtained at the $\mathrm{T}_{0}$ time point were aligned with the images taken at $\mathrm{T}_{1}$ using the best-fit method, as described by Dindaroglu et al. [26] (Figure 5). 


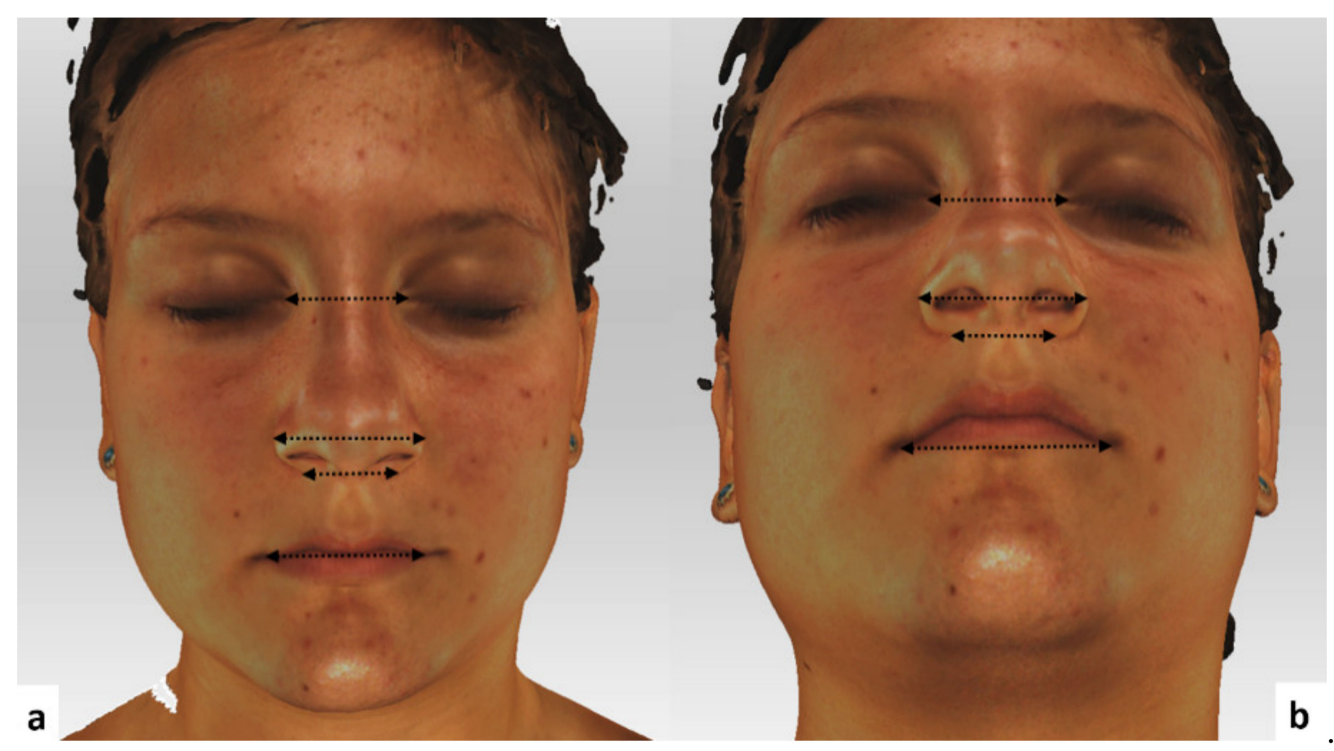

Figure 3. Linear measurements used in our study. (a) Frontal view. (b) Base view.
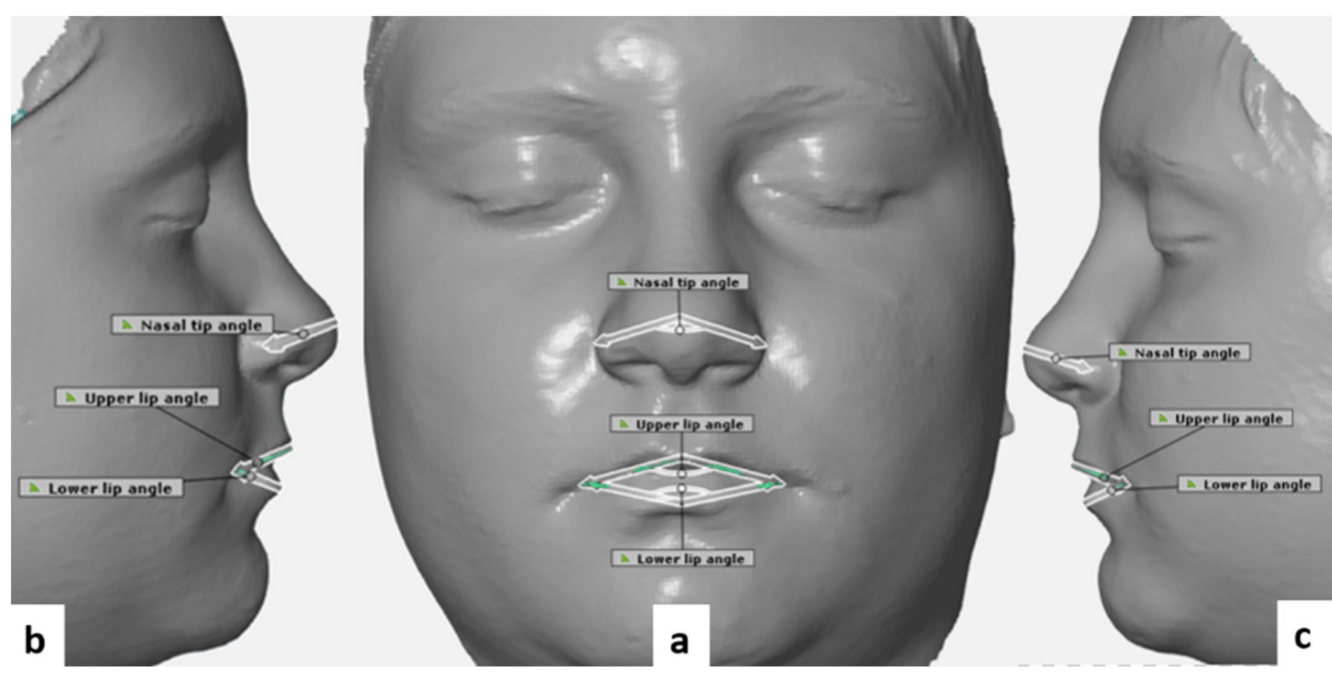

Figure 4. Angular measurements used in our study. (a) Frontal view (b) and (c) lateral views.

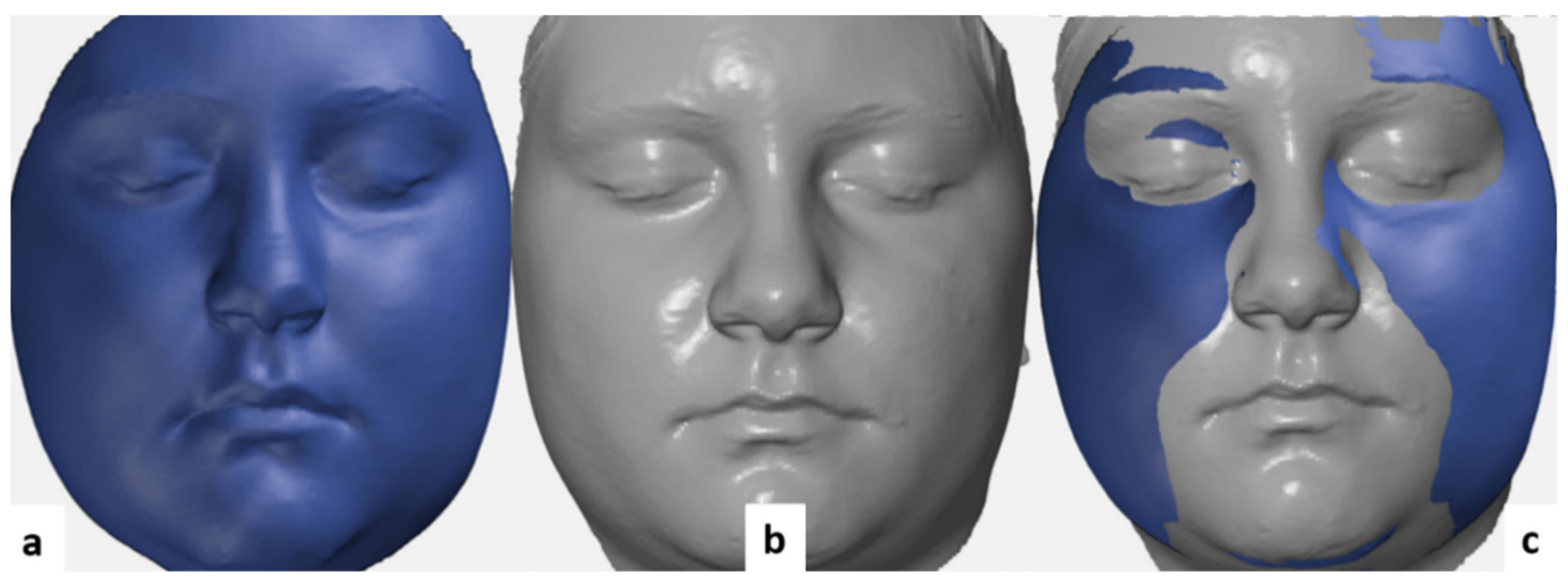

Figure 5. The best-fit method used in our study. (a) $\mathrm{T}_{0}$ mesh. (b) $\mathrm{T}_{1}$ mesh. (c) The final mesh aligned. 
Negative values indicate that $T_{1}$ images were located behind the $T_{0}$ images (blue shades), whereas positive values indicate that $T_{1}$ images were located in front of the $T_{0}$ images (red shades). To create morphological regions, eight lines passing through different points specified on the face were determined and a 3D deviation analysis was made in six morphological regions [26] (Table 2, Figure 6).

Table 2. Definition of morphological regions used for the 3D deviation analyses.

\begin{tabular}{|c|c|}
\hline Region & Definition \\
\hline Total face & $\begin{array}{l}\text { The facial region designated while creating masks prior to alignment } \\
\text { The region between the line passing through the right and left }\end{array}$ \\
\hline Upper face & $\begin{array}{l}\text { Exocanthion points and the line passing through the Subnasal point } \\
\text { parallel to that line }\end{array}$ \\
\hline Lower face & $\begin{array}{l}\text { The region between the line passing through the Subnasal point and } \\
\text { the line passing through the Menton point parallel to that line } \\
\text { The region between the lines passing through the right and left }\end{array}$ \\
\hline Upper lip & $\begin{array}{c}\text { Endocanthion points and the right and left Cheilion points, and the } \\
\text { line passing through the Subnasal point } \\
\text { The region between the lines passing through the right and left }\end{array}$ \\
\hline Lower lip & $\begin{array}{l}\text { Endocanthion points and the right and left Cheilion points, and the } \\
\text { line passing through a Sublabiale point parallel to other lines } \\
\text { The region between the lines passing through the right and left }\end{array}$ \\
\hline Nose & $\begin{array}{c}\text { Endocanthion points that are tangent to the nasal wings and the line } \\
\text { passing through the Subnasal point }\end{array}$ \\
\hline
\end{tabular}
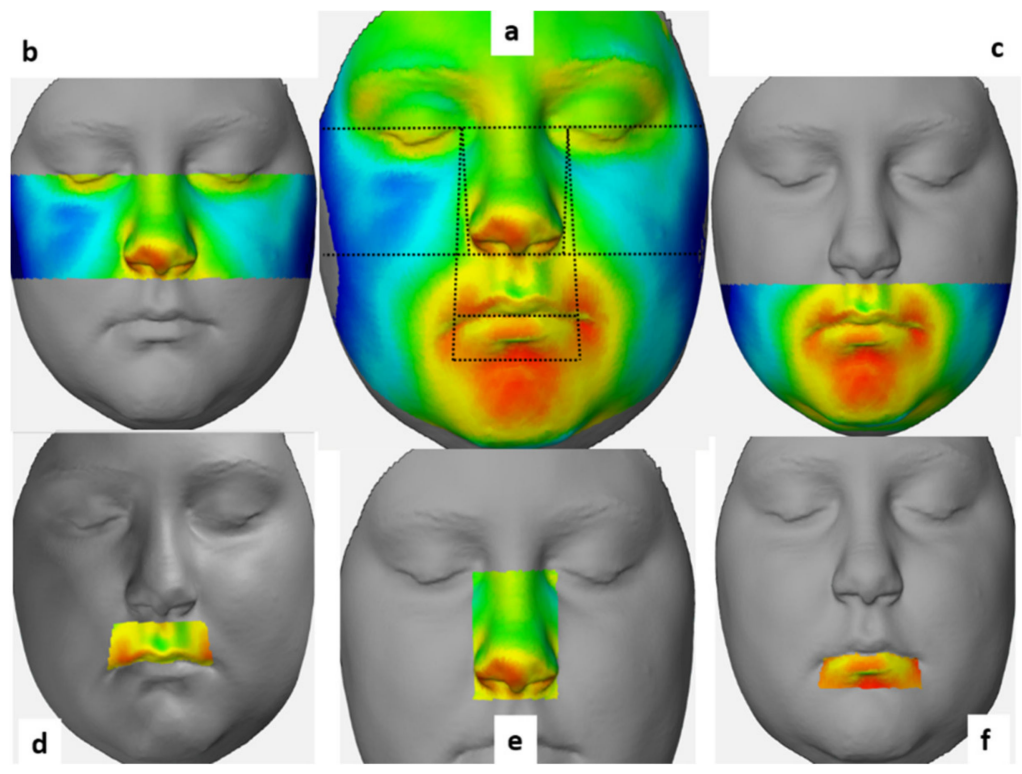

Figure 6. The morphological regions and their reference lines used in our study. (a) Total face region with the reference lines used. (b) Upper face region. (c) Lower face region. (d) Upper lip region. (e) Nose region. (f) Lower lip region.

We also calculated the deviation magnitude for specific facial landmarks directly on the 3D inspected meshes (Figure 7). 


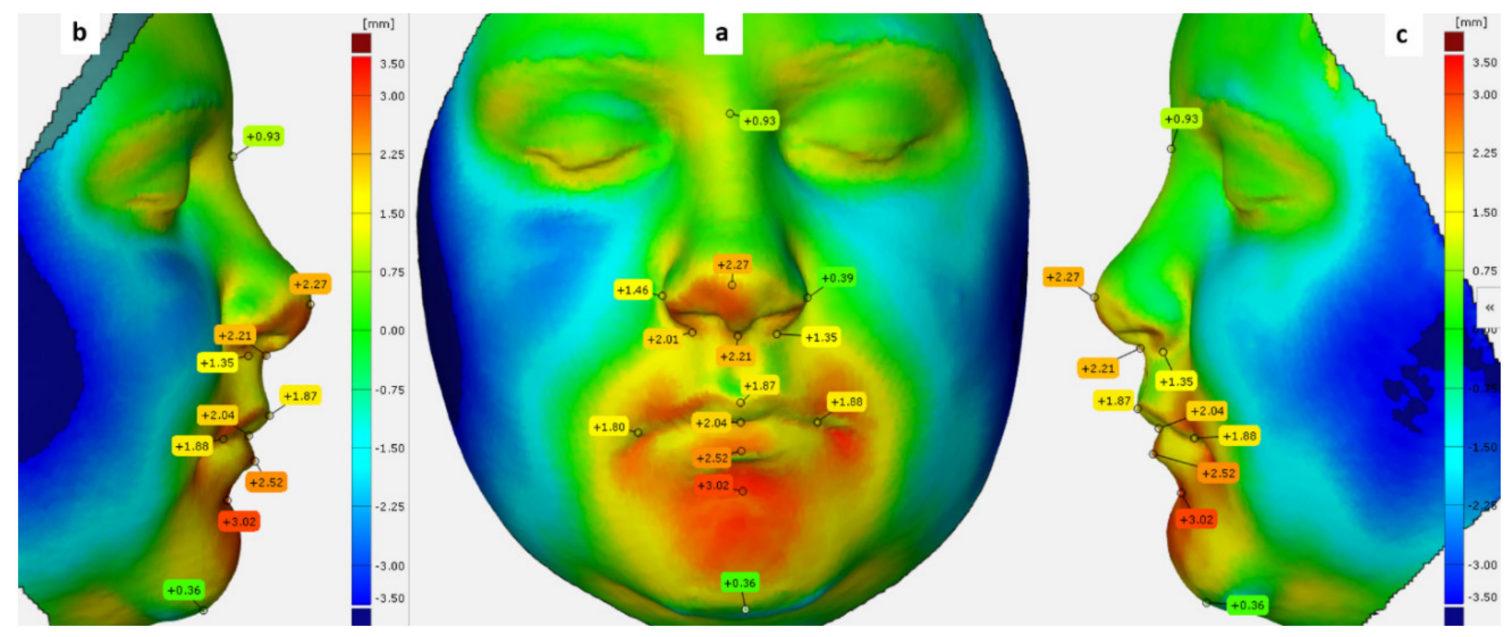

Figure 7. Deviation labels of the facial soft tissue landmarks used in our study. (a) Frontal view (b) and (c) lateral views.

\subsection{Statistical Analysis}

Normal distribution of the data was established with the Shapiro-Wilk and KolmogorovSmirnov tests. To determine the method's reliability, $\mathrm{T}_{0}$ and $\mathrm{T}_{1}$ images of 10 randomly selected patients were re-aligned and the measurements were recalculated one month later by the same investigator. Intra-examiner reliability was assessed to evaluate the reliability of the measurements in the same image and by the same investigator using the Intraclass Correlation Coefficient (ICC).

The random errors were calculated according to the Dahlberg' formula $\left(\mathrm{D}=\sqrt{ } \sum \mathrm{d}^{2} / 2 \mathrm{~N}\right)$ [27], where $\mathrm{D}$ is the error variance and $\mathrm{d}$ is the difference between the first and second measure. $\mathrm{N}$ is the sample size, which was re-measured. The systematic errors were also evaluated by comparing the first and second measurements using the dependent $t$ test.

The $\left(\mathrm{T}_{0}\right)$ and $\left(\mathrm{T}_{1}\right)$ linear and angular measurements were compared. Significant differences at the level of $5 \%$ of significance were tested using a Wilcoxon signed rank test. In addition, for each patient, 3D deviation analysis was performed to calculate not only the maximum positive and negative deviation, but also the mean deviation for the facial meshes. Then, the Pearson correlation coefficient was calculated to determine the correlation between the expansion amount (expressed as the amount of jackscrew activation and resulting width difference of the upper arch) and the facial soft tissue changes. All statistical analyses were performed in SPSS 24.0 (IBM, Armonk, NY, USA).

\section{Results}

All parameters were normally distributed, according to the Shapiro-Wilk and KolmogorovSmirnov tests. No significant errors were found when repeating the measurements. The (ICC) values between the two sets of measurements were a high range of $0.821-0.979$. The amount of random error was small enough (less than $0.5 \mathrm{~mm} /{ }^{\circ}$ ), and no systematic errors were found between the measurements obtained on the two different occasions $(p \geq 0.05)$. The mean value of the jackscrew activation after RME was $7.75 \mathrm{~mm}$ and the mean of the upper arch width difference calculated on the dental casts was $5.46 \mathrm{~mm}$. Statistically significant changes of the soft tissue variables were found after RME using the Wilcoxon rank test (Table 3).

The mean linear changes of the nasal width and the nasal base width after RME were $1.02 \mathrm{~mm}$ and $1.21 \mathrm{~mm}$, respectively, and $2.62 \mathrm{~mm}$ for the mouth width. While we also found significant angular changes after RME, the nasal tip angle increased by $3.2^{\circ}$, while the upper and lower lip angle have increased by $3.47^{\circ}$ and $3.78^{\circ}$, respectively. 
Table 3. Descriptive statistics of the pretreatment $\left(T_{0}\right)$ and post-treatment $\left(T_{1}\right)$ measurements.

\begin{tabular}{|c|c|c|c|c|c|c|c|}
\hline & & \multicolumn{2}{|c|}{$\mathbf{T}_{0}$} & \multicolumn{2}{|c|}{$\mathbf{T}_{1}$} & \multirow{2}{*}{$\Delta=\mathrm{T}_{1}-\mathrm{T}_{0}$} & \multirow{2}{*}{$p$} \\
\hline & & Mean & SD & Mean & SD & & \\
\hline \multicolumn{8}{|c|}{ Linear measurements (mm) } \\
\hline Intercanthal width & $\left(E n_{R}-E n_{L}\right)$ & 30.93 & 2.42 & 31.58 & 2.4 & 0.65 & NS \\
\hline Nasal width & $\left(\right.$ Alar $_{R} \cdot$-Alar. $\left._{L}\right)$ & 31.98 & 2.83 & 33.09 & 3.27 & 1.02 & $0.023 *$ \\
\hline Nasal base width & $\left(A c_{R}-A c_{L}\right)$ & 30.26 & 2.67 & 31.48 & 2.85 & 1.21 & 0.018 * \\
\hline Mouth width & $\left(\mathrm{ch}_{\mathrm{R}}-\mathrm{ch}_{\mathrm{L}}\right)$ & 43.28 & 3.8 & 45.9 & 3.7 & 2.62 & $0.01 *$ \\
\hline \multicolumn{8}{|c|}{ Angular measurements $\left({ }^{\circ}\right)$} \\
\hline Nasal tip angle & $\left(\right.$ Alar $_{R}-\operatorname{Prn}_{-}$Alar $\left._{L}\right)$ & 85.82 & 6.13 & 89.03 & 6.2 & 3.2 & $0.05 *$ \\
\hline Upper lip angle & $\left(\mathrm{Ch}_{\mathrm{R}}-\mathrm{ls}-\mathrm{Ch}_{\mathrm{L}}\right)$ & 110.66 & 4.3 & 114.13 & 5.7 & 3.47 & 0.023 * \\
\hline Lower lip angle & $\left(\mathrm{Ch}_{\mathrm{R}}-\mathrm{li}-\mathrm{Ch}_{\mathrm{L}}\right)$ & 122.16 & 6.1 & 125.94 & 6.34 & 3.78 & $0.047^{*}$ \\
\hline
\end{tabular}

* Significant changes at the level of $5 \%$ level of significance $(\alpha<0.05)$ based on the Wilcoxon signed rank test. NS, Not significant.

We also calculated the descriptive statistics of the maximum positive and negative deviation limits of the meshes, as shown in Table 4.

Table 4. Descriptive statistics of the maximum positive and negative deviation in the morphological regions.

\begin{tabular}{ccccccccc}
\hline $\begin{array}{c}\text { Morphological } \\
\text { Region }\end{array}$ & \multicolumn{3}{c}{ Maximum Positive Deviation Limits $(\mathbf{m m})$} & \multicolumn{3}{c}{ Maximum Negative Deviation Limits (mm) } \\
\hline & Minimum & Maximum & Mean & SD & Minimum & Maximum & Mean & SD \\
\hline Total face & 1.72 & 5.43 & 3.09 & 0.92 & -5.88 & -1.93 & -2.93 & 0.85 \\
Upper face & 0.97 & 3.9 & 2.16 & 0.77 & -3.5 & -0.89 & -1.9 & 0.79 \\
Lower face & 1.47 & 5.22 & 2.81 & 0.87 & -5.88 & -1.34 & -2.78 & 0.89 \\
Nose & 0.68 & 3.9 & 2.04 & 0.71 & -3.49 & -0.47 & -1.25 & 0.67 \\
Upper lip & 0.64 & 5.06 & 2.16 & 0.97 & -5.69 & 0.11 & -1.5 & 1.03 \\
Lower lip & -0.63 & 5.22 & 1.37 & 1.16 & -4.68 & 0.53 & -2.02 & 1.67 \\
\hline
\end{tabular}

The mean of the maximum positive and negative deviation found in the total face were $3.09,-2.93 \mathrm{~mm}$, respectively, 2.16, $2.81 \mathrm{~mm}$ both for the upper and lower face as a positive deviation, and $-1.9,-2.87 \mathrm{~mm}$ for the negative ones. We also found $2.16,1.37 \mathrm{~mm}$ as a positive deviation of both the upper and lower lip regions, and $-1.5,-2.02 \mathrm{~mm}$ as the negative ones while the mean of the maximum positive and negative deviation found in the nasal region were $2.04,-1.25 \mathrm{~mm}$, respectively.

Similarly, the mean, minimum, and maximum limits of the mean values were calculated in Table 5. While soft tissue changes were observed in the nasal and upper lip regions of $0.55,0.53 \mathrm{~mm}$, respectively, the changes observed in the total face region as well as the upper and lower lip regions were very small and almost neglected.

Table 5. Descriptive statistics of the mean deviation in the morphological region.

\begin{tabular}{ccccc}
\hline $\begin{array}{c}\text { Morphological } \\
\text { Region }\end{array}$ & Minimum & Maximum & Mean & SD \\
\hline Total face & -0.25 & 0.12 & -0.02 & 0.08 \\
Upper face & -0.99 & 0.65 & 0.06 & 0.3 \\
Lower face & -0.54 & 0.32 & -0.02 & 0.16 \\
Nose & -0.1 & 0.96 & 0.55 & 0.26 \\
Upper lip & -0.87 & 1.79 & 0.53 & 0.67 \\
Lower lip & -2.54 & 2.19 & -0.04 & 1.24 \\
\hline
\end{tabular}

Changes were also observed at the level of the facial landmarks as seen in Table 6. The deviation found at the level of the right and left Alar points were $0.72 \pm 0.45,0.46 \pm 0.59 \mathrm{~mm}$, respectively. We also found changes at the level of Pronasal and Subnasal points of $0.44 \pm 0.66$, 
$0.66 \pm 0.64 \mathrm{~mm}$, and for the right and left Cheilion landmarks of $0.46 \pm 1.621,0.66 \pm 1.98 \mathrm{~mm}$, respectively.

Table 6. Deviation analysis of the facial soft tissue landmarks.

\begin{tabular}{cccc}
\hline Landmark & & $\begin{array}{c}\text { Deviation Mean } \\
(\mathbf{m m})\end{array}$ & SD \\
\hline Endocanthion (right) & End $_{\mathrm{r}}$ & 0.28 & 0.39 \\
\hline Endocanthion (left) & $\mathrm{End}_{1}$ & 0.25 & 0.55 \\
\hline Sellion & $\mathrm{Se}$ & -0.03 & 0.41 \\
\hline Alar point (right) & $\mathrm{Alar}_{\mathrm{r}}$ & 0.72 & 0.45 \\
\hline Alar point (left) & $\mathrm{Alar}_{1}$ & 0.46 & 0.59 \\
\hline Pronasal & $\mathrm{prn}$ & 0.44 & 0.66 \\
\hline Subnasal & $\mathrm{Sn}$ & 0.66 & 0.64 \\
\hline Cheilion (right) & $\mathrm{Ch}_{\mathrm{r}}$ & 0.46 & 1.62 \\
\hline Cheilion (left) & $\mathrm{Ch}_{1}$ & 0.66 & 1.98 \\
\hline Labiale superius & $\mathrm{Ls}$ & 0.23 & 1.36 \\
\hline Labiale inferius & $\mathrm{Li}$ & 0.2 & 1.37 \\
\hline Stomion & $\mathrm{Sto}$ & -0.11 & 1.31 \\
\hline Sublabiale & $\mathrm{Sl}$ & -0.43 & 0.89 \\
\hline Soft tissue menton & $\mathrm{me}$ & 0.02 & \\
\hline
\end{tabular}

Moderate positive and negative correlations were found between the expansion amount and our variables using the Pearson correlation coefficient, but they did not reach the level of significance, except for the mouth width difference, which showed significant moderate positive correlation with the jackscrew activation at the level of $5 \%$ of significance, as seen in Figure 8.

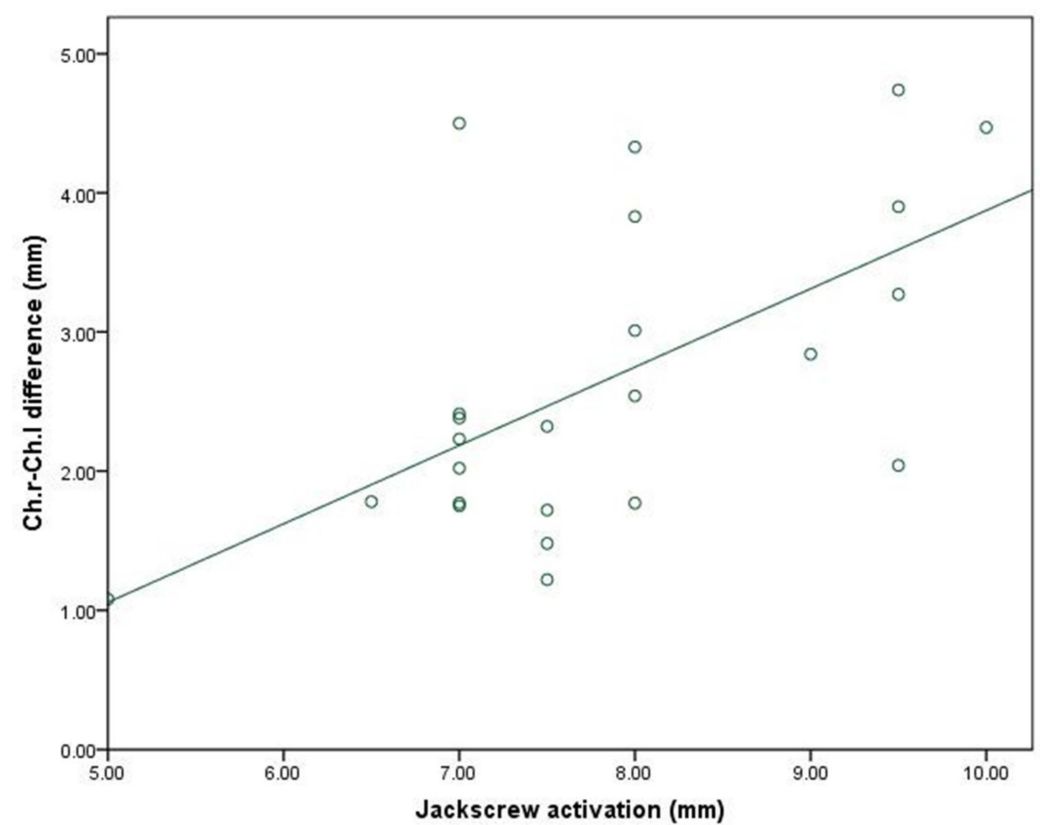

Figure 8. Scatter plot for the correlation between the mouth width difference and the jackscrew activation amount. 


\section{Discussion}

Assessment of the soft tissue changes after RME is a critical step during our orthodontic treatment. Various strategies, including laser scanners, stereophotogrammetry, and structured light scanners have recently been introduced for 3D soft tissue evaluation. It was found that the accuracy of the structured light scanner was at $0.57 \pm 0.07 \mathrm{~mm}$, and seemed to be the best in the midface region [28]. Jung et al. concluded that the accuracy of the structured light system is comparable to the direct anthropometric measurements. Furthermore, it was reported that more reliable 3D datasets are expected if the face of the subject was scanned from a couple of angles at the same time in less than $1 \mathrm{~s}$ [17]. Lee et al. investigated the reliability of 34 facial landmarks using a 3D handheld structured-light scanner (Artec Eva) and they observed constellations of landmarks that showed high reliability in each condition in terms of head posture and image resolution. The Artec EVA scanner is claimed to be comparable to other scanners mentioned in literature and leads to more accurate 3D models as compared to scanning with FaceScan3D [29].

Given the small sample size, the effects of patients' age and sex could not be considered in this study. It was found in previous studies that the stage of maturation (based on the maturation of the cervical vertebrae) and sex had no significant effect on the soft tissue changes brought about by RME [30,31].

Our observations were made in a population of subjects who were in the active growth phase. It was presumed that growth might not cause a considerable interference with the studied parameters if evaluated for a period of 6 to 7 months [32]. Torun et al. found no significant difference between pre-pubertal and post-pubertal subjects [31]. This is in agreement with the outcomes of Johnson et al., who found that the developmental status had no significant effect on the soft tissue changes after RME [30]. Longo et al. proposed that the impact of growth is not a factor if a six-month observation period is used [33]. In their meta-analysis, Huang and co-workers came to the same conclusion [32]. Thus, in this study, a six-month retention period was applied.

To evaluate soft tissue changes, linear and angular measurements were made between point pairs and triads, completed with regional deviation analyses for various morphological regions of the face and for the facial landmarks.

\subsection{Facial Soft Tissue Changes}

Intercantal width increased by a mean of $0.65 \mathrm{~mm}$ after RME expansion. However, this increase did not reach a statistically significant level. Generally, forces generated with the aid of RME are claimed to affect circummaxillary sutures, along with the frontomaxillary, nasomaxillary, and frontonasal ones [34-36]. The previously mentioned findings could provide an explanation for the 3D deviations observed around the eye. Baysal et al. suggested that the significant increase that they found in the intercanthal distance was the result of normal growth and development [37]. Dindaroglu and co-workers noted that, even if 3D facial images are captured rapidly, apparent 3D changes might occur in soft tissues around the eye because of the movement of the eyelids [26].

One of the most frequently examined anatomical regions in connection with RME is the nose, given the close anatomical relationship between the maxilla and the nasal area [26].

In this study, statistically significant increases were observed in nasal width (mean: $1.02 \mathrm{~mm}, p<0.05$ ), nasal base width (mean: $1.21 \mathrm{~mm}, p<0.05$ ), and nasal angle (mean: $3.2^{\circ}$, $p<0.05)$.

Berger and colleagues found a mean increase of $1.6 \mathrm{~mm}$ in nasal width, and a mean increase of $1 \mathrm{~mm}$ in nasal length after RME [10]. Furthermore, Altorkat and colleagues found that RME produces pyramidal expansion with the greatest transverse expansion at the anterior nasal spine landmark (ANS) [19]. However, the authors suggested that these changes may be neither symmetrical nor homogeneous when the anatomical relationship between the nose and maxilla is considered. 
Pangrazio-Kulbersch and co-workers found a mean increase of $1.34 \mathrm{~mm}$ in alar width after RME [38], which is in accordance with our findings. Johnson et al. used direct measurements with an average of $7 \mathrm{~mm}$ of appliance expansion and found less than $1.5 \mathrm{~mm}$ change in nasal base and alar cartilage width, neither of which was clinically significant [30].

Increases were also observed in all transverse linear measurements in the nasal area including nasal base width, alar cartridge width, nasal tip retraction, and flattening of the nasal tip following RME. However, it was reported that these changes were very small and highly variable [19]. On the other hand, Silva Filho et al. used 2D photographs and concluded that RME did not cause changes in nasal morphology [39]. These observations markedly differ from our findings, and the reason for this difference most likely lies in the different scanning methods.

In this study, we found a statically significant increase (mean: $2.62 \mathrm{~mm}, p<0.05$ ) in mouth width after RME, likely because of the transverse expansion of the maxillary halves. We also found statically significant increases in the upper and lower lip angle (mean: $3.45^{\circ}$ $(p<0.05)$ and $3.78^{\circ}(p<0.05)$, respectively).

Our results correspond to those of Altındi $S$ et al. who also found a statistically significant increase in mouth width [18]. Similar changes in mouth width after RME were demonstrated in a recent CBCT study by Kim et al. [20]. On the contrary, the study of Baysal et al. found no statistically significant change in this respect [37], but this lack of significance might well be put down to the small sample size (17 subjects).

Despite the significant changes in both the linear and angular parameters found in the study of Dindaroglu F et al., it was considered that changes measured only in these dimensions may not reflect the actual soft tissue changes properly [26]. Thus, to complete linear and angular measurements, volumetric analyses were also conducted in the present study. A region was characterized by the mean value of all points of measurement within the given region.

We found significant facial soft tissue changes in both the nose and the upper lip regions $(0.55 \pm 0.26,0.53 \pm 0.67 \mathrm{~mm}$, respectively), and we also noticed highly positive and negative deviations in the other facial morphological regions of the face, but the mean deviation for these regions changed only to a negligible extent.

The results of Dindaroglu et al. [26] are quite similar in this respect. The authors found that both positive and negative deviations were below $2 \mathrm{~mm}$ regardless of which morphological region of the face was examined. Specifically, the mean maximum positive and negative deviations for the nose area were $0.77 \pm 0.34$ and $-0.94 \pm 0.41 \mathrm{~mm}$, respectively, and when all the points forming the nose region were considered, the mean deviation was $0.41 \pm 0.21 \mathrm{~mm}$, which is similar to our results.

Regarding the upper lip region, the mean positive and negative change in the same study was $0.87 \pm 0.38$ and $-0.57 \pm 0.14 \mathrm{~mm}$, respectively, while the greatest recorded mean deviation was $1.44 \mathrm{~mm}$ [26].

The mean of the maximum positive deviation for the total face was $3.09 \pm 0.92 \mathrm{~mm}$ in our study. It was $2.16 \pm 0.77,2.81 \pm 0.87 \mathrm{~mm}$ for the upper and lower face regions, respectively, while the mean of the maximum negative deviation was $-2.93 \pm 0.85 \mathrm{~mm}$ for the total face, and $-1.9 \pm 0.79,-2.78 \pm 0.89 \mathrm{~mm}$ for the upper and lower face regions, respectively.

Ong and co-workers, in a 3D study, reported that the mean maximum maxillary deviation was $1.2 \pm 0.4 \mathrm{~mm}$ and $1.0 \pm 0.3 \mathrm{~mm}$ for the right and left sides, respectively [23]. These results are quite close to our findings.

Although, in this study, the greatest mean deviations were recorded in the lower lip region (2.19 and $2.54 \mathrm{~mm}$, positive and negative, respectively). The mean deviation for the whole sample in the lower lip region was negligible $(-0.04 \pm 1.24 \mathrm{~mm})$.

For a more detailed understanding of the soft tissue alterations, deviations were calculated for specific facial landmarks. The greatest deviation was found at the alar point $(0.72 \pm 0.45 \mathrm{~mm})$. Furthermore, the left alar point shifted by $0.46 \pm 0.59 \mathrm{~mm}$, and the subnasal point shifted by $0.66 \pm 0.64 \mathrm{~mm}$. 
Kim et al. evaluated the deviations at different points in various nasal regions and detected a mean deviation of less than $1 \mathrm{~mm}$ for all the points, except for the ones in the sub-nasal region, where a mean deviation of $2.21 \pm 1.23 \mathrm{~mm}$ was found [20]. The authors also found that the position of the left lip commissure changed by $0.65 \mathrm{~mm}$, whereas the position of the right lip commissure changed by a mean of $1.20 \mathrm{~mm}$ [20]. Furthermore, we found that the position of the left and the right lip commissures changed by 0.66 and $0.46 \mathrm{~mm}$, respectively, and also found a positive deviation at the pro-nasal point $(0.44 \mathrm{~mm})$ and negative deviation at the sublabial point $(-0.43 \mathrm{~mm})$. Kim et al. [20] found a positive change of $0.43 \pm 1.24 \mathrm{~mm}$ at the nasion point, which did not change in our study.

Although we found positive and negative correlations between the amount of expansion and most of the facial soft tissue variables, these correlations did not reach a level of statistical significance. Only mouth width showed a moderately significant positive correlation with the amount of jackscrew activation $(p<0.05)$.

\subsection{Limitations}

A major limitation of this study is the small sample size, which prevented us from considering the effect of sex, among other factors, and it is also a limitation that prevents strong conclusions. Another relative limitation is the absence of a control group. However, based on the literature, we had reason to assume that, with a short observation period, it was not likely that normal growth would interfere with the results.

\section{Conclusions}

Significant changes in the nasal region and in the upper lip region were found after RME and six months of retention, and a significant positive correlation between mouth width and the amount of expansion was also observed.

The outcomes show that rapid expansion causes significant soft tissue changes on the surface of the face. While our results are a good starting point, further investigations with larger sample sizes and suitable controls are definitely necessary to allow generalizable statements about soft tissue responses after RME, especially in the long run.

Author Contributions: Conceptualization, A.A. and E.S. Data curation, L.H. Formal analysis, A.A. Project administration, J.P. Software, A.A., R.B., and L.P. Supervision, J.P. and E.S. Validation, A.A., L.P., and E.S. Writing—original draft, A.A. Writing—review \& editing, J.P., G.B., and E.S. All authors have read and agreed to the published version of the manuscript.

Funding: This research received no external funding.

Institutional Review Board Statement: This prospective study was conducted according to the guidelines of the Declaration of Helsinki, and approved by the Human Investigation Review Board, University of Szeged, Albert Szent-Györgyi Clinical Centre (No. 151/2019-SZTE).

Informed Consent Statement: Informed consent was obtained from the parents of all subjects involved in the study. Written informed consent has been obtained from the parents of the patient presented to publish this paper.

Data Availability Statement: Data used in this study are available from the corresponding author upon a reasonable request.

Conflicts of Interest: The authors declare no potential conflict of interest with respect to the authorship or publication of this article.

\section{References}

1. Zeng, J.; Gao, X. A prospective CBCT study of upper airway changes after rapid maxillary expansion. Int. J. Pediatric Otorhinolaryngol. 2013, 77, 1805-1810. [CrossRef]

2. Haas, A.J. Rapid Expansion of the Maxillary Dental Arch and Nasal Cavity by Opening the Midpalatal Suture. Angle Orthod. 1961, 31, 73-90.

3. Haas, A.J. The treatment of maxillary deficiency by opening the midpalatal suture. Angle Orthod. 1965, 35, 200-217. [PubMed]

4. Wertz, R.A. Skeletal and dental changes accompanying rapid midpalatal suture opening. Am. J. Orthod. 1970, 58, 41-66. [CrossRef] 
5. Zimring, J.F.; Isaacson, R.J. Forces produced by rapid maxillary expansion. 3. forces present during retention. Angle Orthod. 1965, 35, 178-186.

6. Adkins, M.D.; Nanda, R.S.; Currier, G.F. Arch perimeter changes on rapid palatal expansion. Am. J. Orthod. Dentofac. Orthop. 1990, 97, 194-199. [CrossRef]

7. Maulik, C.; Nanda, R. Dynamic smile analysis in young adults. Am. J. Orthod. Dentofac. Orthop. 2007, 132, 307-315. [CrossRef] [PubMed]

8. Smith, T.; Ghoneima, A.; Stewart, K.; Liu, S.; Eckert, G.; Halum, S.; Kula, K. Three-dimensional computed tomography analysis of airway volume changes after rapid maxillary expansion. Am. J. Orthod. Dentofac. Orthop. 2012, 141, 618-626. [CrossRef]

9. Abedini, S.; Elkenawy, I.; Kim, E.; Moon, W. Three-dimensional soft tissue analysis of the face following micro-implant-supported maxillary skeletal expansion. Prog. Orthod. 2018, 19, 46. [CrossRef]

10. Berger, J.L.; Pangrazio-Kulbersh, V.; Thomas, B.W.; Kaczynski, R. Photographic analysis of facial changes associated with maxillary expansion. Am. J. Orthod. Dentofac. Orthop. 1999, 116, 563-571. [CrossRef]

11. Chung, C.H.; Font, B. Skeletal and dental changes in the sagittal, vertical, and transverse dimensions after rapid palatal expansion. Am. J. Orthod. Dentofac. Orthop. 2004, 126, 569-575. [CrossRef] [PubMed]

12. Da Silva Filho, O.G.; Boas, M.C.; Capelozza Filho, L. Rapid maxillary expansion in the primary and mixed dentitions: A cephalometric evaluation. Am. J. Orthod. Dentofac. Orthop. 1991, 100, 171-179.

13. Littlefield, T.R.; Kelly, K.M.; Cherney, J.C.; Beals, S.P.; Pomatto, J.K. Development of a new three-dimensional cranial imaging system. J. Craniofac. Surg. 2004, 15, 175-181. [CrossRef] [PubMed]

14. Brons, S.; Van Beusichem, M.E.; Bronkhorst, E.M.; Draaisma, J.; Bergé, S.J.; Maal, T.J.; Kuijpers-Jagtman, A.M. Methods to quantify soft-tissue based facial growth and treatment outcomes in children: A systematic review. PLoS ONE 2012, 7, e41898. [CrossRef]

15. Straub, J.; Kading, B.; Mohammad, A.; Kerlin, S. Characterization of a Large, Low-Cost 3D Scanner. Technologies 2015, 3, 19-36. [CrossRef]

16. Ma, L.; Xu, T.; Lin, J. Validation of a three-dimensional facial scanning system based on structured light techniques. Comput. Methods Programs Biomed. 2009, 94, 290-298. [CrossRef]

17. Jung, J.; Lee, C.H.; Lee, J.W.; Choi, B.J. Three dimensional evaluation of soft tissue after orthognathic surgery. Head Face Med. 2018, 14, 21. [CrossRef]

18. Altindis, S.; Toy, E.; Basciftci, F.A. Effects of different rapid maxillary expansion appliances on facial soft tissues using threedimensional imaging. Angle Orthod. 2016, 86, 590-598. [CrossRef]

19. Altorkat, Y.; Khambay, B.S.; McDonald, J.P.; Cross, D.L.; Brocklebank, L.M.; Ju, X. Immediate effects of rapid maxillary expansion on the naso-maxillary facial soft tissue using 3D stereophotogrammetry. Surgeon 2016, 14, 63-68. [CrossRef]

20. Kim, K.B.; Adams, D.; Araújo, E.A.; Behrents, R.G. Evaluation of immediate soft tissue changes after rapid maxillary expansion. Dental Press J. Orthod. 2012, 17, 157-164. [CrossRef]

21. Solow, B.; Tallgren, A. Natural head position in standing subjects. Acta Odontol. Scand. 1971, 29, 591-607. [CrossRef]

22. Weber, D.W.; Fallis, D.W.; Packer, M.D. Three-dimensional reproducibility of natural head position. Am. J. Orthod. Dentofac. Orthop. 2013, 143, 738-744. [CrossRef] [PubMed]

23. Ong, S.C.; Khambay, B.S.; McDonald, J.P.; Cross, D.L.; Brocklebank, L.M.; Ju, X. The novel use of three-dimensional surface models to quantify and visualise the immediate changes of the mid-facial skeleton following rapid maxillary expansion. Surgeon 2015, 13, 132-138. [CrossRef] [PubMed]

24. Farkas, L.G. Anthropometry of the head and face in medicine. J. Oral Maxillofac. Surg. 1981, 40, 394.

25. Swennen, G.R.J. 3-D Cephalometric soft tissue landmarks. In Three-Dimensional Cephalometry; Springer: Berlin/Heidelberg, Germany, 2006; pp. 183-226.

26. Dindaroglu, F.; Duran, G.S.; Gorgulu, S. Effects of rapid maxillary expansion on facial soft tissues: Deviation analysis on three-dimensional images. J. Orofac. Orthop. 2016, 77, 242-250. [CrossRef] [PubMed]

27. Dahlberg, G. Statistical Methods for Medical and Biological Students. Br. Med. J. 1940, 2, 358-359.

28. Zhao, Y.J.; Xiong, Y.X.; Wang, Y. Three-Dimensional Accuracy of Facial Scan for Facial Deformities in Clinics: A New Evaluation Method for Facial Scanner Accuracy. PLoS ONE 2017, 12, e0169402. [CrossRef]

29. Modabber, A.; Peters, F.; Kniha, K.; Goloborodko, E.; Ghassemi, A.; Lethaus, B.; Holzle, F.; Mohlhenrich, S.C. Evaluation of the accuracy of a mobile and a stationary system for three-dimensional facial scanning. J. Craniomaxillofac. Surg. 2016, 44, 1719-1724. [CrossRef] [PubMed]

30. Johnson, B.M.; McNamara, J.A.; Bandeen, R.L.; Baccetti, T. Changes in soft tissue nasal widths associated with rapid maxillary expansion in prepubertal and postpubertal subjects. Angle Orthod. 2010, 80, 995-1001. [CrossRef]

31. Torun, G.S. Soft tissue changes in the orofacial region after rapid maxillary expansion: A cone beam computed tomography study. J. Orofac. Orthop. 2017, 78, 193-200. [CrossRef]

32. Huang, J.; Li, C.Y.; Jiang, J.H. Facial soft tissue changes after nonsurgical rapid maxillary expansion: A systematic review and meta-analysis. Head Face Med. 2018, 14, 6. [CrossRef] [PubMed]

33. Longo, P. Dimensional Changes of Facial Soft Tissue Associated with Rapid Palatal Expansion. Master's Thesis, Marquette University, Ann Arbor, MI, USA, 2014.

34. Bazargani, F.; Feldmann, I.; Bondemark, L. Three-dimensional analysis of effects of rapid maxillary expansion on facial sutures and bones. Angle Orthod. 2013, 83, 1074-1082. [CrossRef] [PubMed] 
35. Ghoneima, A.; Abdel-Fattah, E.; Hartsfield, J.; El-Bedwehi, A.; Kamel, A.; Kula, K. Effects of rapid maxillary expansion on the cranial and circummaxillary sutures. Am. J. Orthod. Dentofac. Orthop. 2011, 140, 510-519. [CrossRef] [PubMed]

36. Woller, J.L.; Kim, K.B.; Behrents, R.G.; Buschang, P.H. An assessment of the maxilla after rapid maxillary expansion using cone beam computed tomography in growing children. Dental Press J. Orthod. 2014, 19, 26-35. [CrossRef]

37. Baysal, A.; Ozturk, M.A.; Sahan, A.O.; Uysal, T. Facial soft-tissue changes after rapid maxillary expansion analyzed with 3-dimensional stereophotogrammetry: A randomized, controlled clinical trial. Angle Orthod. 2016, 86, 934-942. [CrossRef]

38. Pangrazio-Kulbersh, V.; Wine, P.; Haughey, M.; Pajtas, B.; Kaczynski, R. Cone beam computed tomography evaluation of changes in the naso-maxillary complex associated with two types of maxillary expanders. Angle Orthod. 2012, 82, 448-457. [CrossRef]

39. Silva Filho, O.G.; Lara, T.S.; Ayub, P.V.; Ohashi, A.S.; Bertoz, F.A. Photographic assessment of nasal morphology following rapid maxillary expansion in children. J. Appl. Oral Sci. 2011, 19, 535-543. [CrossRef] [PubMed] 


\title{
Accuracy of virtual planning in orthognathic surgery: a systematic review
}

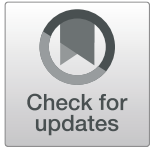

Ali Alkhayer ${ }^{1}$, József Piffkó2 ${ }^{2}$ Carsten Lippold ${ }^{3^{*}}$ (D) and Emil Segatto ${ }^{1}$

\begin{abstract}
Background: The elaboration of a precise pre-surgical plan is essential during surgical treatment of dentofacial deformities. The aim of this study was to evaluate the accuracy of computer-aided simulation compared with the actual surgical outcome, following orthognathic surgery reported in clinical trials.

Methods: Our search was performed in PubMed, EMBASE, Cochrane Library and SciELO for articles published in the last decade. A total of 392 articles identified were assessed independently and in a blinded manner using eligibility criteria, out of which only twelve articles were selected for inclusion in our research. Data were presented using intra-class correlation coefficient, and linear and angular differences in three planes.

Results: The comparison of the accuracy analyses of the examined method has shown an average translation $(<2$ $\mathrm{mm}$ ) in the maxilla and also in the mandible (in three planes). The accuracy values for pitch, yaw, and roll ( ${ }^{\circ}$ ) were $(<2.75,<1.7$ and $<1.1)$ for the maxilla, respectively, and $(<2.75,<1.8,<1.1)$ for the mandible. Cone-beam computed tomography $(\mathrm{CBCT})$ with intra-oral scans of the dental casts is the most used imaging protocols for virtual orthognathic planning. Furthermore, calculation of the linear and angular differences between the virtual plan and postoperative outcomes was the most frequented method used for accuracy assessment (10 out of 12 studies) and a difference less than $2 \mathrm{~mm} /{ }^{\circ}$ was considered acceptable and accurate.

When comparing this technique with the classical planning, virtual planning appears to be more accurate, especially in terms of frontal symmetry.
\end{abstract}

Conclusion: Virtual planning seems to be an accurate and reproducible method for orthognathic treatment planning. However, more clinical trials are needed to clearly determine the accuracy and validation of the virtual planning in orthognathic surgery.

Keywords: Surgery, computer-assisted, Orthognathic surgery, Dentofacial deformities, Cone-beam computed tomography

\footnotetext{
*Correspondence: carstenlippold@yahoo.de

${ }^{3}$ Department of Orthodontics, Universitätsklinikum Münster,

Albert-Schweitzer-Campus 1, Gebäude W30, Waldeyerstraße 30, 48149

Münster, Germany

Full list of author information is available at the end of the article
}

(c) The Author(s). 2020 Open Access This article is licensed under a Creative Commons Attribution 4.0 International License, which permits use, sharing, adaptation, distribution and reproduction in any medium or format, as long as you give appropriate credit to the original author(s) and the source, provide a link to the Creative Commons licence, and indicate if changes were made. The images or other third party material in this article are included in the article's Creative Commons licence, unless indicated otherwise in a credit line to the material. If material is not included in the article's Creative Commons licence and your intended use is not permitted by statutory regulation or exceeds the permitted use, you will need to obtain permission directly from the copyright holder. To view a copy of this licence, visit http://creativecommons.org/licenses/by/4.0/ The Creative Commons Public Domain Dedication waiver (http://creativecommons.org/publicdomain/zero/1.0/) applies to the data made available in this article, unless otherwise stated in a credit line to the data. 


\section{Background}

Two-dimensional (2D) radiographs and manual model surgery are essential parts of the preoperative planning for orthognathic surgery. However, this approach has its limitations, especially in the case of patients with major facial deformity or asymmetry [1], as 2D cephalometric images cannot provide full information about the 3D structures.

When conventional 2D surgical plans are executed, unexpected problems, such as a bony collision in the ramus area, the discrepancy in pitch, roll and yaw rotation, midline difference and chin inadequacy may occur [2].

When two-jaw surgery is performed, an inter-occlusal splint is fabricated to work as an intermediate guide for repositioning the maxilla relative to the intact mandible [3]. Any variation between the plan and the plaster model surgery could lead to a poorly fabricated wafer, which in turn could lead to unexpected (and often undesirable) results, regardless of how skillfully and carefully the surgery is performed [3].

These examples illustrate that the elaboration of a precise pre-surgical plan is of utmost importance when it comes to correcting dentofacial deformities.

Computer-aided surgical simulations using cone beam computed tomography (CBCT) images have revolutionized orthodontics and have been adapted for orthognathic surgery (OGS) to facilitate cephalometric analysis, surgical simulation and splint fabrication [4-9].

In particular, the visualization of skeletal complexities within an asymmetric dentofacial deformity has been greatly enhanced through three dimensional (3D) modeling, which can demonstrate the extent of yaw rotation in the maxilla and mandible, occlusal plane canting and differential length of a mandibular body or the ramus [1, $10,11]$. The 3D simulation method has been accepted for planning in orthognathic surgery and led to significant improvements in surgical outcomes [1, 9, 12]. Intraoperative efficiency has also improved with the fabrication of the templates and jigs to reproduce gaps or spacing between the osteotomies depicted in the virtual plan. These jigs may reinforce intraoperative accuracy of the clinical movement of the virtual plan and aid in orienting and positioning bony segments [10, 13-18]. Thus, the aim of this systematic review is to assess the accuracy of computer-aided planning in orthognathic surgery.

\section{Methods}

A systematic search was conducted of electronic and printed articles that have been published in the period (2007-2017) on virtual planning for orthognathic surgery and in the English language. The databases used were PubMed, EMBASE, Cochrane Library and SciELO.
Keywords and Boolean operators ('OR' and 'AND') were used to join the terms related to orthognathic surgery and virtual planning.

\section{Search strategy \\ Main search}

The systematic search was done by one of the authors (A.A.). The search of PubMed was conducted using the following medical subject heading (MeSH) terms: [('Orthognathic Surgery' OR 'Surgery, Orthognathic' OR 'Maxillofacial Orthognathic Surgery' OR 'Orthognathic Surgeries, Maxillofacial' OR 'Orthognathic Surgery, Maxillofacial' OR 'Surgery, Maxillofacial Orthognathic' OR 'Orthognathic Surgical Procedures' OR 'Procedure, Orthognathic Surgical' OR 'Surgical Procedure, Orthognathic' AND ('Surgery, virtual planning' OR 'virtual planning Surgery' OR 'Computer Assisted Surgery' OR 'virtual planning ,Surgery' OR 'Surgery, virtual planning' OR 'virtual planning Design' OR 'virtual planning Designs' OR 'Design, virtual planning' OR 'virtual planning Manufacturing' OR 'Manufacturing, virtual planning')].

The same search strategy was applied to the Cochrane Library since this also uses $\mathrm{MeSH}$ terms.

For the search of EMBASE, the entry terms 'orthognathic surgery' AND 'virtual planning surgery' were used to carry out a specific search.

Health sciences descriptors were used to search the SciELO databases, 'orthognathic surgery' AND 'virtual planning' were performed.

\section{Eligibility of the studies}

The eligibility of the studies was determined by the author (A.A.), observing the following criteria: (1) the main theme of the paper had to focus on virtual planning for orthognathic surgery; (2) the study had to be original and interventional; (3) the surgical procedure had to be virtually planned with a virtual surgical splint; (4) accuracy measures had to be presented for the surgical procedure; (5) the sample size of the trial had to be $\geq 10$. The latter criterion was determined somewhat arbitrarily, as a reasonable minimum, given the small sample sizes of these studies in general.

\section{Main search}

Three hundred and sixty-seven articles were found in PubMed, 84 in EMBASE, 7 in Cochrane Library and 16 in SciELO. Duplicate papers were removed, leaving a total of 392 possible studies, that have been read and 31 of these were chosen for full-text reading (Fig. 1).

\section{Eligibility assessment}

As part of the eligibility assessment, 31 studies were read in full. At the end of this analysis, only twelve papers were included in the sample for our systematic review. The 


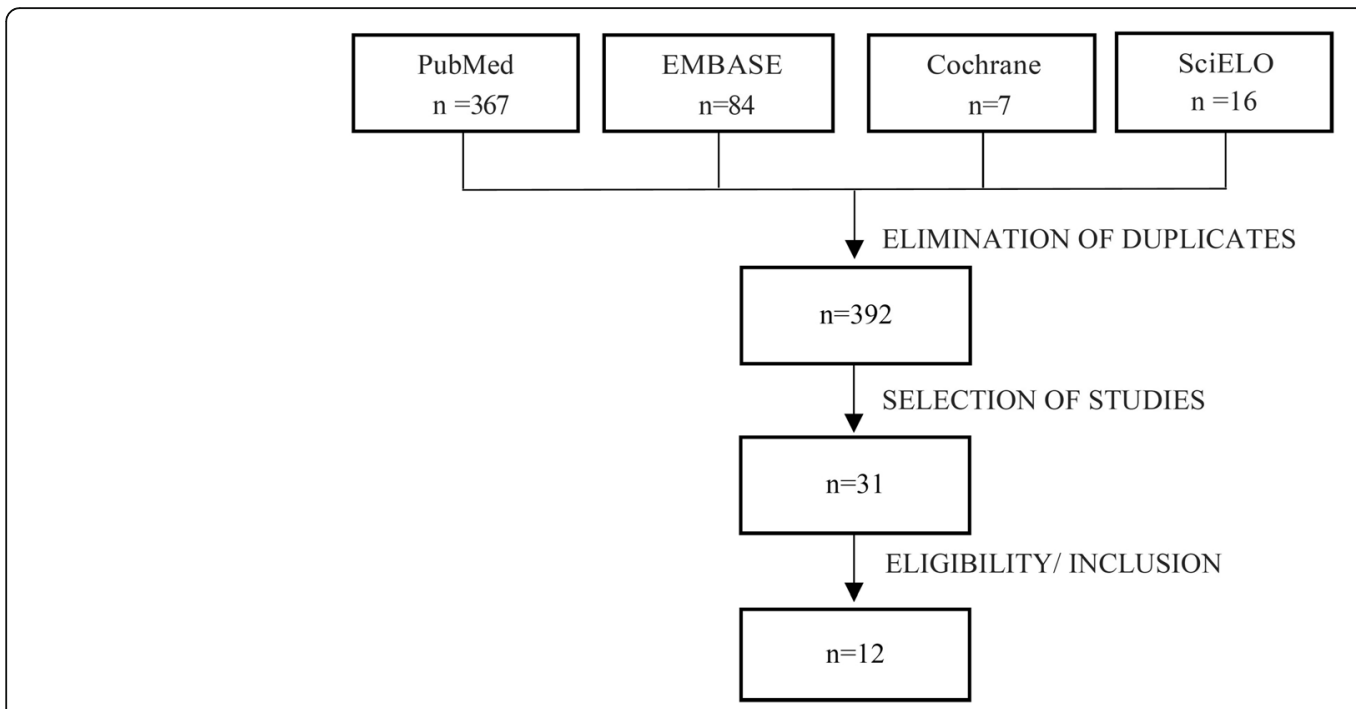

Fig. 1 Flowchart of the review process

other 19 studies were excluded for the following reasons: virtual surgical planning for orthognathic surgery was not the main focus of the paper [19],the paper was not an intervention study [17], or it was not original [5, 20,21], the surgical procedure did not involve a computer-assisted virtual surgical splint [22-24], the accuracy measurements for the surgical procedure were not provided [25-29] and the sample size was less than 10 [16, 22, 30-33].

\section{Quality assessment of the included articles}

The quality of the papers was assessed using an adaptation of the bias analysis proposed by Clementini and colleagues [34]. The criteria were the presence or absence of the following: sample randomization, blind assessment, statistical analysis, defined inclusion and exclusion criteria and reporting of follow-up. With respect to the risk of bias for each analyzed study, papers containing all the above items were considered low risk, studies lacking one or two items were missing were deemed medium risk, and investigations that lacked three or more items were considered high risk.

\section{Results}

Descriptive data of the included studies (sample size, age, gender and type of facial deformity) are presented in (Table 1).

The imaging protocols and the software used for surgical planning varied substantially among the studies, These variations are shown in (Table 2).

The included studies also varied in the type of surgical plan and virtual splints, as well as in the method used for the assessment of accuracy. These variations we summarized in (Table 3).

The actual accuracy values are presented in detail in Additional file 1 (Table S1).
Finally, the papers included in this review were assessed as being medium quality, since the risk of bias was considered medium in ten studies of the twelve. The risk of bias assessement for the included studies are presented in (Table 4).

\section{Discussion}

The use of computerized methods for diagnosis and treatment planning in orthodontics and orthognathic surgery has evolved substantially [42], which is confirmed by the 392 papers on this topic that have appeared in the major databases in the period (2007-2017).

Hsu and colleagues reported that computer-aided techniques enable the accurate correction of maxillary malformations with yaw deviation, alignment of proximal and distal segments and restoration of mandibular symmetry [6].

Lin and co-workers concluded that virtual orthognathic planning yields aesthetically favorable results, a high level of patient satisfaction, accurate translation of the treatment plan and thus making the operation itself easier and safer [20,44].

The analyzed studies used both the CT and CBCT imaging modalities (two of them worked with both). Better identification of soft tissue and less image distortion where metallic elements are present are obvious advantages of CT over CBCT, while disadvantages include image quality, the supine position of the patient during the test (especially because of mandibular retrusion) and larger radiation doses [45-47]. Mandibular retrusion in the supine position during CT image capture was attenuated using central occlusal registry [6, 42]. The major disadvantage of CBCT is the occasional appearance of metal artifacts, but this is diminished by 
Table 1 Descriptive data of the included studies

\begin{tabular}{|c|c|c|c|c|c|}
\hline $\begin{array}{l}\text { Authors, year and country } \\
\text { of origin }\end{array}$ & Type of study & $\begin{array}{l}\text { Sample } \\
\text { size }\end{array}$ & $\begin{array}{l}\text { Age: mean, SD } \\
\text { (variation) }\end{array}$ & Gender & Type of facial deformity \\
\hline De Rio et al. 2017 Italy [35] & $\begin{array}{l}\text { Retrospective } \\
\text { observational study }\end{array}$ & $\begin{array}{l}\mathrm{N}: 49 \\
\text { patients }\end{array}$ & Mean: 26.4 years & $\begin{array}{l}19 \text { males } \\
30 \text { females }\end{array}$ & $\begin{array}{l}\text { Angle class II: } 16 \\
\text { Angle class III: } 20 \\
\text { Open bite: } 4 \\
\text { Facial asymmetry: } 9\end{array}$ \\
\hline Ritto et al. 2017 Brazil [36] & Retrospective study & $\begin{array}{l}\text { N: } 30 \\
\text { patients: } \\
\text { CMS } \\
\text { group: } 15 \\
\text { VSP group: } \\
15\end{array}$ & NA & $\begin{array}{l}\text { CMS group: } 8 \\
\text { females } \\
7 \text { males } \\
\text { VSP group: } 5 \\
\text { females } \\
10 \text { males }\end{array}$ & $\begin{array}{l}\text { CMS group: } \\
4 \text { skeletal class II malocclusion } \\
11 \text { skeletal class III malocclusion } \\
\text { VSP group: } 1 \text { skeletal class I malocclusion, } \\
2 \text { presented class II malocclusion, } 12 \text { presented class } \\
\text { III malocclusion }\end{array}$ \\
\hline Ho et al. 2017 Taiwan [1] & $\begin{array}{l}\text { Prospective case } \\
\text { series, A }\end{array}$ & $\begin{array}{l}\mathrm{N}: 30 \\
\text { patients }\end{array}$ & $\begin{array}{l}\text { Mean: } 22.4 \text { years } \\
\text { Range: (18-26 years) }\end{array}$ & $\begin{array}{l}22 \text { females } \\
8 \text { males }\end{array}$ & Class III malocclusion and facial asymmetry \\
\hline Chin et al. 2017 Germany [37] & A comparative study & $\begin{array}{l}\mathrm{N}: 10 \\
\text { patients }\end{array}$ & $\begin{array}{l}\text { Mean: } 25.3 \text { years } \\
\text { Range: }(18-41) \text { years }\end{array}$ & $\begin{array}{l}4 \text { males } \\
6 \text { females }\end{array}$ & $\begin{array}{l}8 \text { Class III, Prognathism of Mandible } \\
2 \text { Class II retrognathism of Mandible }\end{array}$ \\
\hline Stokbro et al. 2016 USA [38] & $\begin{array}{l}\text { A comparative } \\
\text { retrospective study }\end{array}$ & $\begin{array}{l}\text { N: } 30 \\
\text { patients } \\
\text { CMS } \\
\text { group: } 15 \\
\text { VSP group: } \\
15\end{array}$ & $\begin{array}{l}\text { Mean: } 23.1 \pm 6.8 \text { years } \\
\text { Median: } 21 \text { years } \\
\text { Range: }(18-42) \text { years }\end{array}$ & $\begin{array}{l}10 \text { males } \\
20 \text { females }\end{array}$ & NA \\
\hline $\begin{array}{l}\text { Baan et al. } 2016 \text { Netherlands } \\
\text { [39] }\end{array}$ & Prospective study & $\begin{array}{l}\mathrm{N}: 10 \\
\text { patients }\end{array}$ & $\begin{array}{l}\text { Mean: } 26.5 \text { years } \\
\text { Range: }(17-45) \text { years }\end{array}$ & $\begin{array}{l}4 \text { Males } \\
6 \text { Females }\end{array}$ & Skeletal Class II profile \\
\hline Zhang et al. 2016 China [40] & $\begin{array}{l}\text { A comparative } \\
\text { retrospective study }\end{array}$ & $\begin{array}{l}\mathrm{N}: 30 \\
\text { patients }\end{array}$ & Range: (19-30) years & $\begin{array}{l}16 \text { males } \\
14 \text { females }\end{array}$ & $\begin{array}{l}(n=27) \text { Skeletal class III profile, retrognathia of upper } \\
\text { jaw, Prognathia of lower jaw. } \\
(n=3) \text { Skeletal class II profile prognathia of upper jaw } \\
\text { Retrognathia of lower jaw. }\end{array}$ \\
\hline De Rio et al. 2014 Italy [41] & $\begin{array}{l}\text { Randomized } \\
\text { controlled clinical trial }\end{array}$ & $\begin{array}{l}\mathrm{N}: 20 \\
\text { patients } \\
\text { Virtual } \\
\text { splint: } \\
10 \\
\text { Classic } \\
\text { splint: } 10\end{array}$ & $\begin{array}{l}\text { Virtual splint: Range: } \\
\text { (21-54) years } \\
\text { Classic splint: Range: } \\
(24-47) \text { years }\end{array}$ & $\begin{array}{l}\text { Overall: } 10 \mathrm{M} \\
10 \mathrm{~F} \\
\text { Virtual splint: } \\
3 \mathrm{M}, 7 \mathrm{~F} \\
\text { Classic splint: } \\
7 \mathrm{M}, 3 \mathrm{~F}\end{array}$ & $\begin{array}{l}\text { Class II/class III: NA } \\
\text { All asymmetrical }\end{array}$ \\
\hline Hsu et al. 2013 USA [6] & $\begin{array}{l}\text { A Prospective } \\
\text { Multicenter Study }\end{array}$ & $\begin{array}{l}\text { N: } 65 \\
\text { patients } \\
\text { Houston: } \\
41 \\
\text { Portland: } \\
11 \\
\text { New York: } \\
13\end{array}$ & $\begin{array}{l}\text { Houston: mean } 25 \\
\text { range: }(15-51) \\
\text { Portland: mean } 26.7 \\
\text { range (15-51) } \\
\text { NewYork: mean } 26.7 \\
\text { range (16-46) }\end{array}$ & $\begin{array}{l}\text { Houston } 23 \\
\text { M, } 18 \mathrm{~F} \\
\text { Portland: } 3 \mathrm{M} \text {, } \\
8 \mathrm{~F} \\
\text { New York: } 5 \\
\text { M, } 8 \mathrm{~F}\end{array}$ & NA \\
\hline Sun et al. 2013 Belgium [7] & Prospective case series & $\begin{array}{l}\mathrm{N}: 15 \\
\text { patients }\end{array}$ & NA & NA & NA \\
\hline Zinser et al. 2013 Germany [42] & $\begin{array}{l}\text { Non-randomized } \\
\text { clinical trial }\end{array}$ & $\begin{array}{l}\text { N: } 28 \\
\text { patients } \\
\text { Virtual } \\
\text { splint: } 8 \\
\text { Classic } \\
\text { splint: } \\
10 \text { Surgical } \\
\text { navigation: } \\
10\end{array}$ & $\begin{array}{l}\text { Overall: } 20.8 \pm 4.9(18- \\
35) \text { years } \\
\text { Virtual splint: } 21.6 \pm \\
5.45 \text { (19-35) } \\
\text { Classic splint: } 20.6 \pm 2.6 \\
\text { (18-26) } \\
\text { Surgical navigation: } \\
20.5 \pm 4.1(18-32)\end{array}$ & $\begin{array}{l}\text { Overall: } 15 \mathrm{M}, \\
13 \mathrm{~F} \\
\text { Virtual splint: } \\
4 \mathrm{M}, 4 \mathrm{~F} \\
\text { Classic splint: } \\
6 \mathrm{M}, 4 \mathrm{~F} \\
\text { Surgical } \\
\text { navigation: } 5 \\
\mathrm{M}, 5 \mathrm{~F}\end{array}$ & $\begin{array}{l}\text { Overall: } 5 \text { class II, } 23 \text { class III } \\
\text { Virtual splint: } 8 \text { class III } \\
\text { Classic splint: } 4 \text { class II, } 6 \text { class III } \\
\text { Surgical navigation: } 1 \text { class II, } 9 \text { class III }\end{array}$ \\
\hline $\begin{array}{l}\text { Centenero and Hernández- } \\
\text { Alfaro. 2012, Spain [43] }\end{array}$ & Prospective case series & $\begin{array}{l}\mathrm{N}: 16 \\
\text { patients }\end{array}$ & NA & NA & $\begin{array}{l}9 \text { class II } \\
7 \text { class III }\end{array}$ \\
\hline
\end{tabular}

scanning the plaster casts $[37,40,42]$, intraoral scanning of the dental arches [30, 37], scanning occlusion with reference points $[6,7]$ or by a triple scan procedure $[39,41]$.

Thus, the fusion of facial CT images and dental arch scans is important in computer-aided planning and it is more accurate when reference points are reproducible for both modalities [8].
Evaluation of the accuracy of the virtual planning methods used in Orthognathic surgery

One of the most frequently used methods to evaluate the accuracy of virtual planning is the use of the mean error differences in superimposition between the virtual plan and the postoperative outcomes. Baan and colleagues used this technique to assess the degree of correspondence between the planned and performed 
Table 2 Imaging protocols and software used in the incuded studies

\begin{tabular}{|c|c|c|c|c|}
\hline Author and year & $\begin{array}{l}\text { Imaging } \\
\text { method }\end{array}$ & $\begin{array}{l}\text { Postoperative period of } \\
\text { scanning the dentofacial } \\
\text { complex }\end{array}$ & Imaging of dental arches & Software used for virtual planning \\
\hline $\begin{array}{l}\text { De Rio et al. } 2017 \\
\text { Italy [35] }\end{array}$ & $\mathrm{CBCT}$ & 3rd-5th postoperative days & NA & $\begin{array}{l}\text { (Maxilim, Medicim, Nobel Biocare Group, } \\
\text { Mechelen, Belgium). } \\
\text { (Dolphin®, Dolphin Imaging and Management } \\
\text { Solutions, Chatsworth, CA, USA) for } \\
\text { Cephalometric analysis }\end{array}$ \\
\hline $\begin{array}{l}\text { Ritto et al. } 2017 \\
\text { Brazil [36] }\end{array}$ & CT & $\geq 10$ days after surgery & $\begin{array}{l}\text { Scan of the plaster models } \\
\text { using a 3D laser scanner }\end{array}$ & $\begin{array}{l}\text { Dolphin Imaging software (Dolphin Imaging } \\
\text { and Management Solutions, Chatsworth, CA, } \\
\text { USA) }\end{array}$ \\
\hline $\begin{array}{l}\text { Ho et al. } 2017 \\
\text { Taiwan [1] }\end{array}$ & $\mathrm{CBCT}$ & 1 month after surgery & NA & $\begin{array}{l}\text { SimPlant (Materialize, Leuven,Belgium) } \\
\text { Dolphin software (Dolphin Imaging and } \\
\text { Management solutions, Chatsworth, California) }\end{array}$ \\
\hline $\begin{array}{l}\text { Chin et al. } 2017 \\
\text { Germany }[37]\end{array}$ & $(\mathrm{CT})$ & 1 month postoperatively & $\begin{array}{l}\text { Scan of the plaster models } \\
\text { under final occlusal position }\end{array}$ & $\begin{array}{l}\text { Dolphin Imaging } 11.8 \text { Premium } \\
\text { Assesmant tool / software: Geometric Studio } \\
\text { (Geomagic, Morrisville, NC, USA) }\end{array}$ \\
\hline $\begin{array}{l}\text { Stokbro et al. } 2016 \\
\text { USA [38] }\end{array}$ & $\mathrm{CBCT}$ & 1 week after surgery & NA & $\begin{array}{l}\text { Dolphin 3D (Dolphin Imaging and } \\
\text { Management, Chatsworth, CA, USA) }\end{array}$ \\
\hline $\begin{array}{l}\text { Baan et al. } 2016 \\
\text { Netherlands [39] }\end{array}$ & $\mathrm{CBCT}$ & $\begin{array}{l}\text { one to three weeks after } \\
\text { surgery }\end{array}$ & $\mathrm{CBCT}$ triple scan procedure & $\begin{array}{l}\text { Maxilim (Medicim NV, Mechelen, Belgium) } \\
\text { Assessment tool/software: OrthoGnatic } \\
\text { Analyzer }\end{array}$ \\
\hline $\begin{array}{l}\text { Zhang et al. } 2016 \\
\text { China [40] }\end{array}$ & $(\mathrm{CT})$ & 1 month postoperatively & $\begin{array}{l}\text { surface scanning of the dental } \\
\text { arch }\end{array}$ & $\begin{array}{l}\text { Dolphin Imaging } 11.7 \text { Premium. } \\
\text { Mimics software (version 10.01; Materialise, } \\
\text { Leuven, Belgium }\end{array}$ \\
\hline $\begin{array}{l}\text { De Rio et al. } 2014 \\
\text { Italy [41] }\end{array}$ & $\mathrm{CBCT}$ & 6 months & $\mathrm{CBCT}$ triple scan procedure & $\begin{array}{l}\text { Maxilim (Medicim Nobel Biocare Group, } \\
\text { Belgium) } \\
\text { virtual planning and manufacturing of virtual } \\
\text { splint }\end{array}$ \\
\hline $\begin{array}{l}\text { Hsu et al. } 2013 \\
\text { USA [6] }\end{array}$ & $\mathrm{CT}$ & 6 weeks postoperatively & $\begin{array}{l}\text { Scan of plaster models with } \\
\text { reference points }\end{array}$ & $\begin{array}{l}\text { Simplant OMS (Materialise Dental, Maryland, } \\
\text { USA) } \\
\text { Assesmant tool / software: 3DS max (Autodesk, } \\
\text { CA, USA) }\end{array}$ \\
\hline $\begin{array}{l}\text { Sun et al. } 2013 \\
\text { Belgium [7] }\end{array}$ & $\mathrm{CBCT}$ & 6 weeks & $\begin{array}{l}\text { Scan of bite registration with } \\
\text { reference points for image } \\
\text { fusion with } C T\end{array}$ & $\begin{array}{l}\text { Amira (Visage Imaging, Germany) } \\
\text { virtual planning and manufacturing of virtual } \\
\text { splint VisCAM (Marcam Engineering GmbH, } \\
\text { Germany) }\end{array}$ \\
\hline $\begin{array}{l}\text { Zinser et al. } 2013 \\
\text { Germany }[42]\end{array}$ & $\begin{array}{l}\mathrm{CT} \\
\mathrm{CBCT}\end{array}$ & 6 weeks & Scan of plaster models & $\begin{array}{l}\text { SimPlant Pro OMS } 10.1 \text { (Materialise Dental, } \\
\text { Belgium) }\end{array}$ \\
\hline $\begin{array}{l}\text { Centenero and } \\
\text { Hernández-Alfaro. } \\
\text { 2012, Spain [43] }\end{array}$ & $\begin{array}{l}\mathrm{CT} \\
\mathrm{CBCT}\end{array}$ & 3 months & Scan of plaster models & $\begin{array}{l}\text { SimPlant Pro OMS } 10.1 \text { (Materialise Dental, } \\
\text { Belgium. }\end{array}$ \\
\hline
\end{tabular}

CT computed tomography, CBCT cone beam computed tomography, 3D three dimensional, NA data not provided by the authors, CBCT cone beam computed tomography

positions. They also assessed the repeatability of the surgical procedure performed by different surgeons, and noticed that the discrepancy between the 3D planning and the postoperative results was the greatest regarding the vertical positioning of the maxilla and mandible, suggesting a less accurate intra-operative vertical control of virtual planning [39].

On the other hand, Franz and co-workers suggested that the use of the mean error as an only endpoint to measure the degree of accuracy can limit the generalizability of the studies. They also suggested that the confidence interval does not describe the real range of the method error but defines only the range of values that the mean error can assume from a statistical perspective [23].

Ho and colleagues calculated the accuracy of computer-aided orthognathic planning by evaluating the root-mean square difference (RMSD) of the 3D simulation and postsurgical CBCT images and found that the errors were acceptable, with RMSD $(0.63 \pm 0.25) \mathrm{mm}$ for the maxilla and $(0.85 \pm 0.41) \mathrm{mm}$ for the mandible [1].

De Riu and co-workers also suggested that the simple superimposition of the simulation and the cephalometric results is an unsatisfactory method, as it fails to consider the magnitude of the surgical manipulation leading to an error of a given magnitude. For instance, a slight 
Table 3 Variation in the type of surgical plan, virtual splints and the methodology of accuracy assessment in the included studies

\begin{tabular}{lll}
\hline $\begin{array}{l}\text { Author, year } \\
\text { and country of } \\
\text { origin }\end{array}$ & Surgical planning & Surgical splint \\
\hline $\begin{array}{l}\text { De Rio et al. } \\
2017 \text { Italy [35] }\end{array}$ & Bimaxillary surgery & $\begin{array}{l}\text { Digital intermediate splints to guide } \\
\text { Osteotomies. }\end{array}$ \\
\hline
\end{tabular}

\section{Surgical splint}

Ritto et al. 2017 Bimaxillary surgery Brazil [36]

\author{
Ho et al. 2017 Bimaxillary surgery \\ Taiwan [1] \\ Chin et al. 2017 9: bimaxillary surgery \\ Germany [37] 1: repositioning of the lower jaw.
}

\author{
Stokbro et al. Bimaxillary surgery, \\ 2016 USA [38] Bimaxillary surgery with segmentation of \\ the maxilla, \\ Bimaxillary surgery with genioplasty, \\ Bimaxillary surgery with segmentation of \\ the maxilla and genioplasty
}

Baan et al. 2016 Bimaxillary surgery

Netherlands

[39]

\begin{abstract}
Zhang et al. LeFort I osteotomy of the maxilla
2016 China [40] combined with bilateral SSRO of the mandible. Genioplasty was performed, if indicated (17 patients)
\end{abstract}

De Rio et al. 2014 Italy [41]

Clinical and 3D analysis Bimaxillary surgery (20), planning through maxilla (NA) and mandible (NA)

Hsu et al. 2013

USA [6]

Bimaxillary surgery planning through maxilla

Sun et al. 2013 Belgium [7]

Bimaxillary surgery planning through maxilla

Zinser et al. 2013 Germany [42]

Centenero and
HernándezHernández-

Alfaro .2012,

Spain [43]
An intermediate splint was fabricated virtually

Single occlusal splint

Two surgical splints:

The first splint would guide the repositioning of segmented maxilla The second one is the final position of lower jaw.

Surgical splints and surgical calipers.

Inter-occlusal wafer was milled based on the virtual planning.

Series of surgical templates:

final occlusal splint, two pairs of 3D arms and a pair of bone attachments with indication of osteotomy line

Occlusal splint

Occlusal splint, Bone splint (chin)

Occlusal splint

Occlusal splint, Bone splint (maxilla and mandibular condyle)

Occlusal splint linear and angular differences to record the vector differences.

Wilcoxon signed-rank test and the MannWhitney $U$ test were used to analyze the differences between subgroups of the population

The mean linear difference between the planned movement and the movement obtained for each reference point was calculated, Intraclass correlation coefficient was used for the statistical analysis.

The difference in precision between (2D,3D) methods was determined by t-test for independent samples.

Linear and angular distance between reference points on the $x$ (pitch), $y$ roll), and z (yaw) planes

linear and angular measurements were calculated and compared by using a paired $t$ test

The mean linear differences between the virtual plan and the postoperative outcomes were calculated and compared using Wilcoxon signed-rank test with 95\% confidence intervals, Mann Whitney and U-test were used to analyze differences between the dependent groups.

The clinical success criterion was set at a difference of less than $2 \mathrm{~mm}$

Intraclass correlation coefficient (ICC) was calculated to evaluate the interobserver and intra-observer variability for the rotational and translational measurements of the maxilla and mandible.

Linear and angular differences between simulated and postoperative models were calculated and statically analyzed using Paired $t$ test .

Linear and angular distance between the reference points and the reference lines in relation to FHP, CP, MFP, and the frontal process of the zygomatic bone 3D imaging (voxel-based)

Calculating linear and angular differences, Bland and Altman's statistical method

Linear and angular distance between reference points on the $x$ (pitch), $y$ (roll), and z (yaw) planes, 3D imaging (surface-best-fit), 3ds Max (Autodesk Inc., USA)

Linear distance between the reference points for the $x, y$, and $z$ planes in 3D imaging (voxel-based)

Intra-class correlation coefficient (ICC) of the reference lines and angles; concordance level 3D imaging (NA) 
Table 4 Risk of bias assessment of the included studies

\begin{tabular}{|c|c|c|c|c|c|c|}
\hline Quality criteria for studies & $\begin{array}{l}\text { Sample } \\
\text { randomization }\end{array}$ & $\begin{array}{l}\text { Blind } \\
\text { assessment }\end{array}$ & $\begin{array}{l}\text { Statistical } \\
\text { analysis }\end{array}$ & $\begin{array}{l}\text { Defined inclusion and } \\
\text { exclusion criteria }\end{array}$ & $\begin{array}{l}\text { Report of } \\
\text { follow-up }\end{array}$ & $\begin{array}{l}\text { Risk of bias } \\
\text { assessment }\end{array}$ \\
\hline De Rio et al. 2017, Italy [35] & No & No & Yes & Yes & Yes & Medium Risk \\
\hline Ritto et al. 2017, Brazil [36] & No & No & Yes & Yes & Yes & Medium Risk \\
\hline Ho et al. 2017, Taiwan [1] & No & No & Yes & Yes & Yes & Medium Risk \\
\hline Chin et al. 2017, Germany [37] & No & No & Yes & Yes & Yes & Medium Risk \\
\hline Stokbro et al. 2016 USA [38] & Yes & Yes & Yes & Yes & Yes & Low Risk \\
\hline Baan et al. 2016, Netherlands [39] & Yes & No & Yes & Yes & No & Medium Risk \\
\hline Zhang et al. 2016, China [40] & No & No & Yes & No & No & High Risk \\
\hline De Rio et al. 2014, Italy [41] & Yes & No & Yes & Yes & No & Medium Risk \\
\hline Hsu et al. 2013, USA [6] & No & Yes & Yes & Yes & Yes & Medium Risk \\
\hline Sun et al. 2013, Belgium [7] & No & No & Yes & Yes & Yes & Medium Risk \\
\hline Zinser et al. 2013, Germany [42] & No & No & Yes & Yes & Yes & Medium Risk \\
\hline $\begin{array}{l}\text { Centenero and Hernández-Alfaro. } \\
\text { 2012, Spain [43] }\end{array}$ & No & No & Yes & Yes & Yes & Medium Risk \\
\hline
\end{tabular}

positional error can be completely acceptable for large manipulations, but would be unacceptable when the manipulation takes place at a small scale and thus needs to be extremely precise [35].

The accuracy of the translation of the maxilla with computer-assisted planning for orthognathic surgery was $<1 \mathrm{~mm}$ in the study of Hsu and colleagues, indicating that this type of planning is accurate for the maxilla [6].

The Stokbro group found that the mean linear differences for the maxilla, mandible and the chin segment in all three planes were within $0.5 \mathrm{~mm}$, while the mean precision, measured as the standard deviation, had the smallest deviation superoinferiorly, followed closely by mediolateral deviation, and finally the largest deviation was found anteroposteriorly [38].

De Riu and co-workers found that virtual surgical planning presented a high degree of accuracy for most of the parameters assessed, with an average error of 1.98 $\mathrm{mm}$ for linear measurements and $1.19^{\circ}$ for angular measurements. At the same time, they observed significant differences between planned and achieved anterior facial height $(p=0.033)$. Without genioplasty, no significant difference was observed ( $\mathrm{U}$ test; $p=0.45$ ). The authors concluded that the problem was caused by the virtual model of the soft tissues, which made it difficult to manage the vertical dimension [35].

It has been also shown in the study of Baan and colleagues that the right /left translation has the lowest absolute mean difference between the 3D planning and the surgical results for both the maxilla and mandible $(0.49$ $\mathrm{mm}$ and $0.71 \mathrm{~mm}$, respectively). Furthermore, they noticed that in 7 out of 10 cases, the maxilla was positioned more posteriorly than in the 3D plan, with an absolute mean difference of $1.41 \mathrm{~mm}$. The same tendency was found in the sagittal position of the mandible, where in 8 out of 10 cases the mandible was positioned more posteriorly than planned with absolute mean difference of $1.17 \mathrm{~mm}$ [39]. Lee and colleagues suggested that the condylar position might have been changed during surgery by muscle tone and gravity as the patient was placed in the supine position, which affects the optimal condylar seating [48]. Stokbro et al. (2016) are of the same opinion about this issue.

The clinical analysis of Sun and colleagues, of the twenty three patients, using the OrthoGnathic Analyser, showed an adequate position of the maxilla and mandible in the left/right direction with a deviation of 0.32 $\mathrm{mm}$ and $0.75 \mathrm{~mm}$, respectively. It was found that the maxilla had a lower RMSD $(0.6 \mathrm{~mm})$ than did the mandible $(0.85 \mathrm{~mm})$ [19].

Zhang et al. showed that the overall mean linear difference was $(0.81 \mathrm{~mm})$, and the overall mean angular difference was $\left(0.95^{\circ}\right)$ [40], which was an improvement as compared with their previous study, as a result of surgical experience, 3D printing technology, and improvement of the elasticity modulus of 3D-printed surgical templates [49].

On the other hand, Baan et al. observed that the accuracy of the pitch of the maxilla $\left(2.72^{\circ}\right)$ and the mandible $\left(2.75^{\circ}\right)$ showed the highest discrepancy between the $3 \mathrm{D}$ plans and the actual postoperative status. This variance could be the result of bone conflict between the pterygoid plate and the osteotimized maxilla [39]. Stokbro et al. came to similar conclusions [38].

\section{Comparison of the accuracy between classical and virtual planning methods}

A lot of studies compared computer-assisted planning with classical planning and found favorable accuracy results in all bony segments for computer-aided planning $[36,41,42,50]$. Ziesner and colleagues reported that the 
mandibular condyle maintained a central position in the temporomandibular joint, which did not occur when classic planning was used [42].

Hsu et al. compared the two types of interventions in the chin and found highly favorable accuracy results for computer-aided planning in this bone segment, with the largest difference recorded for translation in the sagittal plane $(2.5 \mathrm{~mm})$ and rotation pitch $\left(3.68^{\circ}\right)$. They explained these differences by the fact that classical planning does not use surgical splints; surgeons are guided by their experience, some internal reference points and the chin plate [6].

Ritto and colleagues reported on a similar level of precision in all evaluated regions when assessing the vertical positioning of the maxilla, but virtual surgical planning (VSP) was more accurate for the anteroposterior position of the maxilla. As for transverse positioning, conventional model surgery (CMS) yielded higher precision only for the upper midline position. However, there was no statistically significant difference between the groups, and the mean imprecision was also $<2 \mathrm{~mm}$ for all regions evaluated [36].

\section{Risk of Bias assessment}

The papers included in this systematic review were classified as medium quality, since the risk of bias was considered medium in ten studies $[1,6,7,35-37,39,41-$ $43]$, that is, the majority.

These studies [1, 7, 35-37, 42, 43] did not report on sample randomization and blinding. Baan et al. (2016) failed to report on blinding and follow-up.

\section{Conclusions}

In conclusion, the results of this systematic review suggest that computer-aided planning is an accurate method for orthognathic surgery of the maxilla and the mandible.

We found that CBCT with intraoral scan of the dental cast is the most frequently used method for virtual orthognathic planning, and SimPlant (Materialise, Leuven, Belgium) and Dolphin (Dolphin Imaging, USA) are the most widely used software.

Despite its limitations, the calculation of the linear and angular differences between the virtual plan and the postoperative status is still the most frequently used method for accuracy assessment, and differences $<2$ $\mathrm{mm} /{ }^{\circ}$ are considered acceptable.

\section{Supplementary Information}

The online version contains supplementary material available at https://doi. org/10.1186/s13005-020-00250-2.

Additional file 1: Table S1. Virtual planning accuracy of the included studies.

\section{Abbreviations}

CT: Computed tomography; CBCT: Cone-beam computed tomography; 2D: Two-dimensional; 3D: Three dimensional; OGS: Orthognathic surgery; MeSH: Medical subject heading; SD: Standard deviation; NA: No information provided by the authors; CMS: Conventional model surgery; VSP: Vitual surgical planning; M: Male; F: Female; FHP: Frankfort horizontal plane; CP: Coronal plane; MFP: Midfacial plane; OcPI: Occlusal plane;

MdPI: Mandibular plane; N: Nasion point; ICC: Intra-class correlation coefficient; VS: Virtual splint; CS: Classic splint; NS: No splint; ANB: A relationship of maxilla and mandible; UAFH: Change of upper anterior facial height; LAFH: Change of lower anterior facial height; UAFH/LAFH: Change of vertical portion of facial height; RMSD: Root-mean square difference

\section{Acknowledgements}

Not applicable.

\section{Authors' contributions}

A.A. collected, analyzed and interpreted the data for this publication. J.P., C.L. and E.S. helped in study design and data interpretation. All authors read and approved the final manuscript.

\section{Funding}

Dr. Alkhayer was supported by Stipendium Hungaricum Scholarship. Open Access funding enabled and organized by Projekt DEAL.

Availability of data and materials

The datasets analyzed during the current study are available from the corresponding author on reasonable request.

Ethics approval and consent to participate Not applicable.

Consent for publication

Not applicable.

\section{Competing interests}

The authors declare that they have no competing interests.

\section{Author details}

${ }^{1}$ Craniofacial Unit, Department of Oral \& Maxillofacial Surgery, University of Szeged, Tisza Lajos krt. 97, Szeged, Hungary. ${ }^{2}$ Department of Oral \& Maxillofacial Surgery, Faculty of Medicine, University of Szeged, Kálvária sugárút. 57, Szeged, Hungary. ${ }^{3}$ Department of Orthodontics, Universitätsklinikum Münster, Albert-Schweitzer-Campus 1, Gebäude W30, Waldeyerstraße 30, 48149 Münster, Germany.

Received: 26 September 2019 Accepted: 24 November 2020 Published online: 04 December 2020

References

1. Ho CT, Lin HH, Liou EJ, Lo LJ. Three-dimensional surgical simulation improves the planning for correction of facial prognathism and asymmetry: a qualitative and quantitative study. Sci Rep. 2017;7:40423.

2. Xia JJ, Gateno J, Teichgraeber JF. New clinical protocol to evaluate craniomaxillofacial deformity and plan surgical correction. J Oral Maxillofac Surg. 2009;67:2093-106.

3. Seres L, Varga EJ, Kocsis A, Rasko Z, Bago B, Varga E, et al. Correction of a severe facial asymmetry with computerized planning and with the use of a rapid prototyped surgical template a case reporttechnique article. Head Face Med. 2014;10:27.

4. Adolphs N, Haberl EJ, Liu W, Keeve E, Menneking H, Hoffmeister B. Virtual planning for craniomaxillofacial surgery--7 years of experience. J Craniomaxillofac Surg. 2014;42:e289-95.

5. Haas OL Jr, Becker OE, de Oliveira RB. Computer-aided planning in orthognathic surgery-systematic review. Int J Oral Maxillofac Surg. 2015;44:329-42.

6. Hsu SS, Gateno J, Bell RB, Hirsch DL, Markiewicz MR, Teichgraeber JF, et al. Accuracy of a computer-aided surgical simulation protocol for orthognathic surgery: a prospective multicenter study. J Oral Maxillofac Surg. 2013;71: 128-42.

7. Sun Y, Luebbers HT, Agbaje JO, Schepers S, Vrielinck L, Lambrichts I, et al. Accuracy of upper jaw positioning with intermediate splint fabrication after 
virtual planning in bimaxillary orthognathic surgery. J Craniofac Surg. 2013;24: 1871-6.

8. Swennen GR, Mollemans W, De Clercq C, Abeloos J, Lamoral P, Lippens F, et al. A cone-beam computed tomography triple scan procedure to obtain a three-dimensional augmented virtual skull model appropriate for orthognathic surgery planning. J Craniofac Surg. 2009;20:297-307.

9. Zinser MJ, Mischkowski RA, Dreiseidler T, Thamm OC, Rothamel D, Zoller JE. Computer-assisted orthognathic surgery: waferless maxillary positioning, versatility, and accuracy of an image-guided visualisation display. Br J Oral Maxillofac Surg. 2013;51:827-33.

10. Farrell $B B$, Franco PB, Tucker MR. Virtual surgical planning in orthognathic surgery. Oral Maxillofac Surg Clin North Am. 2014;26:459-73.

11. Wu TY, Lin HH, Lo L, Ho CT. Postoperative outcomes of two- and threedimensional planning in orthognathic surgery: a comparative study. J Plast Reconstr Aesthet Surg. 2017;70:1101-11.

12. Baker SB, Goldstein JA, Seruya M. Outcomes in computer-assisted surgical simulation for orthognathic surgery. J Craniofac Surg. 2012;23:509-13.

13. Bai $S, B o B, B i$, Wang B, Zhao J, Liu Y, et al. CAD/CAM surface templates as an alternative to the intermediate wafer in orthognathic surgery. Oral Surg Oral Med Oral Pathol Oral Radiol Endod. 2010;110:e1-7.

14. Bai S, Shang H, Liu Y, Zhao J, Zhao Y. Computer-aided design and computeraided manufacturing locating guides accompanied with prebent titanium plates in orthognathic surgery. J Oral Maxillofac Surg. 2012;70:2419-26.

15. Levine JP, Patel A, Saadeh PB, Hirsch DL. Computer-aided design and manufacturing in craniomaxillofacial surgery: the new state of the art. J Craniofac Surg. 2012;23:288-93.

16. Li B, Zhang L, Sun H, Yuan J, Shen SG, Wang X. A novel method of computer aided orthognathic surgery using individual CAD/CAM templates: a combination of osteotomy and repositioning guides. Br J Oral Maxillofac Surg. 2013;51:e239-44.

17. Polley JW, Figueroa AA. Orthognathic positioning system: intraoperative system to transfer virtual surgical plan to operating field during orthognathic surgery. J Oral Maxillofac Surg. 2013;71:911-20.

18. Zinser MJ, Mischkowski RA, Sailer HF, Zoller JE. Computer-assisted orthognathic surgery: feasibility study using multiple CAD/CAM surgical splints. Oral Surg Oral Med Oral Pathol Oral Radiol. 2012;113:673-87.

19. Sun Y, Luebbers HT, Agbaje JO, Schepers S, Vrielinck L, Lambrichts I, et al. Evaluation of 3 different registration techniques in image-guided bimaxillary surgery. J Craniofac Surg. 2013;24:1095-9.

20. Lin HH, Lo L. Three-dimensional computer-assisted surgical simulation and intraoperative navigation in orthognathic surgery: a literature review. J Formos Med Assoc. 2015;114:300-7.

21. Stokbro K, Aagaard E, Torkov P, Bell RB, Thygesen T. Virtual planning in orthognathic surgery. Int J Oral Maxillofac Surg. 2014:43:957-65.

22. de Waard O, Baan F, Verhamme L, Breuning H, Kuijpers-Jagtman AM, Maal T. A novel method for fusion of intra-oral scans and cone-beam computed tomography scans for orthognathic surgery planning. J Craniomaxillofac Surg. 2016;44:160-6.

23. Franz L, Isola M, Bagatto D, Calzolari F, Travan L, Robiony M. A novel protocol for planning and navigation in craniofacial surgery: a preclinical surgical study. J Oral Maxillofac Surg. 2017;75:1971-9.

24. Lu C, He D, Yang C, Huang D, Ellis E 3rd. Computer-assisted surgical planning and simulation for unilateral condylar benign lesions causing facial asymmetry. Oral Surg Oral Med Oral Pathol Oral Radiol. 2017;123:453-8.

25. Grybauskas S, Saiki C, Cintra O, Razukevičius D. A "forced symmetry": surgical planning protocol for the treatment of posterior facial asymmetries. EJCO. 2016:4:e53-9.

26. Shaheen E, Sun Y, Jacobs R, Politis C. Three-dimensional printed final occlusal splint for orthognathic surgery: design and validation. Int J Oral Maxillofac Surg. 2017;46:67-71.

27. Steinhuber T, Brunold S, Gartner C, Offermanns V, Ulmer H, Ploder O. Is virtual surgical planning in Orthognathic surgery faster than conventional planning? A time and workflow analysis of an office-based workflow for single- and double-jaw surgery. J Oral Maxillofac Surg. 2018;76:397-407.

28. Wrzosek MK, Peacock ZS, Laviv A, Goldwaser BR, Ortiz R, Resnick CM, et al. Comparison of time required for traditional versus virtual orthognathic surgery treatment planning. Int J Oral Maxillofac Surg. 2016;45:1065-9.

29. Ying B, Ye N, Jiang Y, Liu Y, Hu J, Zhu S. Correction of facial asymmetry associated with vertical maxillary excess and mandibular prognathism by combined orthognathic surgery and guiding templates and splints fabricated by rapid prototyping technique. Int J Oral Maxillofac Surg. 2015;44:1330-6.
30. Hernandez-Alfaro F, Guijarro-Martinez R. New protocol for three-dimensional surgical planning and CAD/CAM splint generation in orthognathic surgery: an in vitro and in vivo study. Int J Oral Maxillofac Surg. 2013:42:1547-56.

31. Shehab MF, Barakat AA, AbdElghany K, Mostafa Y, Baur DA. A novel design of a computer-generated splint for vertical repositioning of the maxilla after Le fort I osteotomy. Oral Surg Oral Med Oral Pathol Oral Radiol. 2013;115:e16-25.

32. Uribe F, Janakiraman N, Shafer D, Nanda R. Three-dimensional cone-beam computed tomography-based virtual treatment planning and fabrication of a surgical splint for asymmetric patients: surgery first approach. Am J Orthod Dentofac Orthop. 2013;144:748-58.

33. Xia JJ, Gateno J, Teichgraeber JF, Christensen AM, Lasky RE, Lemoine JJ, et al. Accuracy of the computer-aided surgical simulation (CASS) system in the treatment of patients with complex craniomaxillofacial deformity: a pilot study. J Oral Maxillofac Surg. 2007;65:248-54.

34. Clementini M, Morlupi A, Canullo L, Agrestini C, Barlattani A. Success rate of dental implants inserted in horizontal and vertical guided bone regenerated areas: a systematic review. Int J Oral Maxillofac Surg. 2012;41:847-52.

35. De Riu G, Virdis PI, Meloni SM, Lumbau A, Vaira LA. Accuracy of computerassisted orthognathic surgery. J Craniomaxillofac Surg. 2017;46:293-8.

36. Ritto FG, Schmitt ARM, Pimentel T, Canellas JV, Medeiros PJ. Comparison of the accuracy of maxillary position between conventional model surgery and virtual surgical planning. Int J Oral Maxillofac Surg. 2017:47:160-6.

37. Chin SJ, Wilde F, Neuhaus M, Schramm A, Gellrich NC, Rana M. Accuracy of virtual surgical planning of orthognathic surgery with aid of CAD/CAM fabricated surgical splint-a novel 3D analyzing algorithm. J Craniomaxillofac Surg. 2017:45:1962-70

38. Stokbro K, Aagaard E, Torkov P, Bell RB, Thygesen T. Surgical accuracy of threedimensional virtual planning: a pilot study of bimaxillary orthognathic procedures including maxillary segmentation. Int J Oral Maxillofac Surg. 2016;45:8-18.

39. Baan F, Liebregts J, Xi T, Schreurs R, de Koning M, Berge S, et al. A new 3D tool for assessing the accuracy of Bimaxillary surgery: the OrthoGnathicAnalyser. PLoS One. 2016;11:e0149625.

40. Zhang N, Liu S, Hu Z, Hu J, Zhu S, Li Y. Accuracy of virtual surgical planning in two-jaw orthognathic surgery: comparison of planned and actual results. Oral Surg Oral Med Oral Pathol Oral Radiol. 2016;122:143-51.

41. De Riu G, Meloni SM, Baj A, Corda A, Soma D, Tullio A. Computer-assisted orthognathic surgery for correction of facial asymmetry: results of a randomised controlled clinical trial. Br J Oral Maxillofac Surg. 2014;52:251-7.

42. Zinser MJ, Sailer HF, Ritter L, Braumann B, Maegele M, Zoller JE. A paradigm shift in orthognathic surgery? A comparison of navigation, computer-aided designed/computer-aided manufactured splints, and "classic" intermaxillary splints to surgical transfer of virtual orthognathic planning. J Oral Maxillofac Surg. 2013;71(2151):e1-21.

43. Aboul-Hosn Centenero S, Hernandez-Alfaro F. 3D planning in orthognathic surgery: CAD/CAM surgical splints and prediction of the soft and hard tissues results - our experience in 16 cases. J Craniomaxillofac Surg. 2012:40:162-8.

44. Lin HH, Chang HW, Lo L. Development of customized positioning guides using computer-aided design and manufacturing technology for orthognathic surgery. Int J Comput Assist Radiol Surg. 2015;10:2021-33.

45. De Vos W, Casselman J, Swennen GR. Cone-beam computerized tomography (CBCT) imaging of the oral and maxillofacial region: a systematic review of the literature. Int J Oral Maxillofac Surg. 2009;38:609-25.

46. Guijarro-Martinez R, Swennen GR. Cone-beam computerized tomography imaging and analysis of the upper airway: a systematic review of the literature. Int J Oral Maxillofac Surg. 2011;40:1227-37.

47. Lechuga L, Weidlich GA, vs CBCT, Fan Beam CT. A Comparison of Image Quality and Dose Delivered Between Two Differing CT Imaging Modalities. Cureus. 2016;8:e778.

48. Lee CY, Jang CS, Kim JW, Kim JY, Yang BE. Condylar repositioning using centric relation bite in bimaxillary surgery. Korean J Orthod. 2013;43:74-82.

49. Li Y, Jiang $Y$, Zhang $N, X u R$, Hu J, Zhu S. Clinical feasibility and efficacy of using virtual surgical planning in bimaxillary orthognathic surgery without intermediate splint. J Craniofac Surg. 2015;26:501-5.

50. Griffitts TM, Tandon R, Herford AS, Dean J. Computer assisted surgical simulation versus model surgery in Orthognathic surgery: a postoperative comparison of surgical outcomes. J Oral Maxillofac Surg. 2013;71:e18.

\section{Publisher's Note}

Springer Nature remains neutral with regard to jurisdictional claims in published maps and institutional affiliations. 